\title{
WestVirginiaUniversity
}

THE RESEARCH REPOSITORY @ WVU

Graduate Theses, Dissertations, and Problem Reports

2013

\section{Complete Hamstring Rehabilitation Program for Division I Football Athletes}

\author{
Caitlin McFadden \\ West Virginia University
}

Follow this and additional works at: https://researchrepository.wvu.edu/etd

\section{Recommended Citation}

McFadden, Caitlin, "Complete Hamstring Rehabilitation Program for Division I Football Athletes" (2013). Graduate Theses, Dissertations, and Problem Reports. 3615.

https://researchrepository.wvu.edu/etd/3615

This Thesis is protected by copyright and/or related rights. It has been brought to you by the The Research Repository @ WVU with permission from the rights-holder(s). You are free to use this Thesis in any way that is permitted by the copyright and related rights legislation that applies to your use. For other uses you must obtain permission from the rights-holder(s) directly, unless additional rights are indicated by a Creative Commons license in the record and/ or on the work itself. This Thesis has been accepted for inclusion in WVU Graduate Theses, Dissertations, and Problem Reports collection by an authorized administrator of The Research Repository @ WVU. For more information, please contact researchrepository@mail.wvu.edu. 


\title{
Complete Hamstring Rehabilitation Program for Division I Football Athletes

\author{
Caitlin McFadden, ATC, CSCS
}

Thesis submitted to the College of Physical Activity and Sports Science at West Virginia University in partial fulfillment of the requirements for the degree of

Master of Science

$\ln$

Athletic Training

Thesis Committee:

Dr. Michelle Sandrey, Ph. D, ATC, Chair

Michael Joseph, CSCS

Dr. Emidio Pistilli, Ph.D.

\author{
West Virginia University \\ College of Physical Activity and Sport Sciences \\ Morgantown, West Virginia
}

2013

Keywords: Hamstrings, Injuries, Rehabilitation, Division I Football 


\begin{abstract}
Complete Hamstring Rehabilitation Program Division I Football Athletes
\end{abstract}

Caitlin McFadden

Context: Hamstring strains, primarily grade one and two strains, are represented in the literature. However, there is contradicting evidence-based research for rehabilitation of the hamstring as well as limited evidence-based research for preventing de-conditioning of the entire body during the rehabilitation process. Objective: This study combined evidence-based practice and the best clinical experienced to: 1) design a complete program to rehabilitate the hamstring complex and prevent de-conditioning of the entire body with involvement of hamstring researchers, strength and conditioning and athletic training professions; and 2) determine the inclusion of concepts and components of a Five Phase Recovery Process incorporated in the hamstring complex rehabilitation program specifically for National Collegiate Athletic Association Division I Football athletes. Design: Survey study was modeled after the Modified Delphi Technique, using two rounds of questionnaire. Setting: This study took place at West Virginia University; Morgantown, West Virginia. Patients or Other Participants: Of seventy-three potential candidates contacted, the panel consisted of three Athletic Trainers employed with Division I football for more than five year, as well as, one Hamstring Researcher, who had more than five presentations and publications in the area of hamstring injury, rehabilitation or strength training. For the Second Round questionnaire, there were two dropouts. The panel concluded with one Athletic Trainer and one Hamstring Researcher. To qualify for the panel, an athletic trainer and strength specialist must have worked with a Division I Football team for five or more years, and the researcher must have five or more presentations and/or publications in the area of hamstring injury, rehabilitation, or strength training. Interventions: The information was acquired through the Modified Delphi Technique through two rounds of a questionnaire that formulated a consensus on what components and concepts were included in a complete hamstring complex rehabilitation program for Division I football athletes. The qualified panel of experts derived a consensus of $75 \%$ choosing strongly agree or agree with a mean score of 4 or more on components and concepts within specified categories: baseline, contraindications, flexibility focus, range of motion/strength with ATC, core exercise focus, strength and conditioning with SS, and progression to the next Phase. The categories were based on a 5-Phase program following the Recovery Process of the athlete and their interaction and involvement with the Athletic Trainer. The responses were deemed significant through the use of the Likert scale, with available opportunity for panelists to comment further on the specifics of the questionnaire over the course of two rounds. The First Round questionnaire provided the initial rating on related components and concepts on the hamstring complex. The second questionnaire displayed the percentages of panelists' responses as well as additional comments allowing them an opportunity to critique and refine group consensus. The Second Round responses were used to develop the complete hamstring complex rehabilitation program. Cover letters and follow-up cover letters were sent electronically via SurveyMonkey.com to encourage participation for the 
two rounds. Main Outcomes Measures: Responses from the participants using the Modified Delphi Method: baseline, contraindications, flexibility focus, range of motion/strength with ATC, core strengthening, strength and conditioning with Strength Specialist, and progression to the next phase. Results: The First Round questionnaire included 223 rehabilitation components and concepts from best clinical practice and evidence-based research. Prior to the Second Round questionnaire, the expert panel provided an additional twenty-one concepts for evaluation. After the completion of the Second Round questionnaire with additional concepts included, 126 rehabilitation components and concepts met consensus and were included to design the final complete hamstring complex rehabilitation program. Conclusion: The responses from the Second Round by the qualified panel of experts designed the Complete Hamstring Complex Rehabilitation Program specifically for NCAA Division I football athletes. Although there was a dropout of two participants between rounds and no representation of strength specialists on the panel, this rehabilitation program can be utilized as a guideline for clinicians and strength specialists dealing with hamstring injuries throughout the football season. Future research is required for further design and development of the complete Hamstring Complex Rehabilitation Program for NCAA Division I football athletes with the inclusion of strength and conditioning specialists on the panel of experts. 


\section{ACKNOWLEDGMENTS}

I dedicate this thesis to my Aunt Fran. She is the heart and soul to my desire to continue learning. I promised her I would never stop; this is a proof of that promise. I miss you and love you. Thank you for teaching me how.

Mom and Dad, my rock, words are never enough to say thank you. For always being on my side, my cheerleaders, my coaches, my teachers. I hope that one day I will be just like you towards my children, thank you and love you.

Family and Friends, thank you for always lending your ear and always quick with advice in times when my stress level was running high. For all the love and support throughout my college career, especially this thesis process, I could have never done it without all of you.

Dave Kerns and Tony Corely, if it were not for the two of you, I would not have had a thesis topic, I also would not have experienced as much stress. But in all seriousness, thank you is still not enough for the last two years. They went by fast but they were great.

Dr. Sandrey, thank you for the last two years with West Virginia University and all your time throughout this Thesis process. I am greatly appreciative of the experience I acquired being here at WVU.

Mike Joseph, thank you for your knowledge, teachings, and opinions throughout the development of this study, your time and effort in helping me compile the questionnaire, and of course your participation on this committee.

Dr. Pistilli, thank you for your time, commitment and effort throughout the course of this thesis and apart of this committee. I know this subject was a little more outside your research focus; nevertheless, I greatly appreciate your questions, ideas and wisdom.

Philip Johnson and Dr. Jesper Petersen, thank you for providing your opinions as well as your time. I would not have been able to complete this study without you.

Peter, thank you for always being there for me all through college and all throughout this thesis journey. For always being willing to review my work, even at the worst hours. Thank you for giving me the idea to complete a thesis way back when I was only a senior in high school.

Jessa, even though you may be listed last, you will never be last in my book. Thank you for the last year and a half, I seriously could not have made it this far without you. You truly understand the meaning of the phase, "Best Friend." Thank you for being one to me. 


\section{TABLE OF CONTENTS}

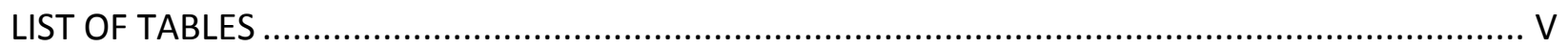

INTRODUCTION

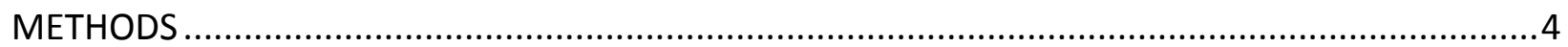

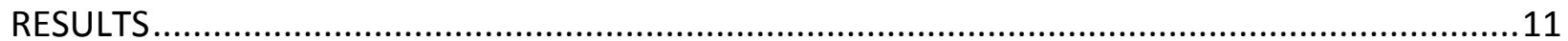

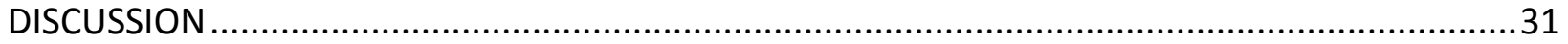

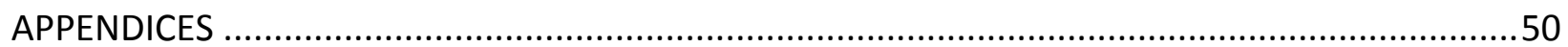

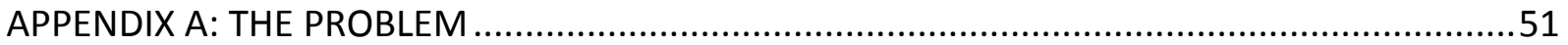

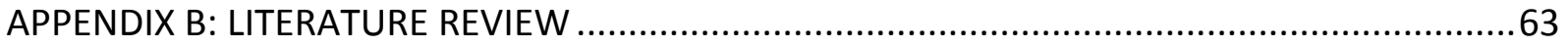

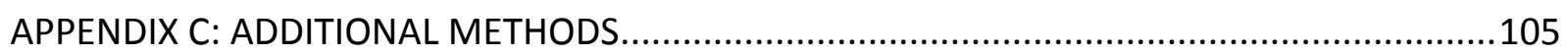

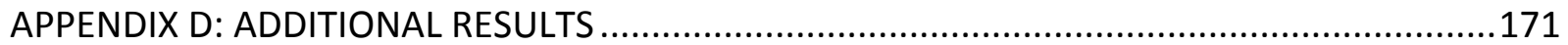

APPENDIX E: RECOMMENDATIONS FOR FUTURE RESEARCH ...................................... 199

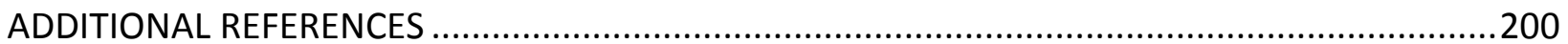




\section{LIST OF TABLES}

TABLE B1. EVIDENCE-BASED REHABILITATION PROGRAM TRIALS. 93

TABLE B2. EVIDENCE-BASED REHABILITATION PROTOCOL 100

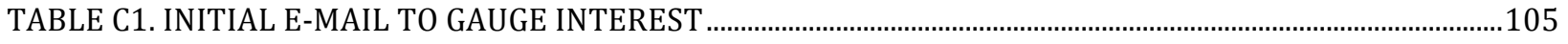

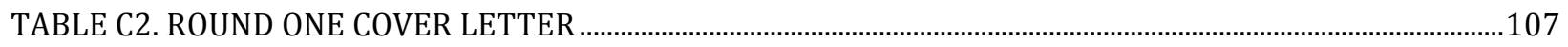

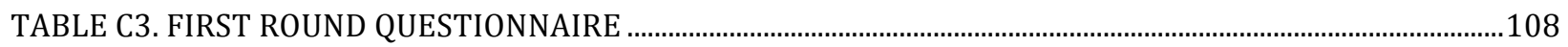

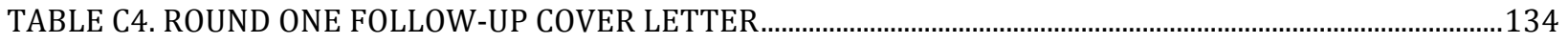

TABLE C5. SECOND ROUND COVER LETTER…………....................................................................................136

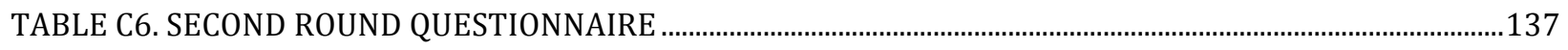

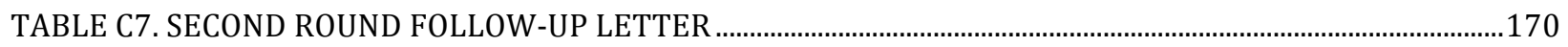

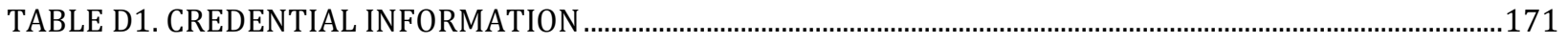

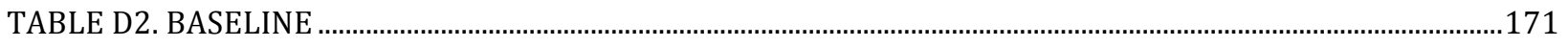

TABLE D3. BASELINE AND REHABILITATION CONCEPTS ........................................................................................172

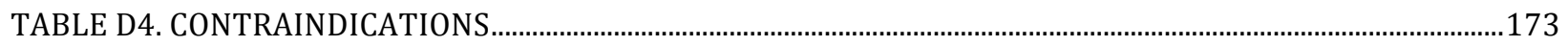

TABLE D5. FLEXIBILITY FOCUS AND RANGE OF MOTION EXERCISE ………….......................................................173

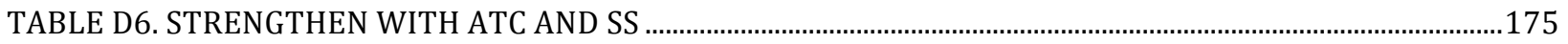

TABLE D7. PROGRESSION TO PHASE II AND CLINICAL TESTS OR EVALUATION …………………………….........176

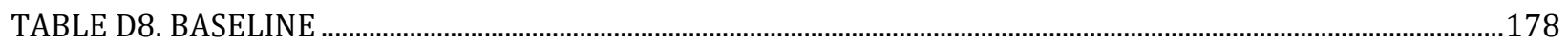

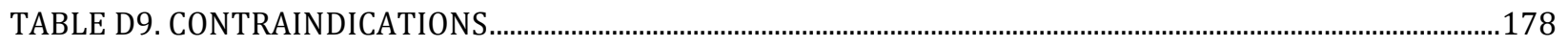

TABLE D10. FLEXIBILITY FOCUS AND RANGE OF MOTION EXERCISES.....................................................................179

TABLE D11. STRENGTHENING WITH ATC AND CORE FOCUS EXERCISES …………………………………............179

TABLE D12. STRENGTHENING AND CONDITIONING WITH SS …….......................................................................181

TABLE D13. PROGRESSION TO PHASE III AND CLINICAL TESTS OR EVALUATIONS ...............................................182

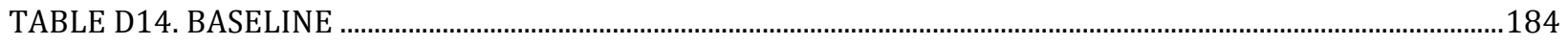

TABLE D16. FLEXIBILITY FOCUS AND STRENGTHENING WITH ATC ……………................................................185

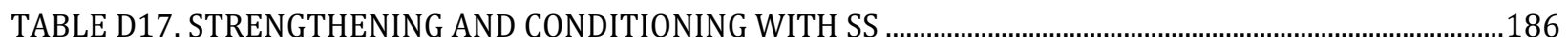

TABLE D18. PROGRESSION TO PHASE IV AND CLINICAL TESTS OR EVALUATIONS ..............................................187 
TABLE D19. BASELINE AND CONTRAINDICATIONS.............................................................................................188

TABLE D20. FLEXIBILITY FOCUS AND STRENGTHENING WITH ATC .....................................................................189

TABLE D21. STRENGTHENING AND CONDITIONING WITH SS ……........................................................................190

TABLE D22. PROGRESSION TO PHASE V AND CLINICAL TESTS OR EVALUATIONS ................................................191

TABLE D23. BASELINE AND CONTRAINDICATIONS................................................................................................ 191

TABLE D24. STRENGTHENING AND CONTINUED MAINTENANCE WITH ATC AND SS.........................................191

TABLE D25. COMPONENTS AND CONCEPTS THAT MET CONSENSUS FOR EACH CATEGORY WITHIN EACH

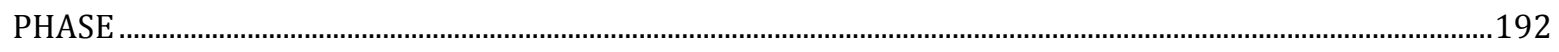

TABLE D26. PRESENTATION OF A GRADE I \& II HAMSTRING COMPLEX STRAIN..................................................192

TABLE D27: PHASE I OF THE COMPLETE HAMSTRING COMPLEX REHABILITATION PROGRAM .....................193

TABLE D28: PHASE II OF THE COMPLETE HAMSTRING COMPLEX REHABILITATION PROGRAM....................194

TABLE D29: PHASE III OF THE COMPLETE HAMSTRING COMPLEX REHABILITATION PROGRAM ..................195

TABLE D30: PHASE IV OF THE COMPLETE HAMSTRING COMPLEX REHABILITATION PROGRAM ..................197

TABLE D31: PHASE V OF THE COMPLETE HAMSTRING COMPLEX REHABILITATION PROGRAM ....................198 
LIST OF FIGURES

FIGURE 1. PHASES OF RUNNING GAIT OR SPRINT SEQUENCE 
Introduction

The prevalence of muscle strains in football is present at any level with percentages higher than most injuries. ${ }^{1}$ During National Football League preseason camp, muscle strains were reported at an occurrence rate of $52 \%$ over a five-week period. ${ }^{2}$ Within that rate, $48 \%$ of the muscle strains occurred during practice and $22 \%$ during games. ${ }^{2}$ In evaluating muscle strain rates even further, hamstrings are the most common muscle injured with a rate of $12-24 \% .^{1,2}$ For Division I football athletes, hamstring complex strains were the third most common orthopedic injury, behind knee and ankle injuries. $^{2}$

A muscle strain occurs when a violent stretch or force is applied to the muscle during an eccentric contraction. ${ }^{4}$ In relation to the hamstring complex, a strain injury typically occurs during deceleration of the lower leg of swing phase. ${ }^{5}$ When a protective eccentric action occurs, tension develops while the muscles lengthen. ${ }^{6}$ This tension increases and when the muscles surpass mechanical limits the strain injury occurs. ${ }^{5}$ The classification for severity of hamstring complex strains varies throughout the literature. The classification for a grade I hamstring complex strain occurs from a typical mechanism of injury with minor swelling and discomfort with no or minimal loss of strength. ${ }^{7}$ A grade II hamstring complex strain is a typical mechanism of injury with clear loss of strength with more discomfort. ${ }^{7}$

Causative factors of hamstring complex injuries are variable in the literature. It is evident that sports with a requirement for sprinting, kicking, jumping, and high-skilled movements have a high occurrence rate for hamstring complex strains..$^{8,9,10,11,12}$ Other causative factors include poor flexibility, $2,8,12,13,14,15$ lack of eccentric hamstring complex strength, ${ }^{6,16,17}$ low back/hip weakness, ${ }^{17}$ improper dynamic warm-up, ${ }^{18,8,13,14,15,12}$ incorrect 
running technique, ${ }^{18,19}$ type of training or the volume/intensity per week, ${ }^{13,19,20}$ lack in core strength, ${ }^{2}$ poor hamstring rehabilitation, ${ }^{20,12,21,12}$ fatigue, ${ }^{8,12,13,14,15,6,21,22}$ poor lumbar-pelvic posture, ${ }^{8,14,6,17,23}$ hamstring weakness, ${ }^{1,8,12,14,15,6,21,22}$ Hamstrings-to-Quadriceps ratio, ${ }^{2,8,11,}$ $12,13,6,17,19$ premature return to play, ${ }^{13,20}$ or prior history.$^{2,13,14,15,12,21,25}$ With all of the probable causative factors that lead to hamstring complex injuries, some are still unknown. Therefore, hamstring complex rehabilitation programs may be designed to accommodate these factors, or are based primarily on the philosophy of the individual designing the program. Although variable in nature, most rehabilitation programs aim to decrease the recovery interval and risk of re-injury. However, these programs do not appear to decrease the re-occurrence rate within the first two weeks upon return to activity. ${ }^{26}$ Either the recovery interval is prolonged, re-injury occurs or the sample size of the study was not large enough to be generalized to the public. ${ }^{6,20}$ Thus, other types of rehabilitation programs should be considered. Of the programs evaluated using individuals with hamstring complex strains, a combination of traditional, eccentric exercises and core stabilization have shown to be successful. ${ }^{2,6}$ More research is necessary, and a study specifically targeting Division I Football athletes is warranted at this time.

De-conditioning of the body is evident during the rehabilitation process as the normal team strength and conditioning program is modified based on the severity of the injury. Thus, strength and conditioning specialists should be involved in the process to reinforce cardiovascular and strength gains acquired prior to injury. Unfortunately, no best clinical practice or evidenced-based hamstring complex rehabilitation program has taken this aspect into account to develop a protocol that will ensure strengthening of hamstring complex, as well 
as, providing proper attention to surrounding muscles that may affect the recovery interval throughout the rehabilitation process. Even though the rate of hamstring complex strains is high, the recovery interval or length of time away from participation can vary from eight days to 25 days between Grade I and II hamstring strains. ${ }^{10}$ It has been suggested that the range in recovery interval is related to the location and severity of the injury, as well as, previous history and variation of the hamstring rehabilitation program. ${ }^{10}$

Therefore, this study will unite evidence-based research with best clinical practice to formulate a complete hamstring complex rehabilitation program based on attention to causative factors, as well as, prevention of de-conditioning of the entire body without an increase risk of injury all with a focus and relation to Division I football. As there is no known program in existence, a study was conducted using the Modified Delphi Technique with the inclusion of qualified panel of experts to generate a consensus on a complete hamstring complex rehabilitation program that focuses on de-conditioning of the entire body with application to NCAA Division I football. Thus, the purpose of this study is to combine evidencebased and best clinical practice to: 1 ) design a complete program to rehabilitate the hamstring complex and prevent de-conditioning of the entire body with involvement of hamstring researchers, strength and conditioning and athletic training professions; and 2) determine the inclusion of concepts and components of a five Phase Recovery Process incorporated in the hamstring complex rehabilitation program specifically for National Collegiate Athletic Association Division I Football athletes. 


\section{METHODS}

The design of this study followed the Modified Delphi Technique with the expectation of five Hamstring researchers, five NCAA Division I head Athletic Trainers and five NCAA Division I Strength Specialists to complete two rounds of the questionnaire to develop a hamstring complex rehabilitation program with a focus on preventing de-conditioning of the entire body throughout the rehabilitation process specifically for NCAA Division I Football athletes.

\section{Participants}

The occupation of the subject population was specified by the inclusion and exclusion criteria for the First Round questionnaire. Of the six potential candidates from the returned First Round questionnaire, four met the inclusion requirements for Athletic Trainers and Hamstring Researcher. There were two dropouts for the Second Round questionnaire, with only two panelists' returning a completed questionnaire. Initially, twenty Division I Football Certified Athletic Trainers (ATC), twenty-four Strength and Conditioning Specialists (SS) and twenty-nine Hamstring Researchers were contacted for the study. Potential candidates had to meet the requirements of employment by a NCAA Division I athletic program with a primary responsibility with Football as a Certified Athletic Trainer or Strength Specialist (SS) with at least five years of clinical/work-related experience. Five or more publications and/or presentations on hamstring injury, hamstring rehabilitation and/or hamstring strengthening components were required for a Hamstring Researcher to be considered for the panel. The exclusion criteria consisted of any candidate who did not meet the requirements for the inclusion criteria listed above. The West Virginia University's Office of Research Compliance approved this study. 


\section{Questionnaire}

Two rounds of the questionnaire were e-mailed to the participants via SurveyMonkey.com. The initial questionnaire included a demographic information section to acquire participant information while still providing anonymity. The second section included 223 categorical components and concepts for each Phase of the hamstring complex rehabilitation program. The program model was based on a Five-Phase Recovery Process with categories that the components and concepts were included based on the Phase. The categories included: baseline, contraindications, flexibility focus, range of motion and strengthening with ATC, core strengthening, strength and conditioning with SS, clinical tests or evaluation for progression, and progression to next Phase. Responses were based on the 5point Likert scale with 1 strongly disagree, 2 disagree, 3 neutral, 4 agree, and 5 strongly agree. Additional space was provided for participants to comment on each component and concept inclusion, as well as, the entire Phase. After submission of the First Round questionnaire, the means and percentages were calculated from those that responded and met the inclusion criteria to evaluate consensus of $75 \%$ and a mean score of 4 for each component and concept. The Second Round questionnaire only included the second section with the calculated data analysis for each component and the additional comments from each participant. The second round allowed the panel to review their initial responses, as well as, the other panelist's responses and to make adjustments if they deemed necessary. With the submission of the responses from the Second Round questionnaire, the investigator used consensus responses for the inclusion of components and concepts of each Phase and generated a complete hamstring complex rehabilitation program for NCAA Division I football athletes. 
Two committee members, a certified athletic trainer and strength and conditioning specialist, as well as, three certified Athletic trainers not involved in the study evaluated the questionnaire for face validity, readability, and clarity. This evaluation of the questionnaires was conducted prior to the panelists' involvement. A psychometric expert evaluated the questionnaire for face and content validity.

The components and concepts included in the questionnaire were from evidence-based research, as well as, best clinical practice. Many concepts were derived from published works of Sherry, ${ }^{3}$ Heiderscheit, ${ }^{6}$ and Petersen. ${ }^{27}$ The information that generated those concepts included isokinetic testing scores for hamstrings-to-quadriceps ratios, eccentric training, and clinical tests to determine return to play status.

The second section of the First Round questionnaire was comprised of the possible components and concepts for the complete hamstring complex rehabilitation program. The components and concepts were distributed throughout five subsections or Phases. The Phases were derived from the evidence-based knowledge of the Recovery Process, as well as, the clinical expectation of the athlete's involvement and interaction with Athletic Trainer and Strength Specialist throughout the rehabilitation process. Within each Phase, components and concepts were further categorized into specific topics: baseline, contraindications, flexibility focus, range of motion and strengthening with the ATC, core strengthening, strength and conditioning with the SS, clinical tests or evaluations for progression, and progression to the next Phase.

Modified Delphi Technique 
Some of the advantages of the Modified Delphi Technique are ease in the instrumentation of policy decision-making and panelists assume ownership of the problem and accompanying solution. ${ }^{28,29}$ The method provides avenues of controlled feedback, anonymity and establishment of consensus based on the panelists responses of hamstring complex rehabilitation program and prevention of de-conditioning for the entire body for Division I football. Finally, the technique provides a framework of panel communication among a variety of professional backgrounds and minimizes the possible physiological and other barriers that are typically present with interview-driven research. ${ }^{28}$

To make the Delphi Technique more specific for the use in the Allied Health field a modified version is applicable. This allows the investigator to ascertain and address such healthrelated concerns that lack evidenced-based research or opposing research. ${ }^{28}$ In utilizing the Modified Delphi Technique, the purpose was to develop a complete hamstring complex rehabilitation program incorporating rehabilitation of the hamstring and prevention of deconditioning specifically for Division I Football athletes that occurred through the collaborative judgments of a qualified panel of experts. A consensus was determined through two rounds of questionnaires provided to the panel. The First Round questionnaire was formatted with 223 rating-scale questions to yield components and concepts related to hamstring complex rehabilitation and training. Upon retrieval of the information, the Second Round questionnaire included feedback of the panels' anonymous responses and allowed another opportunity for consideration and/or change of participant's original ratings and generated a consensus. A consensus was met when $75 \%$ of the expert panelists select strongly agree or agree with a mean score of 4 or more on the Likert Scale. 
Threats to internal and external validity for this study were the generalizability across situations and population, selection bias and repeated questionnaires. Generalizability across situations was that the complete hamstring complex rehabilitation program may not be applicable to all NCAA Division I programs and positions of football. Generalizability across populations was that the panel of experts may not represent the entire allied health care and training professions affiliated with NCAA Division I football. The selection bias within the panel of experts may not evenly represent each qualifying group of Athletic Trainers, Strength and Specialists and Hamstring Researchers. Finally, repeating questionnaires may increase the number of dropouts or decrease interest from the panel due to the demand or requirements involved with the study.

The limitations with the use of the Delphi Technique, modified or not, is the low number of qualified participants involved in the study. Nevertheless, the Technique does not have a required minimum number of participants for study completion. ${ }^{28}$ Other limitations include the panelists' background information and experiences are uncontrolled throughout the study; and panelists' time spent on the responses may be limited due to other obligations resulting in a lower quality response. The determination of the consensus is vague and even unknown throughout the compiling process; finally the significance of the results is based on the panelists and brainstorming efforts which are uncontrollable by the investigator. ${ }^{28}$ Another limitation could be that the skewness of the questions utilized during the evaluation process may cause a high likelihood of misinterpretations of both the standpoints of the panelist and investigator. ${ }^{28,30}$ Intervention 
Seventy-three possible candidates, selected from the NCAA website, journal articles and referral from other Athletic Trainers and Strength Specialists, were contacted via e-mail to gauge interest in this field of study. (Table C1) Eight potential participants responded to the interest email. The First Round cover letter was sent to the four ATCs, two SSs and two Hamstring Researchers. Upon receiving their response, an official cover letter of participation was sent via e-mail. (Table C2) This first cover letter informed participants of the study's purpose and design with the inclusion of the procedure and required involvement along with the link to the First Round questionnaire. (Table C3) It also informed them of the time requirement and series of questionnaires that would be sent to them via the SurveyMonkey website. Within one week after the questionnaire was dispatched a follow up cover letter along with a link to the First Round questionnaire was sent. (Table C4) Participants were also informed that their involvement was voluntary, did not affect their job status, and their responses remained anonymous. Once the investigator received the six completed First Round questionnaire, the demographic section was utilized to determine the qualified panel of experts who met the inclusion criteria. The four panelists' responses were then calculated to determine the First Round and included the second Section of the Second Round questionnaires/ The four qualified panelists were sent a Second Round cover letter (Table C5) through SurveyMonkey including and ling the Second Round questionnaire. (Table C6) Only those participants that responded to the First Round questionnaire and met the inclusion criteria were sent the Second Round questionnaire along with the Second Round cover letter (Table C5). One week later, the Second Round follow up cover letter with link to the questionnaire was sent. (Table C7) 
After the responses of the Second Round questionnaire were received, the investigator determined the consensus and generated the components and concepts included in the complete hamstring complex rehabilitation program specific for NCAA Division I football athletes.

Survey Monkey

Survey Monkey was utilized to electronically distribute the questionnaire to the panel of experts. This online surveying tool provided anonymity of the panelists' though only allowing the investigator to view individual responses through a collector group. This means the investigator had knowledge of who participated in the study and was able to review completed questionnaires, but unable to tell which were their responses. SurveyMonkey also has a program for the investigator to contact the participants to send cover letters and reminders but did not allow direct contact with participants, essentially acting as a middleman to reinforce anonymity and confidentiality of responses. The primary investigator was able to track the status of a questionnaire and if the panelist has participated. Upon viewing the responses in the Analyze section of the SurveyMonkey website, demographic information was minimal and the panelist's name and/or email address was not included or visible. Firewalls were also established-on the SurveyMonkey website to prevent the investigator from exposing which responses correlate with which panelists. More specifically, SurveyMonkey uses a SSL encryption feature that provides an environment where there must be an authentication of key exchanges for an access to information on the SurveryMonkey website. This encryption provides confidentiality and message authentication codes for message security. Data Analysis 
The data analysis of this study included the frequencies of responses and means of responses from two rounds of the questionnaire. The rating and feedback that the panel of experts selected for each component and concept of the complete hamstring complex rehabilitation program questionnaire plus additional write-in comments were compiled for both rounds. The consensus for this study was defined by $75 \%$ of the panel's response of strongly agree or agree (5= strongly agree, 4= agree, $3=$ no opinion, $2=$ disagree, and $1=$ strongly disagree) and a mean score of 4 or more on the Likert scale for each component and concept. All data was analyzed using Survey Monkey. After consensus was met for each Phase, the responses were utilized in designing a complete hamstring complex rehabilitation program for Division I football athletes.

\section{RESULTS}

Demographic Information

Initially, an email was sent to seventy-three potential candidates to gauge interest in their participation. From the potential number of seventy-three, only eight responded with interest in the study. Those eight received the First Round cover letter through SurveyMonkey containing the link to the First Round questionnaire, including the demographic section. Six of the interested eight candidates return a completed First Round questionnaire. Of those six only four met the inclusion criteria for participation in the study with a $67 \%$ return rate in meeting the inclusion criteria. All contact with the participants including the cover letters and questionnaires was completed through SuveryMonkey website to keep anonymity.

Of the four qualified panelists, three were Certified Athletic Trainers and another qualified as a Hamstring Researcher. The other two potential candidates who returned the 
survey did have strength and conditioning backgrounds, however, they did not meet the inclusion criteria due to their limited employment experience with a Division I football program.

The inclusion criteria for participation, a candidate must have been employed with a Division I football program for five or more years as a certified Athletic Trainer or Strength Specialist, presented or published information concerning the hamstring complex. If the inclusion criteria was not met, participants' responses to the questionnaire were not considered. Six potential candidates returned the questionnaire that included the demographic section. Prior to determining the qualified panel of experts, $66.67 \%(n=4)$ candidates attained a master's degree, while $33.33 \%(n=2)$ attained a doctorate of philosophy.

The credentials of the potential candidates included certified athletic trainers $(50 \%$, $n=3)$, certified strength and conditioning specialist $(16.67 \%, n=1)$, and performance enhancement specialist $(33.33 \%, n=2)$. Candidates also listed other credentials not originally provided in the demographic section. Refer to Table D1 for a complete list of credentials.

For employment, 50\% ( $n=3)$ were practicing as Certified Athletic Trainers for more than ten years. Of the three candidates who were Athletic Trainers, $16.67 \%(n=1)$ have been employed with a Division I football program for five to ten years, whereas $33.33 \%(n=2)$ have been employed with a Division I football program for greater than ten years. Only $16.67 \%(n=1)$ of the candidates listed as a practicing Strength and Conditioning specialist. None of candidates, including the potential candidate who was listed as a practicing Strength Specialist, stated that they were practicing Strength Specialists employed with a Division I football program at any time in their career. 
The work setting of the candidates included academic $(66.67 \%, n=4)$, Athletic Training Room $(50 \%, n=3)$ and Weight Room $(16.67 \%, n=1)$. Other settings provided by the candidates included Exercise \& Muscle Physiology Testing \& Consulting (16.67\%, n=1).

Presentations related to the Hamstring Complex made at professional meetings, $16.67 \%$ $(n=1)$ gave five or more, $16.67 \%(n=1)$ gave three to four, $33.33 \%(n=2)$ gave one to two, and $33.33 \%(n=2)$ stated they had not presented information relating to the Hamstring Complex at a professional meetings.

Fifty percent $(n=3)$ of candidates published information in peer-reviewed research journals relating to the hamstring complex. Of the $50 \%$, two candidates had one to two articles published, and one had three to four articles published. The other $50 \%(n=3)$ did not have any research publications relating to the Hamstring Complex in peer-reviewed journals. Hamstring complex rehabilitation program for Division I football athletes

For a component or concept to be included in the rehabilitation program, each topic must meet a $75 \%$ consensus from the panel selecting of strongly agree and agree with a mean score of 4 or more. The process of acquiring the panelists' consensus was through two rounds of a questionnaire, with the Second Round questionnaire exactly the same as the First Round in reference to the original questions. The Second Round questionnaire included the percentages of panelists' responses, as well as, additional comments the panelists provided after the First Round. The supplementary percentages provided the expert panel the opportunity to retain or change their First Round responses and provide their opinion on additional comments.

The second section of the questionnaire was comprised of the possible components and concepts for the complete hamstring complex rehabilitation program. The components and 
concepts were distributed throughout five subsections or Phases. The Phases were derived from a combination of evidence-based knowledge of the Recovery Process, and the clinical expectation of the athlete involvement and interaction with the Athletic Trainer (ATC) and Strength Specialist (SS) throughout the rehabilitation progression. Within each Phase, components and concepts were further categorized into specific topics that include baseline, contraindications, flexibility focus, range of motion and strengthening with the ATC, core strengthening, strength and conditioning with the SS, clinical tests or evaluations for progression, and progression to next Phase.

Phase I

Initial Assessment integrated components and concepts concerning observation and evaluation of the injury and functional ability of the athlete after onset of injury. At this point in the Recovery Process, the expectation or hypothesis of an athlete's interaction and involvement with an ATC is 95\%; whereas, interaction and involvement with the SS is only $5 \%$. Refer to Table D2-D7 for all Phase I results.

Baseline: During the First Round of the questionnaire, one concept regarding the typical presentation of a Grade I \& II hamstring complex strains was highly rated. Pain with knee flexion had a mean score of 4.5 and a frequency of $100 \%$. However, during the Second Round, the concepts that met consensus were pain with knee flexion, decreased strength of hamstring complex, and decreased flexibility compared bilaterally with knee flexion from the 90/90position. The consensus was met with a mean range of 4.5 to 5 and a frequency of $100 \%$. Refer to Table D2 for results.

The typical mechanism of injury for grade I \& II hamstring complex strains that were 
rated higher during the First Round were eccentric contraction with a mean score of 4.5 and a frequency of $100 \%$ and over-reaching during a sprint with a mean score of 4 with a frequency of 75\%. During the Second Round, only one concept met consensus, which was eccentric contraction with a mean score of 4 and a frequency of $100 \%$. The concept of Over-reaching during a sprint for the Second Round actually decreased with a mean score of 2.5 and a frequency of $100 \%$. This last concept will still be included in the final program due to the strength of the literature.

For the First Round, the concept that exercises should be dictated by the ability to complete physical activity immediately post injury occurrence had a mean score of 4 and a frequency of $75 \%$. During the Second Round, the concepts that met consensus included dictation by mechanism of injury via sprinting, ability to complete physical activity immediately post injury occurrence and degree of injury, all with a mean score of 4 and a frequency of $100 \%$. Contraindications: Contraindications for Phase I was rated high in the First Round for eccentric strength exercises with a mean score of 4.25 and a frequency of $75 \%$. It met consensus in the Second Round with a mean score of 5 and a frequency of $100 \%$. For the first three days anything that causes pain also met consensus with a mean score of 4.5 and a frequency of $100 \%$.

Flexibility focus: The concepts concerning completion to not elicit pain during the acute phase of the healing process and should be painfree and the athlete should not over stretch especially this early in the recovery process met consensus in the Second Round (mean score: 4.5, frequency: $100 \%)$. Other concepts concerning flexibility that met consensus in the Second Round were isolation or single joint progression, manual therapy, and the use of a foam roller. 
All met consensus with a mean score of 4 and a frequency of $100 \%$. The panelists' rating during the First Round concerning flexibility exercises focusing on the entire lumbo-pelvic complex was a mean score of 4.25 and a frequency of $75 \%$. This concept during the Second Round met a consensus with a mean score of 4.5 and a frequency of $100 \%$. Refer to Table D5 for a list of results.

Range of motion with ATC: The panelists' rating during the First Round concerning completion of range of motion exercises was a mean score of 4.25 and a frequency of $100 \%$. The Second Round presented with a mean score of 4 with a frequency of $100 \%$, thus meeting consensus. The components concerning exercises for the hamstring complex should be only completed in a painfree range of motion, exercises for the gluteal group was rated high in the First Round and met consensus in the Second Round with a mean score of 4.5 and a frequency of $100 \%$.

Strengthening with the ATC and SS: The First Round presented with only one concept rated high, which was isometric strength concerning Phase I strengthening exercises with a mean score of 4.5 and a frequency of $100 \%$. The Second Round met consensus with a mean score of 4 and a frequency of $100 \%$. Refer to Table D6.

The component of core stabilization exercises was rated high in the First Round and met consensus for the Second Round. The First Round had a mean score of 4.75 with a frequency of $100 \%$, while the Second Round had a mean score of 4.5 with a continued frequency of $100 \%$. Core exercises should be more of a stabilization focus, and was rated high in the First Round (mean score: 4.75, frequency: 100\%) and met consensus for the Second Round (mean score: 4.5 and frequency: 100\%). Lifting and conditioning concerning exercises without involvement of the 
injured limb and progression for the rest of the body were rated high for the First Round and met consensus for the Second Round. Consensus was met with a mean range of 4 to 4.5 and a frequency of $100 \%$.

The only concept concerning aerobic conditioning for Phase I that was rated high in the First Round and met consensus for the Second Round was upper body ergometer sprints. The Second Round had a mean score of 4.5 with a frequency of $100 \%$. Refer to Table D6 for results.

Progression to Phase II and clinical tests/evaluations: Concepts determining athlete's ability to progress to Phase II that were rated high in the First Round were perform activities of daily living painfree, walking painfree, and athlete has full painfree range of motion. The Second Round had a mean range of 4.25 to 5 and a frequency of $100 \%$. Two concepts for clinical tests or evaluations completed to determine progress to Phase II met consensus for Second Round. With Second Round results of a mean score of 4 while the frequency increased to $100 \%$. Refer to Table D7.

Phase II

Implementation of Functional Activity includes components and concepts concerning the progression of the Recovery Process and functional activity incorporation. At this point in the Recovery Process, the expectation or hypothesis of an athlete's interaction and involvement, with an ATC is $75 \%$; where as, interaction and involvement with the SS is $25 \%$. For all results in Phase II refer to Table D8-13.

Baseline: Performing activities of daily living painfree and walking painfree concepts for baseline of the athlete met consensus for the Second Round with a mean score: 5 and frequency: $100 \%$. Refer to Table D8 for additional results. 
Contraindications: Only one concept met consensus for the Second Round. Heavy weight lifting of injured limb with a mean score of 4 and a frequency of $100 \%$, in the First Round, had a frequency $75 \%$ with a mean score of 3.75. (Table D9)

Flexibility Focus, range of motion exercises: The component concerning flexibility being addressed during Phase II met consensus for the Second Round, with a mean score: 4 and frequency: $100 \%$. Dynamic stretching exercises, manual therapy techniques and light massage concepts concerning the flexibility focus were rated high in the First Round. The Second Round results had those three concepts, as well as, additional concepts provided for continued evaluation of hip somatic dysfunction met consensus. The mean score of all consensus concepts for the Second Round was 4 with a frequency of $100 \%$. The concept of flexibility exercises completed more aggressively in Phase II compared to Phase I met consensus for the Second Round. The First Round mean score was 4 with a frequency of $75 \%$, while the Second Round also had a mean score of 4 with the frequency of $100 \%$. Refer to Table D10.

The continuation of Range of Motion exercises in Phase II component met consensus for the Second Round. The First Round had a mean score of 4.75 and a frequency of $75 \%$ that increased for the Second Round with a mean score of 5 with a frequency of $100 \%$.

Strengthening with ATC and core focused exercises: The strengthening exercises with the ATC concepts concerning isometric strength, endurance, concentric strength, strengthening exercises of the low back and lumbo-pelvic complex, and utilization of eccentric exercises met consensus for Second Round. All had a frequency of $100 \%$ and a mean range of 4 to 4.5 . Refer to Table D11.

The functional activity component and concept of completion of activity in a pool and 
once painfree met consensus for the Second Round with a common frequency of $100 \%$ and a mean score of 4 . Functional activity concepts for Phase II that met consensus for the Second Round included walk/job progression and aerobic training on a weight-bearing machine. The First Round results had a mean range of 4.25 to 4.75 with a frequency of $100 \%$. The Second Round results had a mean range of 4 to 4.5 , again with a frequency of $100 \%$.

Core strengthening and stabilization components met consensus for the Second Rounds. The First Round results had a mean range of $4.5-4.75$ with a frequency of $100 \%$. The Second Round results had a mean range of $4-4.5$ with the same frequency as the First Round. Refer to Table D11.

Strength \& conditioning with SS: Exercise concepts with the involvement of the injured limb included when weight is light, lift/conditioning movements that caused pain are not performed and through painfree range of motion that met consensus with a mean score of 4 and a frequency of $100 \%$ in the Second Round. The Second Round results were a minimal change from the First Round (mean score: 4 - 4.33, frequency: 75 - 100\%). Refer to Table D12.

Components concerning lifting and conditioning progression should be normal for the rest of body in Phase II met consensus for the Second Round (mean score: 4, frequency: 100\%), also rated high for the First Round (mean score: 4.75, frequency: 100\%). Aerobic conditioning concepts for Phase II during the First Round that were rated high were upper bike ergometer sprints and hydrotherapy running with a (mean score: 4, frequency: 75-100\%). For the Second Round only upper bike ergometer sprints met consensus with a mean score of 4 again and a frequency of $100 \%$. The components of dynamic warm up and beginning walk/job/run progression met consensus for the Second Round. The First Round results had a mean score of 
4.25 with a frequency of $100 \%$. The Second Round results had the same frequency with an increase in the mean score to 4.5. Refer to Table D12.

Progression to Phase III and clinical tests or evaluations: Three concepts concerning the status of the athlete prior to progression to Phase III was rated high for the First Round including no pain during hamstring stretch, walking lunges do not cause pain with full range of motion, and when functional activity is started (mean score: 4, frequency: 75 - 100\%). The Second Round results including when athlete feels ready, walking lunges do not cause pain with full range of motion and when functional activity is started all met consensus (mean score: 4, frequency: $100 \%)$.

Clinical test or evaluation concepts to determine progression to Phase III for the Second Round that met consensus were active straight leg raise to max range of motion painfree with max effort and leg swings (forward/backwards) with full range of motion painfree with a mean score of 4 and a frequency of $100 \%$. Refer to Table D13.

Phase III

Re-education of the Fundamentals of Strength \& Conditioning included components and concepts concerning progression of the Recovery Process and introduction and education of the fundamentals and skills required to perform strength and conditioning properly. The expectation or hypothesis of an athlete's interaction and involvement with an ATC and SS is 50\%. Refer to Table D14 - 18 for complete list of Phase III results.

Baseline: Perform functional activity with minimal pain and without pain concepts concerning the baseline of an athlete was rated highly for the First Round (mean score: $4-4.5$, frequency: 100\%). The concept of performing functional activity without pain was the only one 
to meet consensus for the Second Round with a mean score of 4 and a frequency of $100 \%$. Refer to Table D14.

Contraindications: The concept that met consensus after the Second Round was no restrictions with weight lifting of entire body, including injured limb (mean score: 4, frequency: $100 \%)$.

Flexibility Focus, range of motion and strengthening with ATC: Dynamic stretching component to increase hamstring flexibility met consensus for the Second Round (mean range: 4 - 4.35, frequency: 100\%). Concepts for strengthening exercises for the hamstring complex that met consensus for the Second Round were endurance, concentric strength and eccentric strength, and power with a mean range of 4 to 4.5 and a frequency range of 75 to $100 \%$. The component for eccentric exercises increasing in intensity and volume met consensus for the Second Round with a mean score of 4 and a frequency of $100 \%$ when compared to the First Round results. Inclusion of strengthening exercises of the lumbo-pelvic complex met consensus for the Second Round. The First Round results revealed a mean score of 4.5 and a frequency of $100 \%$. The Second Round results decreased the mean score to 4; nevertheless, the frequency remained the same. Refer to Table D16.

Strengthening and conditioning with SS: Functional activity concepts that met consensus for the Second Round included: jog/sprint progression, conditioning with team and agilities/skills performed at moderate pace, and moderate to high-speed sprinting progression. The Second Round results presented a smaller mean range (4 - 4.5) with a frequency of $100 \%$. The component concerning core stability exercises with a plyometric base with challenges in multiple planes did meet consensus for the Second Round. The First Round had only three 
panelists' responses (mean score: 4.33 , frequency: $75 \%$ ). The Second Round had a mean score of 4 and a frequency of $100 \%$. Refer to Table D17.

Components regarding educational exercise demonstration to re-enforce proper sprinting technique met consensus during the Second Round with a mean score to 4 and frequency of $100 \%$. The components and concepts for power lifting exercises with lightweight, exercises involving the injured limb, and lifting and conditioning progression in conjunction with team progression met consensus for the Second Round. The Second Round results had a mean range of 4 to 4.25 and a frequency of $100 \%$. Refer to Table D17.

Concepts regarding aerobic and anaerobic conditioning with the team that met consensus for the Second Round were the injured athlete may perform at as-tolerated pace during endurance running, un-weighted running can be utilized to return speed and endurance to pre-injury levels, and circuit training with injured limb involvement. The mean range for the Second Round was $4-4.5$ with a frequency of $100 \%$. Use of dynamic warm-up completed with the team and athlete fully participating in skill, individual and agility drills with team component met consensus for the Second Round. The consensus was a mean score of 4 with a frequency of $100 \%$.

Progression to Phase IV and clinical tests or evaluations: The concern of re-injury within the first two-weeks post return to full participation component met consensus for the Second Round. The First Round was rated highly (mean score: 4.5 and frequency: 100\%), the frequency stayed the same for the Second Round with a mean score of 5. The concepts concerning clinical tests or evaluations to determine return to full participation that were rated high for the First Round are athlete returned to participation for full contact and full speed drills without 
presentation of pain/soreness, full strength bilateral no pain at 0 degree and full flexion of knee, 5-10 repetitions of a highly intense eccentric exercise and flexibility equal bilateral (mean score: $4.25-4.5$, frequency: $75-100 \%)$. The concepts that met consensus for the Second Round were athlete returned to participation for full contact and full speed drills without presentation of pain/soreness, 5-10 repetitions of a highly intense eccentric exercise and flexibility equal bilateral with a mean range of 4 to 4.5 and a frequency of $100 \%$. Refer to Table D18. Phase IV

Re-conditioning of the Body includes components and concepts concerning the Return to Play progression and conditioning of the athlete. The expectation or hypothesis of an athlete's interaction and involvement with an ATC has decreased to $25 \%$, where as, the SS has increased to $75 \%$. Refer to Table D19 - 23 for Phase IV results.

Baseline and contraindications: Concepts for the baseline and contraindications all met consensus for the Second Round, with the mean score of 4 and frequency of $100 \%$. Refer to Table D19.

Flexibility focus and strengthening with ATC: The concepts concerning dynamic stretching completed with team and flexibility exercises completed as needed met consensus for the Second Round. The First Round results had a high rating (mean score: 4.25 - 4.5, frequency: 75 - 100\%). The Second Round results had a mean score of 4 and a frequency of $100 \%$ for both concepts.

Strengthening exercises for the hamstring complex and returning strength, endurance, and power to pre-injury levels met consensus for the Second Round. The results revealed a mean range of $4-4.5$ and a frequency of $100 \%$. Strengthening exercises to increase strength of 
lumbo-pelvic complex with proprioceptive challenges, lower extremity plyometric exercises, and rehabilitation exercises focused on maintaining correct hamstring complex function met consensus for the Second Round. The mean score, for all concepts, was 4 with a frequency of 100\%. The component concerning lengthened-state eccentric exercises completed if weight lifting does not included eccentric exercises in team program did not meet consensus for the Second Round, however, due to the strength of the literature, this component will be included in the final program. Refer to Table D20.

All functional activity completed with team agilities and conditioning met consensus for the Second Round. The difference between the rounds was the mean score decreased from 4.5 to 4 while the frequency stayed the same at $100 \%$. Core exercise components completed during team weight lifting and are not a primary focus during Phase IV met consensus for the Second Round with a mean score of 4 , an increase from the First Round at 3.75, and a frequency of $100 \%$.

Strength \& conditioning with SS: The components regarding sprinting technique and power lifting exercises with progression to weight prior to injury met consensus for the Second Round. The Second Round results presented a mean score of 4 and a frequency of $100 \%$. Full participation in skill, agility and contact requirements met consensus for the Second Round, with a final mean score of 4 and a frequency of $100 \%$.

Progression to Phase $V$ and clinical tests or evaluations: The clinical tests or evaluation concepts to determine progression to Phase $V$ and no concern or fear of re-injury met consensus for the Second Round. The final results displayed a mean range of 4.5 - 5 and a frequency of $100 \%$. Refer to Table D22 for results. 
Phase V

Reintroduction of Physical and Positional Demands includes components and concepts concerning continued maintenance of the rehabilitation program and full participation of the athlete with their specific position. The expectation or hypothesis of an athlete's interaction and involvement with an ATC is 5\%, where as, the SS is 95\%. For Phase $\mathrm{V}$ results refer to Table D23 - 24.

Baseline and contraindications: The components and concepts met consensus for inclusion into the program. Second Round results had a mean score of 4 and a frequency of 100\%. Refer to Table D23 for list of concepts.

Strengthening and continued maintenance with ATC and SS: The component for completion of endurance exercises for the hamstring complex three times per week met consensus for the Second Round. The Second Round resulted with a mean score of 4 and a frequency of $100 \%$.

Strength and conditioning components with the SS regarding athlete's full return, continuation of team weight lifting/conditioning program and perform all strength and speed requirements at pre-injury level met consensus for the Second Round. The First Round had a mean range of $4.5-4.75$, which increased to a range of $4-5$ after the Second Round. The frequency for both rounds was a consistent $100 \%$.

Continued maintenance: Continued maintenance component with the athlete instructed to continue maintenance program to decrease risk of re-injury met consensus for the Second Round. The component resulted with a mean score of 5 and a frequency of $100 \%$. Variance between rounds 
Of the 223 components and concepts presented in the First Round, 112 were rated favorably. For the Second Round, 244 were presented with twenty-one being additional comments from the First Round panel of experts. Of the 244 components and concepts for the Second Round, 126 met consensus and are included in the rehabilitation program. Between rounds, fourteen components and concepts that were rated favorably in the First Round did not meet consensus in the Second Round. The variation between rounds is due to the panel of experts having the opportunity to review the percentage of group responses along with additional comments and original components and concepts. This opportunity allowed the panel to change their original response. The variation is also due to the decrease in the number of Second Round participants. The results were affected by participants changing responses, as well as, a decrease in the number of participants between rounds. There were six responses in the First Round, with two qualifying for the exclusion criteria. For the Second Round, only two participants of the original qualifying four submitted their responses. According to the premise of the Modified Delphi Technique, consensus is met when a panel responds to several rounds of the questionnaire and allow for the opportunity for the panel to change responses for each round. Refer to Table D25 for totals of components and concepts with consensus. Final rehabilitation program

The Modified Delphi Technique was used to generate a complete hamstring complex rehabilitation program through the use of two rounds of a questionnaire provided to a qualified panel of experts. The following Table D25 displays the 126 components and concepts that met consensus following the Second Round of the questionnaire. For a component or concept to meet consensus, $75 \%$ of the panel must chose strongly agree or agree and a mean score of 4 or 
more. An additional seven components and concepts were included in the final rehabilitation program that did not originally meet consensus. Six of the additional inclusions were from the literary findings, while one was based on best-clinical practice.

Overall, this rehabilitation program is a guideline for ATCs and SSs in reference to the applicability of the rehabilitation program specifically for the Division I football athlete. Over the course of the five Phases, the components and concepts that met consensus or were included in the program due to strength in the literature do reflect the development of specific skills, such as speed and power that all football athletes need to perform at the elite level. Furthermore, this is not a program that provided guidelines for the use of modalities or manual therapy, but strictly rehabilitation therapies and techniques. Also, this program is a component and concept based, therefore, does not provide specific exercises or techniques. Instead this builds a base on which ATCs and SSs may utilize knowledge and understanding of the components and concepts by implementing their techniques within the confines of the program guidelines.

Phase I: From the results, the consensus on components and concepts does follow the original interaction percentages provided by the research prior to the completion of the questionnaire. For this Phase, the interaction between the athlete and ATC is 95\%, with the components and concepts reflecting that, whereas the percentage for Strength Specialist is 5\%. Refer to Tables D26 -27 for the number of specific components and concepts that met consensus for each category.

Within this Phase, the components and concepts that met consensus also provided the ATC with possible mechanisms of injury, which will play a role in how the rehabilitation 
program is implemented. It is important to note that the focus of Phase I is to not cause more pain to the athlete after the initial injury. These components are what the panel of experts made consensus on after the completion of the Second Round. For example, the components and concepts that met consensus concerning core focused exercises were for stability instead of strength, and does follow an evidence-based rehabilitation program. However, there is a concept that did not meet consensus but was included in this program due to the strength of the literature. Evidence-based research provides information that over-reaching during a sprint is a common mechanism of injury to the hamstring complex; therefore, inclusion into this program is necessary. This is because this mechanism will dictate the implementation of the rehabilitation program. Proper sprinting technique should be both the ATC and SS's emphasis when the athlete is returning to functional activity.

The evaluation of hip somatic dysfunction through Phase I and II was included due to the strength in the literature that lumbo-pelvic dysfunction can be a possible cause of injury to the hamstring complex. Therefore, it can be postulated that it is important for the clinician to evaluate the function of the lumbo-pelvic complex to rule out or treat any possible malalignments.

Another guideline aspect is that the high involvement of the ATC is mainly to set limitations on the athlete in regards to physical activity and participation in football. Overall, the components and concepts that met consensus for the inclusion into the final rehabilitation program did not specifically concern exercise techniques, instead places and increased role on the ATC to protect the injured area through limitation of the athlete in regards to physical activity. 
Phase II: As seen in Table D28, this Phase provided the components and concepts that should be utilized after the athlete is able to meet the baseline requirements of Phase II. The panel met consensus on beginning a light functional activity progression, as well as, increasing the intensity and aggressiveness of the exercise components when compared to Phase I.

The Phase reflected the interaction percentages with the athlete, the ATC and the SS. The panel also met consensus on components and concepts that provide progression of the athlete that is not aggressive and cause for concern of high re-injury risk. In addition, the panel does not meet a strong consensus on the use of flexibility focused exercises as a component or concept throughout the rehabilitation program. The panel did met consensus on the utilization of those exercises to increase hip motion if necessary, however, the panel made a point to not over-stretch the injured hamstring complex during Phase I. The panel also did not met consensus on any static stretching components or concepts for Phase II.

Light static stretch should utilize the PNF technique met inclusion due to the strength in the literature. This type of technique will aid in increasing the hamstring complex's strength, both concentrically and eccentrically, while keeping mobility of the injured muscle. The ATC will also be able to adjust intensity of the exercise to not cause further injury or pain but still allow benefits to be acquired.

It is important to note that there is an increase in the number of actual exercise components and concepts that are completed by the athlete during this Phase. Unlike Phase I, where protection of the injured hamstring complex is a main concern, this Phase is the start of returning the correct function back to the hamstring complex.

Phase III: This Phase met the expectation of the interaction and involvement between 
the athlete and ATC at 50\%, with the SS at 50\%. See Table D29 for Phase III guidelines. The panel did met consensus on components and concepts that still highly involve the ATC, such as, function activity progression, the continued use of range of motion exercises, and the increase in aggressiveness of the strengthening exercises. In addition, it is obvious that the number of exercises completed with the ATC has notably decreased, whereas the SS's responsibility increased. This Phase is the start of the educational process concerning the proper sprint technique needed to potentially decrease risk of re-injury. This is strongly supported in the literature and the panel met consensus on components and concepts concerning proper sprint technique.

One concept concerning clinical tests and evaluations was included due to the strength and focus in the literature. The $75 \%$ difference of eccentric hamstrings to concentric quadriceps functional ratio was most likely misunderstood by the panel during the Second Round of the questionnaire. Nevertheless, inclusion is important because during gait while the quadriceps are concentrically contracting, it is the responsibility of the hamstring complex to control that contraction through an eccentric contraction. Therefore, the knowledge of the ratio difference will provide the clinician with information on where the progression of the athlete is in reference to both Phase IV and return to full participation.

Phase IV: This Phase does not follow the progression of percentage interaction between the athlete, ATC and SS. The hypothesis was that as progression through the rehabilitation occurred, there would be a decrease in the responsibilities of the ATC and an increase of the SS. However, the panel met consensus on many components and concepts concerning involvement with the ATC. The emphasis of this Phase was for the SS to re-educate the athlete on proper 
technique as well as return the athlete to strength and ability levels acquired prior to the current hamstring complex injury. Refer to Table D30.

The Panel met consensus on components and concepts specific to football; however, emphasis was placed under the jurisdiction of the ATC instead of the SS.

Lengthened-state eccentric strengthening exercise component was included in this Phase due to the strength of the literature. Successful outcomes were apparent in evidencebased research with the use of eccentric training; therefore, inclusion is a requirement.

Phase V: The emphasis of this Phase was placed on continued maintenance, as the most common cause of re-injury is prior history. The list of components and concepts in Table D31 met the hypothesized interaction percentage of the ATC at $5 \%$ and the SS at $95 \%$. The panel placed a large emphasis on the SS to return the athlete to original strength and speed levels, as well as, continue to condition them to be prepared for elite football activity. This Phase is an extension of Phase IV in regards to full participation of the athlete. The ATC has already returned the athlete to participation; however, the concern during Phase IV was possible reinjury especially during the first two weeks post return to play. Phase $V$ is the continuation of the return to play process, as well as, the education of the athlete to risk of re-injury. Continuation of the rehabilitation program to preserve the hamstring complex functioning properly as well as lowering the level of risk is paramount in Phase 5. Refer to Table D31.

\section{DISCUSSION}

To provide a complete hamstring rehabilitation program using Athletic Trainers and Strength and Conditioning Specialists, this study was developed to generate a rehabilitation program that a clinician can use as a guideline throughout the course of the recovery process to 
Return to Play. The study was modeled after the Modified Delphi Technique with the use of two rounds of a questionnaire. The First Round included 223 potential components and concepts concerning hamstring complex rehabilitation that were initially provided to a panel of experts.

The Second Round, included 244 potential components and concepts with additional comments added for the panel's review. The components and concepts were categorized into baseline, contraindications, flexibility focus, range of motion and strengthening with the Athletic Trainer, core focus, strength and conditioning with a Strength Specialist, clinical tests or evaluations for progression, and progression to the next Phase over the course of a Five-Phase program. The components and concepts had to meet a consensus of $75 \%$ of strongly agree and agree with a mean score of 4 or more to be considered for inclusion. Upon the conclusion of the Second Round questionnaire, 126 components and concepts met consensus. Those 126 components and concepts, with the addition of seven components comprised the complete hamstring complex rehabilitation program. The Five-Phase rehabilitation program was developed from best clinical practice and evidence based research incorporating the athlete's interaction percentages with the Athletic Trainer and Strength Specialist throughout the recovery process. Phases I - III and V all follow the percentage of involvement and interaction between the athlete, ATC and SS. Phase IV did not follow this percentage hypothesis with too much emphasis placed on the ATC. Therefore, a suggestion is that more research be conducted to determine the proper exercise components and concepts for Phase IV, as well as, a reviewal if the percentage of interaction and involvement of the ATC and SS throughout the rehabilitation process follows clinical findings.

The panel of experts for the First Round of the questionnaire included three Athletic 
Trainers and one Hamstring Researcher. However, there were two dropouts from the First to Second Round. The Second Round panel consisted of one Athletic Trainer and one Hamstring Researcher. Although the comments and selections were helpful in determining the final program, a Strength and Conditioning Specialist (SS) did not meet the inclusion criteria for participation on the panel of experts. Thus, the time point and responsibility of the Strength and Conditioning specialist can only be interpolated from the responses of the Athletic Trainers and Hamstring Researcher.

The likelihood of hamstring complex strains in football at the professional level, increases within the first five weeks of training with a rate of $52.2 \% .^{2}$ At the collegiate level, hamstring complex strains account for $18.9 \%$ of all injuries throughout a season. ${ }^{1}$ While these numbers may appear small in respect to all injuries that may occur over the course of one season, hamstring complex strains have the second highest rate of injury occurrence only falling slightly behind knee injuries. ${ }^{2}$ With injury occurrence rates being as high as they are it is necessary for clinicians and other health care professionals to have available the information for a successful return to play for the athlete. This final rehabilitation program developed does provide a good start to developing a complete hamstring complex rehabilitation program, but further research is necessary to complete the role of the Strength and Conditioning Specialist. Evaluation of the complete hamstring complex rehabilitation program

Overall, the progression of the Phases does share similarities with evidence-based rehabilitation programs, such as Heiderscheit et al, ${ }^{6}$ Schmitt et al, ${ }^{31}$ and Petersen et. al. ${ }^{27}$ However, due to the nature of the final rehabilitation program, it cannot be directly compared to the listed evidence-based rehabilitation programs due to the lack of specific rehabilitation 
techniques and exercises. For example, in Phase 1 of Schmitt et al, $^{31}$ single leg balancing is suggested. ${ }^{31}$ Whereas Phase I of this rehabilitation program, does have the same goals as Schmitt et al., ${ }^{31}$ it only provides components or concepts of a specific topic like the completion of isometric exercises. If this rehabilitation program is generally comparable to the ones presented in research, especially in reference to some of the goals obtained for each Phase. Petersen et al. ${ }^{27}$ presents a 5 Phase program with the progression based on the healing process of the injured tissue. However, there are significant differences such as inclusion of a time period for each phase, as well as, only focusing on the injured tissue instead of the whole picture. ${ }^{27}$ This rehabilitation program's progression of Phases is a combination of the recovery process with re-training of the athlete in preparation for return to elite physical activity in the sport of football.

As this complete rehabilitation program was to be developed for Division I football, some components and concepts were pertinent, while others were not. Due to the lack of a Strength Specialist on the panel of experts, the rehabilitation program vaguely relates to Division I football athletes. There are inclusion of components and concepts regarding power exercises, skill and agility drills with the team, and re-education of sprint technique that do relate to the development of speed, change in direction and vertical ability, which do predict on-the-field performance measures for the elite level of Division I football. ${ }^{32}$ Thus, although this information is pertinent for this rehabilitation program, the maintenance of football skills was not specific enough. Davis et. al. ${ }^{32}$ did postulate that high bench press and heavy hang clean are strong predictors specifically for lineman, whereas speed and vertical jump are specifically for skill and combination positions. ${ }^{32}$ To be specific to football, this rehabilitation program should 
present and include the components and concepts that look to develop speed and vertical jump ability more than a heavy bench and hang clean because skill and combination positions have a higher risk of hamstring complex injury. ${ }^{1}$ In a review of overall numbers, Elliott et al. ${ }^{1}$, found that skill and combination positions had 120 hamstring complex strains per season compared to lineman who only had 22. More specifically, the defensive secondary had 41, with wide receivers sustaining 37 per season. ${ }^{1}$ Therefore, it is extremely important that the ATC and SS focus on returning speed and vertical jump ability, as well as, making sure the athlete is psychologically ready to return to play in efforts to not only decrease risk of re-injury to the hamstring complex, but also decrease risk of injury overall and prepare the injured athlete to participate at the elite football level. Additional research is necessary to make this complete rehabilitation program more specific to Division I football.

Another purpose of this complete rehabilitation program was to prevent deconditioning of the body over the course of the recovery process. There is limited evidencebased research concerning this aspect, with minimal studies including cardiovascular fitness into the rehabilitation program. ${ }^{27}$ Or research primarily focuses reconditioning the hamstring complex instead of the entire body, which negates the systemic atrophy that occurs during times of low physical activity. ${ }^{2}$ This rehabilitation program incorporates conditioning exercises, as early as Phase I, without causing pain or further injury and potentially decreasing the likelihood of decreased strength overall.

As the Phases progressed, the Range of Motion components and concepts decreased in importance. By Phase III, the panel ruled out the use or need of Range of Motion exercises. An interesting note is that overall flexibility components and concepts that met consensus were 
regarded as basic exercises that should not be focused on throughout the entire rehabilitation process. In a similar fashion, core focused components and concepts decreased in attention with the Athletic Trainer's involvement and increased with the Strength Specialist's attention. The core focused components and concepts met consensus throughout the five Phases with a stabilization focus instead of a strength factor. This follows the evidence-based research with core stability exercises as an important component in hamstring complex rehabilitation programs. ${ }^{2,6}$

When comparing the results to the literature, all follow the most recent research. Pervious literary findings stated that flexibility and range of motion exercises are the two most important concepts when rehabilitating a hamstring complex strain. ${ }^{34,78,35}$ However, most recent evidence based research suggests that early on in the rehabilitation process the injured area must be protected, therefore, flexibility and range of motion exercises should not be utilized until after the acute phase. ${ }^{5,27,6}$ Some current research does not even utilize flexibility exercises throughout their rehabilitation programs. ${ }^{31}$ Most research now places emphasis on completion of core focused exercises. ${ }^{2,6}$ Some literature labels core exercises as trunk stabilization or lumbo-pelvic stabilization, nevertheless, all have the same goal of increasing the stability of the lumbo-pelvic region to decrease the amount of stress applied to the hamstrings. $^{33,6}$

In reference to Strength and Conditioning Specialist's involvement, the panel of experts met consensus on a component concerning core exercises completed during Team lift and conditioning, however, those exercises are not a focus point for the rehabilitation program. The components and concepts included in the Strength and Conditioning area of expertise are 
mostly from best-clinical practice. Nevertheless, the inclusion of eccentric exercises did met consensus for Phase III - V and followed the literature for application for Strength and Conditioning. ${ }^{27,3,6,31}$

There were several components and concepts that were expected to rate highly throughout the two rounds, however, consensus was not met for the Second Round and were not included into the final program automatically. Hamstring-to-quadriceps strength ratios were listed in the questionnaire with different percentages for a possible number value used to determine progression to the next Phase and return to play status. However, for every Phase none of the given percentages met consensus for either round. Another interesting note was that a panelist in the First Round provided an additional comment concerning the use of isokinetic values for hamstring complex strains were obsolete as studies ${ }^{10}$ have indicated that there is no difference between injured vs. non-injured ratios. This additional comment was provided to the panel in the Second Round and did not met consensus as well. It was speculated that this could be due to the limitation of the study or that the panel did not agree with the comment. Conflicting views are evident in regard to evidence based research. It has been noted in studies ${ }^{5}$ that isokinetic strength differences between recurrent hamstring complex strains versus no prior history lead to hamstring weakness as a causative factor for reinjury. However, this study does not specifically state the optimal hamstring-to-quadriceps strength ratio. Many other studies have presented different ratios to be ideal, but none have yet to be standardized. ${ }^{8,34}$

Phase I: The hypothesis of this Phase was to have the athlete's main involvement with the ATC at $95 \%$ and the SS at $5 \%$. The panel did confirm this hypothesis and also reinforced the 
component of avoiding anything that caused pain and focused on protection of the injured area. For Phase I, the high involvement percentage for the ATC is mainly to control participation in physical activity and set limitations with strength and conditioning techniques as to decrease risk of further injury.

In Heiderscheit et al., ${ }^{6}$ the first two phases are listed with the goals of protection. Within those phases, end-range or full range of motion is not achieved unless it is painfree or does not cause soreness after completion of the exercise. ${ }^{6}$ The components and concepts that met the inclusion criteria for the final tool do follow the literature.

Some of the concepts that met consensus included light flexibility exercises not to elicit pain for three days post injury and do not over stretch. The emphasis from the panel on increasing flexibility, specifically for the lumbo-pelvic area instead of the hamstring complex, portrays recent evidence-based hamstring complex rehabilitation programs that place focus on the lumbo-pelvic hip complex and not the hamstring complex alone. ${ }^{34,78,35}$ Furthermore, the lack of emphasis on the hamstring complex does correlate with epidemiological findings in that lack of flexibility is a low causative factor for hamstring complex strains and that continued research must be completed to ascertain the true mechanism of injury. ${ }^{34,8,35}$ There may be other reasons as to why inclusion of flexibility components and concepts of utilization were rated low and may be based party on the limitations of this study.

Starting in this Phase, the SS's role is minimal; nevertheless, conditioning with the rest of the body is warranted in the prevention of de-conditioning. This follows the purpose of the study in generating a complete hamstring complex rehabilitation program with the prevention of de-conditioning of the rest of the body. It would be difficult to bring in the literature due to 
the variance of strength and conditioning protocols that can be utilized. Nevertheless, the emphasis is to rehabilitate and prevent de-conditioning, as long as the injured limb is not involved in the exercises with the SS.

Phase II: Unlike most evidence-based rehabilitation programs, functional activity is started during this Phase. This is most likely linked to the Baseline requirements at the start of Phase II. The panel met consensus on inclusion of the beginning of a walk/jog progression, and completion of functional activity in a pool. In the second of three phases labeled the Subacute Phase, Croisier et al. ${ }^{5}$ does state that swimming pool activities may be completed for proper gait pattern correction. However, Croisier's ${ }^{5}$ expectations may be too passive, when compared to the presented rehabilitation program, as baseline for this Phase is painfree walking and completion of activities of daily living painfree. Therefore, the correction of a gait pattern would not be necessary.

This Phase is still predominately with the ATC as functional activities and strengthening exercises (isometric, concentric and light eccentric) are completed. The transition of focus and responsibility is starting to shift to the SS as dynamic warm-up and light, painfree lifting with the injured limb is stressed. The continued emphasis from the SS's perspective is to prevent deconditioning as long as it does not cause further damage or pain. Again it is difficult to incorporate the literature due the lack of evidence based research on the interactions of the ATC and SS during the rehabilitation process, but clinically the percentages and the deconditioning focus appear reasonable based on best-clinical practice.

Phase III: The inclusion of more extensive eccentric exercises was evident in this phase. An understanding of the eccentric mechanism of injury and the use of eccentric exercises such 
as Nordic hamstrings to decrease the re-injury rate of the hamstring complex is becoming apparent. ${ }^{3,27,36}$ Mjølsnes et $\mathrm{al}^{37}$ and Petersen et. $\mathrm{al}^{27}{ }^{27}$ both conducted studies concerning the use of eccentric hamstring training and the subsequent results of changes in strength and injury rates. Mjølsnes et $\mathrm{al}^{37}$ competed a randomized controlled trial of two groups completing a hamstring strengthening program. One group completed concentric exercises and the other group completed the Nordic hamstring exercises for 10 weeks. The results showed that the Nordic hamstring group significantly increased in eccentric hamstring strength when measured isokinetically. ${ }^{37}$ It was also found that the Nordic hamstring group significantly increased in hamstring-to-quadriceps strength ratios and maximal isometric torque tested at three angles of the knee. ${ }^{37}$ Petersen et $\mathrm{al}^{27}$ also completed a ten week progressive Nordic hamstring strengthening program and evaluated the resultant injury rate and time away from full participation. The study was randomized controlled trial consisting of 942 men's soccer players on fifty-four different teams. The intervention group of twenty-three teams, suffered fifteen hamstring complex injuries, while the control group of twenty-seven teams suffered fifty-two. ${ }^{27}$ The intervention group had a told of 454 days absent from soccer, where as, the control group had 1344 days absent from soccer. ${ }^{27}$

Another component that was stressed in the literature and met requirements for inclusion was the educational exercises demonstrated to re-enforce proper sprinting technique. In epidemiological reports, with a focus on football, the common mechanism of injury to the hamstring complex occurs from acceleration or running at maximum velocity. ${ }^{3,12,34}$ The understanding is that during the late swing phase, there is a high eccentric contraction of the hamstrings and gluteal muscles to decelerate hip flexion and knee extension all the while, the 
hamstrings are being placed on a stretch further increasing the amount of stress. ${ }^{17,34}$ If poor sprint technique occurs during the late swing phase, the likelihood of injury to the hamstring complex is high. ${ }^{34,38}$ From this literature, education of proper sprint technique is necessary.

During this Phase, the role of the strength and conditioning specialist increased, which is similar to what was hypothesized with the interaction percentages set prior to the completion of the questionnaire. Power lifting and light conditioning with involvement of the injured limb has begun. The primary focus is to not cause further injury or pain to the athlete, but to start anaerobic and aerobic activity with the team, as well as, incorporating skill, individual and agility drills with the team, all to prevent deconditioning. However, with the increasing intensity of functional activity during this Phase, there are a limited number of components that specifically apply to the training of Division I Football. Due to the limitations of this study, further research is warranted to develop this Phase more specifically for the football athlete.

Phase IV: During this Phase, the athlete is returning to play and the role of the ATC is decreasing. However, the components and concepts that met consensus, the football specificity is still being placed with the ATC instead of the SS. The problem with this is that ATCs do not have a background in football specific training, unlike the SS. Concepts with focus from the SS that did meet consensus include continuation of sprint work and power lifting progressing back to pre-injury weight. However, with the panel's lack of an SS's participation, the specific role in this phase can only be interpolated from the other participants. This is an area that required further evaluation. In addition, this Phase does not follow the hypothesized percentages of involvement and interaction for the ATC and SS.

The components of lengthened-state eccentric exercises completed if weight lifting is 
not included in exercises in team program did not meet consensus for the Second Round. Nevertheless, there is strong support in the literature for the utilization of lengthened-state eccentrics; therefore, the concept was included in the final rehabilitation program. ${ }^{94,10}$ Lengthened-state eccentrics has been shown to increase strength at the end range of knee extension. ${ }^{94,10}$ The background information is that these exercises strengthen the hamstring complex muscle when it is most vulnerable during the late swing phase due to hip flexion and knee extension and lengthened position of the biarticulate hamstring muscles. ${ }^{4,34,65}$ By increasing the strength of the hamstring complex muscles in this lengthened-state it could decrease injury rate for that specific mechanism of injury. ${ }^{10}$

Phase V: The main emphasis of this phase was a complete return to physical activity, to complete a full sprint without pain and hesitation and perform at pre-injury levels. However, there was no mention to maintain flexibility of the lumbo-pelvic region in the final rehabilitation program. Nevertheless, continuation of increasing mobility should occur for an overall decrease of risk of injury. ${ }^{26}$ The understanding of the decrease in risk is from the muscle's ability to absorb forces at end range. If the muscle is lacking the range of motion required to efficiently complete a movement, the stress is placed on non-contractile tissue and further increases risk of injury. ${ }^{39}$ Another example is when there is a decrease in hip and quadriceps flexibility as this will decrease the range of motion allotted to the hip. In a static position increased stress is placed on the pelvis, causing a hip anterior rotation and lengthening the hamstring complex. ${ }^{34}$ When running gait is then required from this changed positioning, the hamstring complex is now required to properly function throughout movement in a maximum length, further increasing the risk of injury ${ }^{34}$ 
The athlete is fully returned with the expectation that speed and strength have returned to levels prior to injury and that strengthening is completed with the SS rather than the ATC. Moreover, though there is the inclusion of speed and strength exercises with the SS. Phase $\mathrm{V}$ is still not specific to what is necessary for the elite participation in Division I football. As stated previously, the strong predictors of high performance within Division I football are high vertical jump and fast times with a 36.6 sprint and shuttle run. ${ }^{32}$ Phase $V$ does not provide any comparable components or concepts to meet those needs. Further research is needed in this area to be as sport specific to Division I football as possible.

\section{Clinical Application}

The final complete hamstring complex rehabilitation program can be used as a guideline for ATCs and SSs. Due to the nature of this rehabilitation program being designed with components and concepts, it is easily generalizable to any situation, position or individual with Division I Football. A football team is made up of several varying positions that are not placed under the same stressor, nevertheless, they may experience hamstring complex strains. This program allows for individualization and specificity for each situation that may arise over the course of a season. The design of the program makes it easy for ATCs and SSs to develop an individualize protocol for their athlete while providing opportunity to individualized techniques instead of having to conform to a generalized protocol. This program also reminds ATCS and SSs of the importance of communication between professions, while generating the protocol and progression throughout the rehabilitation process.

Generally, the components and concepts do follow evidence-based rehabilitation programs; however, this program cannot be compared due to the lack of specific exercises or 
techniques presented. It cannot be postulated on exact exercises clinicians will include in their rehabilitation program when using this tool. Therefore, this tool cannot be compared to other evidence-based programs such as Sherry et. al's. ${ }^{3}$

Nevertheless, the components and concepts included in this program display progression not just through the Phases but also agree with the present technique utilization and progression that was not present several years ago. For example, the use of core focused exercises, although not stressed in this program is a rather new component added to hamstring complex rehabilitation. ${ }^{33}$ It is not defined clearly so that studies are unsure what the specific name should be, some authors describe this as trunk stabilization. ${ }^{3}$ The point of these exercises is to increase lumbo-pelvic control and decrease the risk of injury to the hamstring complex. ${ }^{34}$ Studies $^{33}$ show a decrease in recurrence rates with the inclusion of core stability exercises. Therefore, it can be hypothesized that with the inclusion of core stability exercises in this complete rehabilitation program the risk of re-injury to the hamstring complex is decreased.

It is strongly suggested that continued research on the topic of complete hamstring complex rehabilitation with the balance between ATC and SS to promote healing and decrease de-conditioning of the body be completed specifically for Division I football athletes. Research should be completed to evaluate the success of this rehabilitation program on decreasing recurrent hamstring complex strains, as well as, the recovery period or length of time an athlete is away from full participation. Finally, further evaluation into the role of causative factors such as fatigue and dehydration may have on the risk of hamstring complex strains, as well as, how they can be implemented into the rehabilitation program as preventative measures. 
Limitations

The limitations of this study were due to the low number of participants for the Second Round, including the two dropouts between rounds of the questionnaire. Even though the Modified Delphi Technique does not specifically state a minimum number of panelists, it does suggest an ideal number to be least ten members. ${ }^{28}$ The selection bias was also a limitation. Due to the inclusion requirements, only four of the initial six potential participants qualified for the study. Of those qualified, three were Athletic Trainers and one was a Hamstring Researcher. There was no representation of a Strength Specialist on the panel. Other limitations include the panelists' time spent on the completion of the questionnaire and the panel's understanding of the components and concepts presented. This could lead to a high likelihood of misinterpretations of both the standpoints of the panelists and investigator. ${ }^{28,30}$ Finally, completing the questionnaire twice may be the reason for dropouts due to the time demand and prolonged involvement in the study. The several rounds may have decreased the participant's interest in the review of the original information further decreasing the significance of their responses.

\section{CONCLUSIONS}

The Second Round questionnaire included 244 components and concepts regarding the complete hamstring complex rehabilitation process. 126 components and concepts met consensus and were included in the final rehabilitation program. An additional seven components and concepts were included based on the strength of the findings in the literature and best-clinical practice. In the evaluation of the Phases overall, Phases I - III and V complement the hypothesis and definition requirements, however, Phase IV does not met the 
hypothesis which may be due to the lack of a Strength Specialist on the panel of experts. For the Second Round the panel was only made of up two participants, an Athletic Trainer and Hamstring Researcher, nevertheless, they still provided a starting point for this novel complete hamstring complex rehabilitation program. As a result, it is strongly suggested that this study be completed again with the expectation of a large number of participants, including Strength and Conditioning Specialists, as well to evaluate the success of the complete hamstring complex rehabilitation program for the Division I football athlete. 


\section{REFERENCES}

1. Elliott M, Zarins B, Powell J, Kenyon C. Hamstring muscle strains in professional football players: a 10-year review. Am J Sport Med. 2011;39(4):843-850.

2. Feeley B, Kennelly S, Barnes R, Muller M, Kelly B, Rodeo S, Warren R. Epidemiology of national football league training camp injuries from 1998-2007. Am J Sports Med. 2008;36(8):15971603.

3. Sherry M, Best T, Silder A, Thelen D, Heiderscheit B. Hamstring strains: basic science and clinical research applications for preventing the recurrent injury. Strength Cond J. 2011;33(3):56-71.

4. Foursekis K, Tsepis E, Poulmedis P, Athanasopoulos S, Vagenas G. Intrinsic risk factors of non-contact quadriceps and hamstring strains in soccer: a prospective study of 100 professional players. Br J sports Med. 2011;45:709-714.

5. Croisier J. Factors associated with recurrent hamstring injuries. Sports Med. 2004;34:681-695.

6. Heiderscheit B, Sherry M, Silder A, chumanov E, Thelen D. Hamstring strain injuries: recommendations for diagnosis, rehabilitation, injury prevention. J Orthop Sports Phys Ther. 2010;40(2):67-81.

7. Craig T, ed. Comments in Sports Medicine. Chicago, IL: American Medical Association;1973.

8. Brockett C, Morgan D, Proske U. Predicting hamstring strain injury in elite athletes. Med Sci Sport Exerc. 2004;36(3):379-387.

9. Levine W, Bergfeld J, Tessendorf W, Moorman C. Intramuscular corticosteroid injection for hamstring injuries. Am J Sports Med. 2000;28(3):297-300

10. Linklater J, Hamilton B, Carmichael J, Orchard J, Wood D. Hamstring injuries: anatomy, imaging and intervention. Seminars Musculoskeletal Radio. 2010;14(2):131-161.

11. Rosene J, Fogarty T, Mahaffey B. Isokinetic hamstrings: quadriceps ratios in intercollegiate athletes. JAT. 2001;36(4):378-383.

12. Woods C, Hawkins R, Maltby S, Hulse M, Thomas A, Hodson A. The football association medical research programme: an audit of injuries in professional football - analysis of hamstring injuries. Br J Sports Med. 2004;38:36-41.

13. Foreman T, Addy T, Baker S, Burns J, Hill N, Madden T. Prospective studies into the causation of hamstring injuries in sport: a systematic review. Phys Ther Sport. 
2006;7:101-109.

14. Gabbe B, Bennell K, Finch C, Wajswelner H, Orchard J. Predictors of hamstring injury at the elite level of Australian football. Scand J Med Sci Sports 2006;16:7-13.

15. Gabbe B, Finch C, Bennell K, Wajswelner H. Risk factors for hamstring injuries in community level Australian football. Br J Sports Med. 2005;39:106-110.

16. Clayton M. Delphi: a technique to harness expert opinion for critical decision-making task in education [electronic version]. Edc Psyc. 1997;17:373-387.

17. Verrall G, Slavotinek J, Barnes P, Fon G, Spriggins A. Clincal risk factors for hamstring muscle strain injury: a prospective study with correlation of injury by magnetic resonance imaging. Br J Sports Med. 2001;35:435-440.

18. Aguilar A, DiStefano L, Brown C, Herman D, Guskiewicz K, Padua D. A dynamic warm-up model increases quadriceps strength and hamstring flexibility. J Strength Cond Res. 2012;26(4):1131-1141.

19. Cameron M, Adams R, Maher C. Motor control and strength as a predictor of hamstring injuries in elite players of australian rules football. Phys Ther Sport. 2003;4:159-166.

20. Upton $P$, Noakes $T$, Juritz J. Thermal pants may reduce the risk of recurrent hamstring injuries in rugby players. Br J Sports Med. 1996;30:57-60.

21. Orchard J, Seward H. Epidemiology of injuries in the Australian football league, seasons 1997-2000. Br J Sports Med. 2002;36:39-45.

22. Orchard J. Intrinsic and extrinsic risk factors for muscle strains in australian football. Am J Sport Med. 2001;29(3):300-303.

23. Mason D, Dickens V, Vail A. Rehabilitation for hamstring injuries. Cochrane Database Systematic Reviews. 2007;4:1-26.

24. Sugiura Y, Saito T, Sakuraba K, Sakuma K, Suzuki E. Strength deficits identified with concentric action of hip extensors and eccentric action of hamstrings predispose to hamstring injury in elite sprinters. J Orthop Sport Phys Ther. 2008;38(8):457-464.

25. Arnason A, Sigurdsson S, Gudmundsson A, Holme I, Engebretsen L, Bahr R. Risk factors for injuries in football. Am J Sports Med. 2004;32(1):5S-16S.

26. Koulouris G, Connell d. Evaluation of the hamstring muscle complex following acute injury. Skeletal Radiol. 2003;32:582-589.

27. Petersen J, thorborg K, Bachmann M, Budtz-Jorgensen E, Holmich P. Preventive effect of 
eccentric training on acute hamstring injuries in men's soccer. Am J of Sports Med. 2011;39(11):2296-2303.

28. Sandrey M, Bulger S. The Delphi method: an approach for facilitating evidence based practice in athletic training. Athl Train Edc J. 2008;3(4):135-142.

29. Sahakian C. The Delphi Method. Skokie, IL: The Corporate Partnering Institute;1997.

30. Murry J, Hammons J. Delphi: a versatile methodology for conducting qualitative research. Rev Higher Edc. 1995;18:423-436.

31. Schmitt B, Tyler T, McHugh M. Hamstring injury rehabilitation and precention of reinjury using lengthened state eccentric training: a new concept. IJSPT. 2012;7(3):333-341.

32. Davis D, Barnette B, Kiger J, Mirasola J, Young S. Physical characteristics that predict functional performance in division I college football players. J Strength Cond Res. 2004;18(1):115-120.

33. Sherry M, Best T. A comparison of 2 rehabilitation programs in the treatment of acute hamstring strains. J Orthop Sports Phys Ther. 2004;34(3):116-125.

34. Hoskins $\mathrm{W}$, Pollard $\mathrm{H}$. The management of hamstring injury- part 1 : issues in diagnosis. Manual Therp. 2005;10:96-107.

35. Mair S, Seaber A, Glisson R. The role of fatigue in susceptibility to acute muscle strain injuries. Am J sport Med. 1996;24:137-147.

36. Oliver (razor curl)

37. Mjolsens R, amason A, Osthagen T. A 10-week randomized trial comparing eccentric vs. concentric hamstring strength training in well-trained soccer players. Scand J Med Sci Sports. 2004;14:311-317. 2004

38. Ekstrand J, Healy J, Walden M, Lee J, English B, Hagglund M. Hamstring muscle injuries in professional football: the correlation of mri findings with return to play. Br J Sports Med. 2012;46:112-117.

39. Burkett L. Causative factors in hamstring strains. Med Sci Sport Exerc. 1970;2(1);39-42. 


\section{APPENDICES}




\section{APPENDIX A}

\section{THE PROBLEM}

\section{Research Question}

High injury risk in any level of football has become a norm; therefore, there is a need for proper prevention and efficient rehabilitation to return to the field without increasing risk of reinjury. A most recent ten year review of NFL injuries from 1998-2007 during preseason camp, there was an average of 52.2 injuries per year over the five week span. ${ }^{2}$ Further evaluation of the high injury rate, muscle strains are the most common. ${ }^{2}$ Within the number of muscle strains, the location of the second highest occurrence was to the hamstring complex with 85 occurrences. Of the hamstring complex strains, $46 \%$ occurred during practice while $22 \%$ occurred in games. The high injury rate to the hamstring complex is not just evident at the professional level, it is also occurring at the collegiate and high school football levels. High school football experience a injury rate of $12-24 \%$ of muscle strains. ${ }^{1}$ At the collegiate level, there is a $7.7 \%$ rate of hamstring strains per player per year, with $18.9 \%$ of those strains occurring during the season. ${ }^{1}$ Even in the Australian Football League (AFL), $16 \%$ of all playing time missed over the course of one season is due to a hamstring complex injury. The AFL also has a reoccurrence rate of $34 \% .{ }^{8,40}$ This high occurrence rate of hamstring complex injuries is evident in football, but also other sports such as soccer and rugby. ${ }^{14}$

Even though the rate of hamstring complex strains is high, the recovery interval or length of time away from participation can vary from eight days to 25 days. ${ }^{6}$ Research suggested that the range in recovery interval is related to the location and severity of the injury, 
as well as previous history and variation of the hamstring rehabilitation program. ${ }^{6}$ The main focus of most research is tracking the occurrence rates of hamstring complex strains; however, there are limited and conflicting publications on the prevention and the rehabilitation of hamstring complex strains.

High rates of hamstring complex strains occur because of the required actions. Hamstring complex stains typically occur in sports that require sprinting, kicking, or high-speed skilled movements. ${ }^{3}$ Elliott et. al. ${ }^{1}$ completed a study regarding football and hamstring complex, the defensive secondary consisting of cornerbacks and safeties, had the highest percentage of hamstring strains at $23.1 \% .{ }^{1}$ Compared to other positions, the defensive secondary had a frequency of 41 per season with wide receivers at 37, running backs at 22 and linebackers at 20. ${ }^{1}$ In Division I Football, hamstring injuries typically occur during sprinting activities with many other causative factors preceding the moment of injury. Nevertheless, evidence-based research has found that $74.4 \%$ of the hamstring injuries were attributed to sprinting. ${ }^{1}$

While epidemiology reports are thorough in providing occurrence rates of hamstring injuries, the causative factors or etiology of hamstring strains vary greatly. Usually hamstring strains are attributed to include poor flexibility, ${ }^{3,8,12,13,14,15}$ lack of eccentric hamstring complex strength, ${ }^{6,16}$ low back/hip weakness, ${ }^{16,38}$ improper dynamic warm-up, ${ }^{17,8,13,14,15,12}$ incorrect running technique, ${ }^{18,19}$ type of training or the volume/intensity per week, ${ }^{13,20}$ lack in core strength, ${ }^{3}$ poor hamstring rehabilitation, ${ }^{21,12}$ fatigue, ${ }^{8,12,13,14,15,6,22,23}$ poor lumbar-pelvic posture, ${ }^{8,14,6,16,24}$ hamstring weakness, ${ }^{1,8,12,14,15,6,22,23}$ Hamstrings-to-Quadriceps ratio, ${ }^{3,8,11 \text {, }}$ $12,13,6,16,20$ premature return to play, ${ }^{13,21}$ or prior history. ${ }^{3,13,14,15,12,23,25}$ The number of causative factors provides difficulty in preventing hamstring complex strains, as well as, 
designing a hamstring complex rehabilitation program. This is due to the lack of evidencebased or best clinical practice guidelines for a complete hamstring rehabilitation, including rehabilitating the hamstring injury as well as preventing de-conditioning of other areas not affected by the injury.

There are many rehabilitation programs presented in the literature that only focus on specific risk or causative factors without the involvement of strength and conditioning aspect to assist in the prevention of de-conditioning of the entire body. For example, some evidencesbased rehabilitation programs share common themes such as the inclusion of trunk stabilization or eccentric exercises. ${ }^{3}$ However, those rehabilitation programs differ by emphasizing an increase in flexibility and proper dynamic warm-up as included in a rehabilitation program by Sherry et. al. ${ }^{33}$ Whereas, Heiderscheit et. al. ${ }^{6}$ places more emphasis on overall hamstring strength. There is a need for a complete rehabilitation program that decreases both risk of re-injury and recovery interval all the while maintaining conditioning of the entire body, especially during a sport season. Therefore, several questions to ask when designing a complete hamstring complex rehabilitation program are: 1) What was the mechanism of injury of the original hamstring complex strain injury? 2) Does that mechanism of injury dictate how the program should be designed or focused? 3) If this is a recurrent hamstring complex strain injury, is it due to an inadequate rehabilitation program? If so, what needs to be changed?

Exploration of possible causative factors and potential rehabilitation programs presented in evidence-based research utilized after a hamstring injury had been evaluated; however, attention or emphasis did not include the strength and conditioning aspect. In 
Division I football, there is constant access to both the athletic training and weight rooms.

Therefore, neither profession ceases their interaction once an injury occurs, and in fact interaction increases to a higher level. It is important that the strength and conditioning field be incorporated into a rehabilitation program while the athlete is recovering.

To further support the increased interaction between the medical and physical training fields during injury, and the balance and involvement throughout the Recovery Process. Evidenced based research demonstrated that a Division I football athlete requires specific talents and skills in order to perform at an elite level including agility, coordination and strength. ${ }^{32}$ Therefore, training or defining these talents and skills can never cease. Davis et al. ${ }^{32}$ noted a correlation with the $\mathbf{3 6 . 6}$ meter sprint and vertical jump as valid predictors of high performance on the football field. The same can be said for high bench press, long sit and reach and heavy hang clean as these predicted a faster 18.3 meter shuttle run time. ${ }^{32}$ However, a high body composition provided slower shuttle run times. Therefore, skill and combination position athletes are expected to have a fast 36.6 meter sprint and shuttle time with a high vertical jump. Whereas high body composition, and heavy bench and hang clean are requirements for linemen for elite performance at the Division I level. ${ }^{32}$ Because of the expected speed and strength outputs from head coaches for success in football, strength specialist may be exposing athletes to the potential mechanisms of injury to the hamstring as well. Thus understanding and the application of proper techniques and exercises to condition and strengthen the entire body is very important and required consistently throughout a Division I Football season. However, when a hamstring complex strain occurs, rehabilitation will primarily focus on the hamstring complex, while the rest of the body has a potential to de- 
condition as a result of discontinued activity. Therefore, this de-conditioning should be addressed throughout the recovery interval of the hamstring complex strain and not when the athlete returns to their sport. If not, the increase risk of re-injury because of the requirement for the athlete to perform at previous level may occur.

In conclusion, general hamstring complex rehabilitation programs with focus on prevention of de-conditioning and incorporation of causative factors is lacking in the literature. Therefore, the following research questions are being asked:

\section{Research Questions}

1. What should be the Baseline of the athlete at the start of each Phase during a complete hamstring complex rehabilitation program for Division I Football athletes?

2. What should the Contraindications for each Phase of a complete hamstring complex rehabilitation program for Division I Football athletes?

3. Which Phase should Flexibility be conducted during a complete hamstring complex rehabilitation program for Division I Football athletes?

4. What Flexibility focused components and concepts should be included in each Phase of a complex hamstring complex rehabilitation program for Division I Football athletes?

5. Which Phase should Range of Motion and Strengthening with the Athletic Trainer be conducted during a complete hamstring complex rehabilitation program for Division I Football athletes?

6. What range of motion and strengthening components and concepts should be included in each Phase of a complex hamstring complex rehabilitation program for Division I Football athletes?

7. Which Phase should Core focused exercises be included in a complete hamstring complex rehabilitation program for Division I Football athletes?

8. What Core focused exercise components and concepts should be included in each Phase of a complex hamstring complex rehabilitation program for Division I Football athletes?

9. Which Phase should Strength and Conditioning with the Strength Specialist be included in a complete hamstring rehabilitation program for Division I Football athletes? 
10. What Strength and Conditioning components and concepts should be included in each Phase of a complex hamstring complex rehabilitation program for Division I Football athletes?

11. What clinical tests and evaluation components and concepts should be included concerning progression to next Phase in a complete hamstring complex rehabilitation program for Division I Football athletes?

12. What Phase should Return to Play process be completed prior to a Division I Football athlete returning to full physical activity after a complete hamstring complex rehabilitation program?

13. Will a panel of experts agree on exercise components and progression of the hamstring complex rehabilitation program for Division I Football athletes?

\section{Experimental Hypotheses}

1. There will be consensus of the participants (75\%) in the study and a mean score of 4 on the Likert Scale concerning Baseline components and concepts of each Phase related to the hamstring complex injuries.

2. There will be consensus of the participants (75\%) in the study and a mean score of 4 on the Likert Scale concerning Contraindication components and concepts of each Phase related to the hamstring complex injuries.

3. There will be consensus of the participants (75\%) in the study and a mean score of 4 on the Likert Scale concerning Flexibility focused components and concepts.

4. There will be consensus of the participants (75\%) in the study and a mean score of 4 on the Likert Scale concerning Range of Motion and Strengthening with the Athletic Trainer components and concepts.

5. There will be consensus of the participants (75\%) in the study and a mean score of 4 on the Likert Scale concerning hamstring strengthening exercise components and concepts.

6. There will be consensus of the participants (75\%) in the study and a mean score of 4 on the Likert Scale concerning Core focused exercise components and concepts.

7. There will be consensus of the participants (75\%) in the study and a mean score of 4 on the Likert Scale concerning Strength and Conditioning with the Strength Specialist components and concepts.

8. There will be consensus of the participants (75\%) in the study and a mean score of 4 on the Likert Scale concerning Clinical Evaluation components and concepts. 
9. There will be consensus of the participants (75\%) in the study and a mean score of 4 on the Likert scale concerning Progression to the next Phase components and concepts.

10. There will be consensus of the participants (75\%) in the study and a mean score of 4 on the Likert Scale concerning Return to Play process components and concepts.

11. There will be consensus of the participants (75\%) in the study and a mean score of 4 on the Likert scale concerning Continued Maintenance components and concepts.

Assumptions

1. All participants will remain in the study to complete both rounds of questionnaires.

2. Each individual participant will answer all the questions based on clinical knowledge.

3. The questionnaire developed will be valid and reliable.

4. Questionnaires will be returned in a timely manner.

5. All respondents will answer the questionnaire honestly.

6. Questions included in the questionnaires are related to the topic being reviewed.

\section{Delimitations}

1. A small panel of experts, based on expertise, will be chosen to participate in this study.

2. This study will only be generalizable to hamstring complex rehabilitation of NCAA Division I Football athletes.

3. This study will only include expert panelists specified by the inclusion and exclusion criteria. The exclusion criteria are possible candidates not meeting specified standards.

4. The panel of experts will consist of Division I Football Certified Athletic Trainers and Strength and Conditioning Specialists with at least five years of clinical/work-related experience.

5. The panel of experts will consist of hamstring researchers who have five or more publications and/or presentations on hamstring injury, rehabilitation and/or strengthening components.

6. The results of the questionnaire will be based solely on the opinions of the chosen panel of experts. 


\section{Operational Definitions}

1. Athlete- Person who is on the roster of a NCAA Division I Football team.

2. Athletic Trainer (ATC)- A person who passed the Board of Certification exam in athletic training and fulfills the continued education credits through the Board of Certification, Inc.

3. Circuit/Complex Training - Training method that alternates multi-joint exercises with a limited rest period. ${ }^{41}$

4. Complete hamstring rehabilitation program - Program created to achieve specific goals or parameters that entails general risk factors of hamstring complex injury and deconditioning of other areas not affected by the injury.

5. Component - A stand-alone general aspect in relation a category within each Phase. The panel of experts will respond in order to meet consensus on.

6. Conjugate Training - Method that combines multiple forms of training over a single training cycle. Forms of training may include Hypertrophy, Power, Olympic or Endurance aspects.

7. Consensus - A point when there is $75 \%$ or greater agreement on a specific topic with a mean score of 4 on the Likert Scale.

8. Concept - An example of a general aspect or topic related to a listed category within each Phase. The panel of experts will respond in order to meet consensus on each concept listed not the including a component it may be attached to.

9. Core Stabilization - The ability to transfer the body's center of gravity around the trunk or stationary supporting base. These exercise techniques focus training on transverse abdominus, multifidius, and quadratus lumbarum muscles that surround the lumbar spine for increased control of lumbar and hip motion. ${ }^{42}$ In addition, spinal stabilization in a balance and unbalanced environment for increase control of lumbar, hip motion, and movement of the extremities is also stressed.

10. De-conditioning or Detraining - Cessation or decrease in anaerobic training or reduction of frequency, volume, and/or intensity results in decreased performance and loss of the physiological adaptations acquired from resistance training. ${ }^{41}$

11. Dynamic warm-up - Stretching techniques that are similar to the movements of football, focusing on working through the range of motion required to prepare the body for the high demands of football which requires a stretch-shortening cycle of high intensity. ${ }^{41}$ 
12. Eccentric hamstrings exercises - Exercise technique that creates a contraction in which the hamstring muscle lengthens while being activated. ${ }^{42}$

13. Experts - A specified person who meets the predetermined requirements of five or more years with Division I Football as an athletic trainer or strength and conditioning specialist; five or more publications and/or presentations on hamstring injury, rehabilitation, and strength training.

14. Flexibility - Goniometric measurement utilized to assess maximal static range of motion around a specific joint or region of the body. ${ }^{43,44,45}$

15. Functional Activity - Position specific activities designed to prepare an athlete for return to activity. ${ }^{42}$

16. Hamstring complex - Group of muscles which perform both hip extension and knee flexion. The hamstring complex is composed of the semimembranosus, semitendinosus, long/short head of biceps femoris, and adductor magnus.

17. Hamstring Complex Strain - A strain injury occurs during the deceleration of the lower leg throughout swing phase. ${ }^{5}$ Hamstring complex experiences a protective eccentric action, tension develops while the muscles lengthen, when the muscles surpass mechanical limits the strain injury occurs. ${ }^{5}$ Classification for grade I hamstring complex strain occurs from a typical mechanism of injury with minor swelling and discomfort with no or minimal loss of strength. ${ }^{6}$ Classification for a grade II hamstring complex strain is a typical mechanism of injury with clear loss of strength with more discomfort. ${ }^{7}$

18. Hamstring-to-quadricep strength ratio (Ham:quad ratio) - Isokinetic testing of hamstrings and quadriceps for comparative peak torque ratios. In general, the ratio is utilized to examine the differences in moment-velocity patterns, magnitude of torque generated and overall muscle strength. ${ }^{42}$

19. Hamstring researcher - A person who has published or presented information on hamstring function, injury, rehabilitation or strength training.

20. Hip Complex - Composed of muscles primarily in the hip joint which may also assist with lumbar-pelvic and hamstring complexes in the movement and stabilization of the lower limbs. Primary muscles of the hip include muscles of the low back and thigh that act on the hip region.

21. Hydration status - Adequate level of total body water percentage or fluid balance which is based on body composition. This fluid balance is achieved by the regulation of fluid intake through changes in thirst sensations and regulation of loss by the kidneys. ${ }^{41}$

22. Isolation flexibility progression - Static stretching exercises to optimize range of one specific joint or muscle. ${ }^{42}$ 
23. Isokinetic Training - Type of high level training or conditioning that requires maximizes force or effort against resistance that is controlled by specified speed or velocity. ${ }^{42}$

24. Lengthened-State Eccentrics - Eccentric strengthening exercise completed isokinetically or isometrically. The exercise is completed in a seated position with an increased amount of hip flexion. The athlete resists passive knee extension from 90 degrees to 0 degrees. This positioning and controlled resistance places the hamstring complex in a fully lengthened position. ${ }^{31}$

25. Likert Scale - 1-5 ordinal scale correlating to categorical labels allowing readers to ascertain a number value to a categorical response. The categorical labels are a range of responses, those responses include: disagree, somewhat disagree, somewhat agree and agree.

26. Low back complex/ Lumbar-pelvic complex - Composed of muscles functioning in the lumbar spine and pelvis. May also assist in stabilization of the lower limbs.

27. Methodology - Individuals experienced-based practice on a specific injury.

28. Modified Delphi Technique - Technique modeled after the Delphi Technique. The main purpose is to provide a questionnaire to a panel of experts and utilize responses to meet a consensus and produce the best evidence based practice and establish policies and procedures in an area in the athletic training field where research is limited or contradictory. ${ }^{28}$

29. Multi-joint flexibility progression - Dynamic exercises to optimize motion of a specific movement requirements of football, not emphasizing on specific muscle or joint range of motion. ${ }^{41}$

30. NCAA Division I Football - National Collegiate Athletic Association: Governing body of all college athletics, divided into three divisions with specific education and athletic requirements for each level. Division I is considered the highest level of athletic talent/ability with the inclusion of high academic standards and the distribution of athletic scholarships.

31. Panel of Experts - Number of people who meet the qualifications of "expert."

32. Position (Football player position) - Specific to each player on the football team, determines what demands or requirements athlete will perform during the course of play or physical activity. Labels are:

a. Skill positions - wide-receiver, running back, quarterback, corner back, safety

b. Combo positions - tight end, defensive end, linebacker, full back 
c. Linemen - offensive/defensive linemen

33. Strength Specialist or Strength and Conditioning Specialist - A person who completed the certification of Strength and Condition specialist and fulfills continuing education credits through the National Strength and Conditioning Association.

34. Recovery Interval - Period or length of time from initial moment of injury to complete return to play.

35. Sprinting Technique - Skill-specific exercise to promote the ballistic mode of locomotion with an alternating flight phase and single-leg support phase. The method to increase performance in running strides that repeatedly launch the athlete's body as a projectile at maximal acceleration and/or velocity over brief distances and durations. ${ }^{41}$

36. Training Team - Includes athletic trainer and strength specialist working together to achieve one common goal.

37. 5-Phase Program - The five Phases are: Initial Assessment, Implementation of Functional Activity, Re-education of the Fundamentals of Strength and Conditioning, Reconditioning of the Body, and Reintroduction of Physical and Positional Demands. The Phases were generated based on the amount of involvement and interaction the athlete has with the Athletic Trainer and Strength Specialist. Within each Phase, components and concepts were categorized into baseline, contraindications, flexibility focus, range of motion and strengthening with Athletic Trainers, core focus, strength and conditioning with a Strength Specialist, clinical tests or evaluations and progression to the next Phase.

\section{Limitations}

1. The panel must have expertise in the rehabilitation of hamstring strains and the prevention of de-conditioning of the entire body.

2. The panel's personal and professional responsibilities may limit the amount of time and effort that each expert can provide to completing the questionnaire. ${ }^{28}$

3. Drop out of participants may occur between the two rounds of questionnaires.

4. There will be a time delay between questionnaire submission from the author until the completion from the panel.

5. There will be a time delay between round 1 and 2 of the questionnaire.

Threats to Internal and External Validity 
1. Generalizability across situations - The complete hamstring rehabilitation program may not be applicable to all programs or positions of Division I football.

2. Generalizability across people - The panel of experts may not represent the entire allied health care and training professions', who are affiliated with Division I football.

3. Selection bias - The panel of experts may not be evenly represented within each of the three groups: strength and conditioning specialists, athletic trainers and hamstring complex researchers.

4. Repeated questionnaires - Several rounds of the questionnaire are required to form a consensus for the formation of the complete hamstring rehabilitation program. This may cause an increase in dropouts due to the demand or prolonged involvement or decrease interest in the review of the original information making the responses mundane or not applicable.

Significance of the Study

The design of a complete hamstring complex rehabilitation for National Collegiate Athletic Association Division I football athlete will be a guideline for clinicians and Strength Specialists when a hamstring complex strain occurs. It will provide some understanding as to why hamstring injuries re-occur and what should be a focus during the Recovery Process. The program will also prepare the athlete for return to elite participation and decrease the reoccurrence rate that occurs with premature return to play. 
APPENDIX B

\section{LITERATURE REVIEW}

Participating in Division I football, the athlete accepts the risk of injury associated with the sport. With the sport of football there is a variety of positions and skill sets required to perform. Therefore, an injury occurrence can at a point in time be unpredictable and make it difficult in understanding the cause of mechanism. Evidence-based research provides confirmation that a risk of injury is two times more likely to occur in football when compared to basketball at the high school level. ${ }^{41-43}$ In high school, muscle strains account for $12-24 \%$ of all injuries per year. ${ }^{1}$ Even though those numbers are from the high school football level, an epidemiological study completed at the collegiate football level found that the rate of injury is 8.61 per 1000 athlete-exposure, whereas high school only has a rate of $4.36 .^{41}$ In addition, to the injury rate of football at the collegiate and high school levels, there is a high occurrence rate at the professional level as well. ${ }^{2}$ In a review of National Football League preseason camps from 1998-2007, there was an average of $52.2 \%$ injury rate over the span of 5 weeks. ${ }^{2}$

Evaluating those numbers, the knee is the highest injured area acquiring 120 occurrences with the diagnosis being knee sprains. ${ }^{2}$ Only second to the knee was posterior thigh. The diagnosed injury was hamstring strains with 85 occurrences. ${ }^{2}$ The more common cause for knee sprains or knee injuries in general are contact or direct blow. ${ }^{41}$ Therefore, knee injuries are rarely a part of the ambiguous injuries that occur with the sport of football when the mechanism of injury or causative factor is unknown.

Muscle strains, on the other hand, are the main injuries that can present with obtuse evaluations or presentations and involve multiple ways to treat, rehabilitation and return to 
play while having a high re-injury rate. As stated previously, hamstring strains have a high injury rate, coming only in second to knee injuries. ${ }^{2}$ In respect to all muscle strains, at the collegiate level hamstring strains account for $18.9 \%$ of the injuries over the course of one season. ${ }^{1}$ Further more, hamstring strains occur at a rate of $7.7 \%$ per person per year. ${ }^{1}$ In another epidemiological review of the National Football League, it was found that $23.1 \%$ of total injuries were hamstring strains, with defensive secondary, including cornerbacks and safeties, acquiring a large percentage. ${ }^{1}$ In comparison to other positions, defensive secondary was found to have a mean frequency of 41 per season, whereas wide receivers have 37 , running backs have 22 , and linebackers have $20 .^{1}$

Therefore, why is discussion and further research about hamstring injuries and rehabilitation significant? The reasoning is that there is a vast number of epidemiological research providing the percentages of occurrence rates for injuries such as hamstring strains, however, research is lacking in respect to the effectiveness of evidences-based programs and inconsistency over the techniques included. Therefore, hamstring injuries continue to have high percentage of injuries throughout collegiate football. ${ }^{2}$ Not only are these numbers seen in American Football, but also in Australian Rules football. Australian Rules Football is a combination of soccer and Gaelic football and has a $15 \%$ hamstring injury rate and a re-injury rate of $34 \% .{ }^{13,24}$ With hamstrings having both a high injury rate and re-injury rate the need for proper preventative treatment rehabilitation that provides results is in high demand.

Evidenced-based research presents a conundrum to the topic of hamstring strains. More specifically the evaluation and presentation of hamstring strains vary with every case. ${ }^{27}$ Clinical presentation for grading hamstring strains is typically based on point tenderness, range of 
motion and strength deficits. ${ }^{34}$ Most articles base grade I \& II strains by the length of time away from the sport, which is after the fact. Elliott et. $\mathrm{Al}^{1}$ provides a definition for minor, moderate and major hamstring strains. The article classifies minor (grade I) strains with a presentation of the recovery interval less than seven days, moderate (grade II) strains with between seven to twenty-one days and major (grade III) strains are out for longer than twenty-one days. ${ }^{1}$ Another definition of a hamstring strain is a combination of key features, such as, the presentation of minor pain, initial loss of function, presence of point tender pain and where the pain location in proximity to the ischial tuberosity. ${ }^{43}$ Other research provides clinical presentation of a minor (grade I) hamstring strain should not produce visible discoloration, swelling or palpable defect in the muscle and range of motion and should also recover quickly over the next few days. ${ }^{44}$ For this field of study, the definition of a grade I hamstring strain presents with a typical mechanism of injury with minor swelling and discomfort with no or minimal loss of strength. ${ }^{4}$ Grade II hamstring strain presents with a mechanism of injury and a clear loss of strength with more discomfort. ${ }^{4}$-The pathophysiological aspect for Grade I strain only has minor or minimal tearing of a few muscles or tendon fibers, whereas, Grade II has a more severe partial tear without complete disruption of the musculo-tendonous junction. ${ }^{4}$

Most clinicians as well as scholarly publications will refer to the posterior thigh strain as, "hamstring strain." However, this label generates the false notion that only the three hamstring muscles are involved the strain/injury. This assumption is incorrect due to the use of Magnetic Resonance Imaging (MRI) after posterior thigh injuries, the results showed Adductor Magnus involvement. ${ }^{43}$ Therefore, the posterior thigh injury as a "Hamstring Complex Strain" is use to encompass all the possible tissue involvement. 
The following information will address hamstring complex anatomy, biomechanics, possible causative factors, epidemiology, etiology, rehabilitation programs and the return to play process for hamstring complex strains.

Hamstring complex anatomy

The anatomical musculature of the posterior thigh includes the muscle bellies of the semitendonosus (ST) and semimembranosus (SM) on the medial side, and biceps femoris (BF) (long and short heads) on the lateral side. While all four muscles are the primarily knee flexors, $\mathrm{ST}, \mathrm{SM}$ and the long head of BF (LHBF) also assist in hip extension. Therefore, ST, SM, LHBF cross two joints and are called biarticulate muscles. Due to the biarticulate complex, these muscles have to withstand significant amounts of tensile stress. ${ }^{9}$ The increased tensile stress requires anatomical adaptations to accommodate, which also assists in torque production..$^{45,46}$ These adaptations are length of proximal and distal tendons of SM, ST, and LHBF to endure the stress and increase force production simultaneously. ${ }^{9}$ The force production is also increased by muscle fibers of the fast twitch type II fibers, which will allow the hamstring to be capable of producing large forces. ${ }^{34}$ The fast twitch provides relatively short latency to develop peak muscle tension generating faster muscle contraction of greater intensities during an anaerobic environment. ${ }^{9}$ With long tendons and large MTJs, there is a greater "spring effect" which increases athletic performance, however, also increases the risk of injury. ${ }^{9,46}$ This risk of injury is due to the merging of mobile muscle fibers and stiff tendon fibers constructing the weakest point throughout any muscle and typical location of injury. 9 When a hamstring injury occurs, the actual tear typically occurs at the MTJ but can also occur in the muscle belly or proximal 
tendon origin of the LHBF and ST. ${ }^{46}$ The injury presentation of proximal free tendon of LHBF involved in $33 \%$ of all cases. ${ }^{43}$

The proximal tendons of SM, ST, LHBF originate from the ischial tuberosity. Specifically, the SM tendon originates on the upper lateral aspect of the ischial tuberosity, whereas the ST and LHBF originate on the lower, medial aspect as one common tendon. ${ }^{9}$ The ST/LHBF tendon origin constructs an environment where ST/LHBF are intertwined for up to nine centimeters from the ischial tuberosity, at which point they separate and join their respective medial and lateral compartments of the posterior thigh. ${ }^{9}$ Another structure that increases the strength of the ST/LHBF common tendon origin is the sacrotuberous ligament, which extends off the angles of the sacrum and inserts on the ischial tuberosity and common tendon of the ST/LHBF. ${ }^{9}$ The intersection of the sacrotuberous ligament into the common tendon is the primary connection between the hamstring to the lumbar-pelvic region. ${ }^{9}$ The importance of this connection will be discussed shortly.

After the separation of ST/LHBF, the ST becomes part of the medial thigh and eventually inserts at the Pes Anserine on the anteriomedial boarder of the tibia just distal to the medial tibial plateau. ${ }^{9}$ This area is also the insertion point for Sartorius and Gracilis, which becomes secondary assistors in knee flexion during certain ranges of motion. ${ }^{47}$ Important anatomical observation is that half way down the ST muscle, the tendon begins. Due to this long distal tendon there is a complex neurological component splitting that muscle into superior and inferior regions, both of which are innervated by two separate branches of the Tibial nerve. $^{9}$ 
On the lateral side after separating from ST, LHBF is joined by short head, which attaches to the muscle belly of LHBF to construct a common distal tendon, and inserts at the fibular head. ${ }^{9}$ Prior to the common distal tendon, the short head of BF originates on the Linea Aspera of the Femur and therefore, is only a one-joint muscle with knee flexion as the primary action. ${ }^{9}$ This also means the short head does not suffer the same amount of tensile stress applied to the other three hamstring muscles. In turn, the short head has the lowest risk of injury, whereas, the LHBF has the highest of all hamstrings. ${ }^{23,47-49}$ Some research $^{34}$ suggested $^{4}$ the BF has a high injury rate due to the innervation of two different nerves. The LHBF is innervated by a single branch of the Tibial nerve and SHBF is innervated by Peroneal nerve. Because of the involvement of two neural components, there is an increased chance of misfiring or synced firing. ${ }^{34}$ Another suggestion of increased injury rate is that due to the long distal tendon, the largest MTJ $(27.5 \mathrm{~cm})$ of the three hamstring muscles is evident. ${ }^{9}$ It is also evident that $\mathrm{BF}$ is the connection to the lumbar-pelvic region as well as to knee and ankle joints. The sacrotuberous ligament intersects the common tendon of ST/LHBF at the ischial tuberosity. ${ }^{9}$ The sacrotuberous ligament extends off the ischial tuberosity crossing the sacrum and attaches to the thoracolumbar fascia. ${ }^{34}$ The fascia is a common insertion point for Latissimus Dorsi, Transverse Abdominus, Internal Oblique, Splenius Capitis and Cervicus tendons, lumbar vertebrae and posterior superior iliac spine of the llium. ${ }^{34}$ So functionally, the BF is connected to the lumbar-pelvic spine, upper torso, shoulders and skull. ${ }^{34}$ Therefore, an increase in hamstring tension will increase thoracolumbar fascia, through the sacrotuberous ligament and decrease Sacro-iliac joint motion. ${ }^{34}$ It can be suggested that decrease in lumbar motion or flexibility can increase hamstring tightness or increase tension on hamstring and 
develop an opportunity for injury. Another way in which the connection of hamstrings to lumbar-pelvic region increases risk of injury is the adaptation of the hamstrings' type II fibers to slow twitch fibers to provide stabilization of the pelvic region when muscles of the hips and low back fail to perform. ${ }^{34}$ This means when hamstrings are required to produce a large force at a fast speed injury occurs due to inability to complete..$^{34}$

At the distal end, with the BF tendon inserting on the Fibular head there is also a tendinous expansions connecting to Peroneus Longus and the proximal Tibiofibular joint. ${ }^{34}$ Research suggested that during an evaluation of posterior thigh, the proximal Tibiofibular joint integrity should be assessed as well as history of ankle injuries for both may play a potential role in the risk of hamstring injuries. ${ }^{34}$

Returning to the medial side, the SM lies anterior to the ST and inserts on the posterior tibial plateau. A special note is that the distal tendon of the SM starts mid-thigh and has the largest cross-sectional muscle belly, mean area of $15.7 \mathrm{~cm}^{2}$, out of all hamstrings, whereas ST is $8 \mathrm{~cm}^{2}$ and $\mathrm{BF}$ is $10 \mathrm{~cm}^{2} .{ }^{9}$ This combination of tendon length and muscle belly width, gives the SM the ability to generate the most force production of the hamstrings; however, it also has the slowest contraction velocity so that force production is rarely challenged. ${ }^{9}$ The distal tendon inserts on the medial tibial condyle with tendinous expansions extending to the joint capsule of the knee and medial menisco-tibial and menisco-femoral formations. ${ }^{34}$ It is also innervated by a branch of the Tibial nerve and sometimes directly by the Sciatic nerve. ${ }^{9}$

Even though the above information is the factual muscular anatomy of the hamstring muscles, the low back, hip and knee are all part of the kinetic chain and therefore act as one. This means the posterior thigh not only includes the four muscles that are labeled 
"hamstrings," functionally the hip and knee utilized other muscles during locomotion. Therefore, the term "hamstring complex" will refer to the functional anatomy of the posterior thigh, as previously noted. The hamstring complex includes SM, ST, BF (Long/Short heads) and Adductor Magnus (AM). Though the name of AM may provide the assumption that it is a primary adduction, this is a misconception. AM functions more like a hamstring through primarily assisting in hip extension. ${ }^{9}$ The origin and insertion of AM are the two aspects that control or determine function. The adductor origin and hamstring insertion, both of which have their own innervations and create the atmosphere of two primary functions within one muscle. ${ }^{9}$ The AM originates on the transverse ridge of the ischial tuberosity and inserts on the adductor tubercle of the medial condyle of the femur. ${ }^{9}$ Nevertheless, even with its involvement with the hamstring, MRI findings validate that this muscle is affected by the mechanism of hamstring strains, yet it is rarely the primary location of injury. ${ }^{9}$

Biomechanics of the hamstring complex

Transitioning from the functional anatomy to the biomechanical process of the hamstring complex, it is important to mention the structure of the kinetic chain. The biomechanical function of the hamstring complex during locomotion is the involvement in the kinetic chain, therefore, interacting with surrounding structures and muscles to complete actions or movement. This interaction includes the involvement of other surrounding muscle groups and structures, such as the gluteals, gastroc-soleus complex and sacroiliac joint. Furthermore, the actual contraction rate and intensity of the hamstrings during walking gait or sprinting gait varies among research. Nevertheless, the continued exploration of the biomechanical process of the posterior thigh during walking gait and/or sprinting activities may 
assist in the understanding and reasoning of the high injury and re-injury rates of the hamstring complex.

With the biological framework of long tendons and large musculotendinous junctions (MTJ) that allows the opportunity for storage of large amounts of elastic energy, therefore providing optimal athletic performance through physical activities, such as, the vertical jump or sprint speed. ${ }^{9,23,49,50}$ The fibers of the hamstring muscle bellies are primarily fast-twitch fibers, therefore, it is easier for these muscles to develop peak muscle tension, allowing faster muscle contraction at a great intensity. ${ }^{9}$ This increases performance ability in sprint times or sports that require fast foot speed and acceleration such as football. ${ }^{9,50,49}$

Sprint cycle break down

When it comes to high performance, function and muscle length, no muscle has optimum length at rest. Because the limb progresses through a specific range of motion, the length of the muscle must be able to accommodate as well as have sufficient strength to either stabilize or contract to allow correct function to occur. ${ }^{23,49,50}$ The time at foot strike to ipsilateral toe off is the stance phase. ${ }^{51}$ Time from toe off to ipsilateral foot strike is the swing phase. ${ }^{51}$ Period between toe off and contralateral foot strike is the flight phase. ${ }^{51}$ (Figure 1 ) Figure 1. Phases of Running Gait or Sprint Sequence

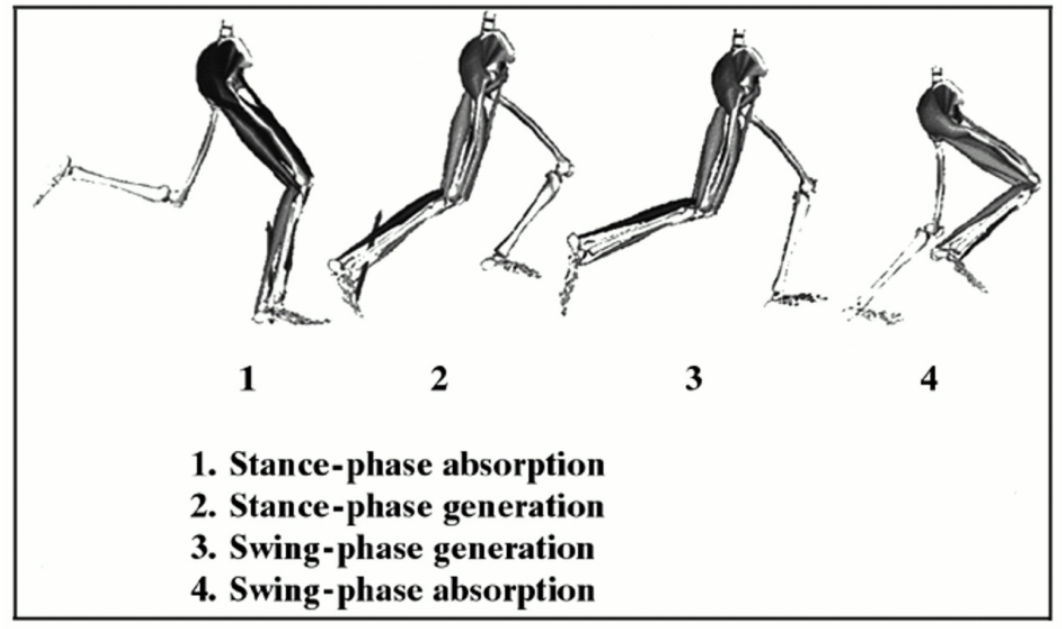


In reference to $\mathrm{MTJ}$, the MTJ has the longest length within all hamstring muscles during late stance and later swing phase..$^{51}$ During the swing phase, therefore, when the hip is flexed and the knee is extended the biarticulate hamstring complex muscles are at a disadvantage because their muscle length is overexerted. This overexerted positioning occurs primarily during the swing phase of gait. The hamstring complex is eccentrically working to control hip flexion and knee extension at the same time (Figure 1). ${ }^{23,47}$ Therefore, if a concentric contraction is required during the swing phase there is a large increase in risk of injury due to the stretched myosin and actin filament crossover. If a concentric contraction were attempted the muscle would be unable to produce action and an injury could occur. More specifically, if the muscle forces a concentric contraction in an elongated position, even if the length is still within normal range of motion, a muscle disruption will occur. ${ }^{23,47}$ Therefore, understanding the muscle length/tension relationship to maximize contraction of the hamstring complex is important especially when applied to forward motion of the lower limb. When specifically evaluating gait, hamstring complex contraction occurs throughout two phases, swing and stance. $^{23,47,48}$ However, research is inconsistent in referencing when the hamstring complex is primarily involved or when highest tension is experienced during gait. Some evidence reports that during the transition of swing phase, after toe off, the lower leg positioning of knee flexion and hip extension will cause the hamstring complex to eccentrically contract to slow the forward progression of the lower limb until the foot comes in contact with the ground. ${ }^{23}$ Throughout swing phase, the hamstring complex's negative work of the eccentric contraction aims to slow down hip flexion and knee extension as the lower limb prepares for heel strike. ${ }^{23}$ This negative work provides the optimal environment for a muscle injury to occur. ${ }^{5}$ Muscle 
strains predominately occur when a large magnitude of force is required during eccentric contraction. ${ }^{23,34,45}$ The primary muscle that is affected during the swing phase is BF. ${ }^{49}$ Another aspect during terminal or swing phase that must be noted is that as speed increases, gait mechanics change, such as, increased knee extension. ${ }^{45}$ Therefore, there is an even larger amount of negative work occurring on the hamstrings. This increase of negative work during terminal or swing phase is one of the intrinsic risk factors of causation for hamstring complex strains. This increase in eccentric work is typically why most hamstring complex rehabilitation programs include eccentric exercises to increase strength or control during this phase, with the hypothesis being that an increase in eccentric control will decrease the likelihood of the hamstrings failing. ${ }^{5,46,53}$

As the limb continues forward to the end of swing phase, the center of gravity will start to shift forward and the limb will prepare for initial contact or heel strike. ${ }^{48}$ During the initial stance phase, this is when the heel contacts the ground. Some research ${ }^{48,49}$ stated that this phase has the greatest risk of injury as a result of the magnitude of the concentric contraction at ground contact. This assumed risk of injury is attributed to the quick transition from eccentric to concentric contraction. Nevertheless, most evidence-based research equated occurrence of injury during this phase with poor or improper gait mechanics. ${ }^{45}$

Increasing gait speed demonstrates a strength-speed relationship between eccentric and concentric contraction. During eccentric contraction speed and torque increase, therefore, with the increase in torque concentric contraction is initiated. Once concentric contraction occurs torques decreases. ${ }^{45}$ This relationship can also be seen through the stretch-shortening behavior during swing phase, with the position of the hamstring tendons lengthening or 
'stretching' to absorb the elastic energy associated with eccentric deceleration of the lower limb during forward propulsion. ${ }^{24}$ Again, this relationship reinforces the point that increasing gait speed escalates risk of injury through the amount of negative work required of the hamstrings. ${ }^{5}$

In hamstring complex anatomic function throughout gait, electromyography studies show that the LHBF lengthens throughout swing phase and significantly increases eccentric contraction just prior to ground contact, a point for high risk of injury. ${ }^{49}$ With this lengthening of the LHBF as well as a lengthening of ST and SM tendons, torque increased while power output decreased. $^{47}$

ST's risk of injury varies throughout literature. Due to its proximal origin being the common tendon with BF, it is evident that ST injury occurs in combination with BF. ${ }^{55}$ However, the primary muscle location for a strain injury is rare. ${ }^{48}$ This is a result of the distal tendon insertion on the posterior tibial plateau. ${ }^{9}$ The fact that the insertion is in close proximity to the joint line of the knee the lever arm is extremely short making is difficult for ST to be a primary knee flexor decreasing the total amount of tensile stress applied throughout gait. ${ }^{48}$ Therefore, $^{\circ}$ throughout the swing phase ST muscle activity is minimal until enough knee flexion is achieved for the lever arm to be purposeful. ${ }^{48}$ Epidemiology

On a larger scale, hamstring complex strains occur in a variety of sports that require sprinting or jumping types of activities. ${ }^{11}$ Those sports include track and field, rugby, soccer, and football. ${ }^{14,46,55}$ Australian Rules Football (AFL) and Professional soccer are the two primary sports evaluated for hamstring complex strain epidemiology. Between 1997 to 2000 about 6 
hamstring complex injuries per club per season (15\% of all injuries) with a $34 \%$ re-occurrence rate was evident in the $\mathrm{AFL} .{ }^{24}$ When evaluating overall percentages of re-injury rates associated with the AFL, hamstrings were $17 \%$ of all new injuries, the highest shown in research. ${ }^{24} \mathrm{As}$ a result of the high hamstring complex injury rate, $16 \%$ of playing time is missed over the course of one season. $^{31}$

As for professional soccer, with $47 \%$ of muscle strains occurring during training or matches are to the hamstring complex. ${ }^{23}$ Twelve to $16 \%$ of all injuries are hamstring strains. ${ }^{13,}$ $26,53,56$ Within that, $10 \%$ of all players in a soccer league will sustain a hamstring complex strain within one season. ${ }^{13,46}$ In a longitudinal study ${ }^{5}$ of 100 soccer players over a 10 month period, 28 non-contact muscle injuries occurred, with 16 (57\%) hamstring complex strains.

Three hundred and six first-string Pro soccer players suffered 75 muscle strains, which was $30 \%$ of all injuries $(n=244) .{ }^{26}$ Thirty-one were to the posterior thigh, which was the location for the highest injury occurrence. ${ }^{26}$ This study ${ }^{26}$ utilized Magnetic Resonance Imaging (MRI) to diagnose hamstring complex strains. While 31 were clinically diagnosed hamstring strains, 14 (45\%) had a normal MRI and a recovery interval of an average 6.6 days (range $2-12$ ). ${ }^{55}$ Upon follow-up, none of the negative MRI's sustained re-injury. ${ }^{55}$ The other 17 (55\%) of the 31 had an abnormal MRI. Abnormal MRI presented with an absence of a muscle lesion classifying the injuries as Grade II hamstring complex strains. ${ }^{55}$ The recovery interval for the Grade II were 20.2 days. However, two players within the study suffered re-injuries to the same hamstring over the course of two seasons. ${ }^{55}$ In addition, a study found that $19 \%$ of all clinically diagnosed hamstring complex strains in the AFL, presented with negative MRIs. ${ }^{55}$ This study also evaluated the specific muscle involvement for each clinically diagnosed hamstring strain. Of the 17 Grade 
II hamstring strains, MRI showed 13 of those cases to include BF involvement; while 7 cases had ST involvement. ${ }^{55}$ Other evidence-based research has presented similar information with BF being the primary hamstring injury location. In a study ${ }^{59}$ with $14 \mathrm{MRI}$ diagnosed hamstring strains, 6 (43\%) involved BF, and 5 (36\%) involved SM. Another study ${ }^{60}$ of 15 hamstring strains, 11 (73\%) were BF, 8 (53\%) were ST and only one was SM. However, research presents inconsistent evidence of ST and SM involvement in injury location.

On the topic of re-injury, AFL has a $30-34 \%$ re-occurrence or re-injury rate within one season. ${ }^{6,14}$ of 749 muscles, $67 \%$ were hamstring strains, which acquired a re-injury rate of $33 \%$ during a game. ${ }^{6}$

\section{Etiology}

Mechanism of hamstring complex injuries is common in running and sprinting athletes. ${ }^{13,61}$ Typically, the mechanism involves eccentric contraction during rapid knee extension. ${ }^{5,62}$ Sports that include that mechanism are Track and Field, Soccer, Football, and Rugby. Another mechanism of injury is through imposing positions of maximum length on the hamstring muscles. The sports that include this second mechanism are dance and martial arts. $^{5,62}$

The mechanism of injury with the sport of football is due to the acceleration or running requirements at maximum velocity. ${ }^{3,11,34}$ Hamstring complex muscle fibers are at a disadvantage to tearing from this acute mechanism. ${ }^{34}$ Because hamstring muscles have relatively high amounts of fast twitch type II fibers to produce large torque or force, there is also an increased risk of injury. ${ }^{34,63}$ This increased risk is from the strain injury occurrences when an aggressive stretch is placed on an biarticulate eccentrically contracting hamstring 
muscle. ${ }^{4,34,65}$ The aggressive stretch or force triggers the hamstring complex to increase tension during the natural eccentric contraction to control the forward progression of the leg during swing phase. As a result the hamstring muscle is forced to lengthen beyond mechanical limits and an injury occurs. ${ }^{5}$ Overall, strain injuries are related to magnitude of force, rate of force development and/or length change over time..$^{53}$

When a strain injury occurs research varies in the clinical presentation. Generalizing a Grade I or mild hamstring complex strain by presentation of the location of the injury, tear of a few muscle fibers, point tenderness, no discoloration or swelling, no abnormal deformity, pain with resisted contraction and passive stretch and minimal restriction of movements. ${ }^{54,55}$ Grade II or moderate hamstring complex strains present with greater damage of muscle with clear loss of strength. ${ }^{54}$

Typically, injury occurs during the high activity of an eccentric contraction of late swing phase, when the hamstring complex decelerates hip flexion and knee extension. ${ }^{18,34}$ Peak hamstring complex stretch and force occur during late swing phase of running gait cycle and that force increases significantly with speed. ${ }^{58}$ This mechanism of injury apparently causes significant acute decline in function, nevertheless, a faster recovery interval. ${ }^{53}$

Hamstring complex strains may also occur during stance phase when hamstring concentric activity is high. ${ }^{24,34}$ The suggestion for injury occurrence during stance phase could be due to inhibition of gluteus maximus or poor sprint technique. ${ }^{34,66}$ This also includes involvement of the lumbar-pelvic region during gait. Increase risk of injury through inhibition of lumbar-pelvic stabilizers such as multifidus or transverse abdominis as a result of increased improper erector spinae activity during the stance phase can also be a cause. ${ }^{34,67}$ 
Analyzing the hamstring muscles that are compromised during the strain injury primarily consist of BF with ST second in involvement. ${ }^{55}$ As a result the common location of injury is at the proximal MTJ of LHBF. This also provides the explanation for ST involvement. The reasoning for ST injury risk is chiefly due to sharing a common tendon of origin with LHBF. ${ }^{55} \mathrm{SM}$, on the other hand, has the lowest involvement risk because the MTJ is half way down the posterior thigh constructing an environment where proximal strains are almost impossible. ${ }^{55} \mathrm{MRI}$ studies of 180 hamstring injuries indicated 151 (84\%) were found to have LHBF muscle belly involvement, $20(11 \%)$ were found to have SM involvement, and $9(5 \%)$ were found to have ST. ${ }^{63}$ With the use of MRI studies, classification is easier through the location of present edema seen after suffering the mechanism of muscle strain in T2 setting. ${ }^{55}$ Hemorrhaging is seen with partial or grade II strains, this difference assist in the diagnosis of severity. ${ }^{55}$

MRI studies have been utilized to find correlations between imaging and recovery intervals. The parameters of longitudinal length and cross-sectional area of injury shows correlation with injury severity. ${ }^{69}$ It is also evident that MRI negative hamstring strains have significantly faster recovery intervals compared to positive MRI and less likely to re-occur. ${ }^{69}$ Causative factors

There is an overlap on possible causative factors of hamstring complex strains. Many studies $^{26}$ examine the potential intrinsic (person-related) or extrinsic (environment-related) causative factors. Intrinsic examples include age, prior history, career duration, athlete factors, muscle flexibility, strength, and proprioception. ${ }^{4,26}$ Extrinsic examples include lack of training, environment factors, physical contract. ${ }^{4,26}$ Intrinsic causative factors are more predictive of hamstring complex strain occurrence. ${ }^{25}$ However, there is a lack of evidence-based research in 
relation to mechanism of injury to the hamstring complex specifically in football. The lack of evidentiary support is due to the majority of studies being retrospective in design, therefore, unable to determine if prospective causative factors were causes or effect of a hamstring complex strain. $^{26,70}$

Age: While age has been found to be primary causative factor, the rational is that type II fibers decrease strength with age; therefore, the decreased strength increases risk of injury. ${ }^{26 \text {, }}$ $14,39,8,12,13$

Prior history: Prior history has been found to be the strongest predictor and causative factor for hamstring complex strains. ${ }^{14,18,25,39}$ Literature presents significant evidence supporting prior history to be the most important predictive causative factor of hamstring complex strains. ${ }^{12-14,18,25,39}$ A study found prior history to be significant causative factor to the ipsilateral side. ${ }^{26}$ The results demonstrated that of the hamstring complex strains that occurred during the study, $13 \%$ had a prior history. ${ }^{26}$

Evidence-based research of prior history is five times more susceptible to re-injury compared to no prior history. ${ }^{13,18}$ Suggestion for influence is that the rehabilitation program was inadequate or that causative factor of the original hamstring complex strain was not addressed. ${ }^{13}$ Another reason is that prior history amplifies risk due to the changes or adaptations in biomechanics. ${ }^{25}$

Fatigue: It is evident in the literature that fatigue is a causative factor for most muscle strains, especially hamstring complex injuries. ${ }^{34,56,72}$ In general, one-half of all injuries encountered during match occurred in the last third of the $1^{\text {st }}$ and $2^{\text {nd }}$ halves. ${ }^{5,34}$ 
Epidemiological studies ${ }^{34}$ have found that two-thirds of hamstring complex injuries occurred late in training or matches.

An understanding of the affects of fatigue on the body is primarily on the nervous system. ${ }^{34}$ The central nervous system, peripheral nervous system and local changes of muscle are all affected by fatigue. ${ }^{34}$ This affect provides several reasons as to why fatigue is a causative factor for hamstring strains. Fatigue decreases production of glycogen levels in muscle, alterations to neurological activity at both local and systemic levels and causes modifications in sprint mechanics. ${ }^{34}$ Fatigue also decreases the amount of force a muscle can produce. ${ }^{13}$ The result of fatigue directly correlates with the hamstring complex function and failure. ${ }^{11}$ Fatigue may also induce physiological changes in muscle, alter coordination, technique concentration, overall, predisposing muscle to injury. ${ }^{5}$ Research suggested-other reasons for muscle fatigue could be a result of poor running mechanics, poor training and/or nutritional deficits. ${ }^{13,73-75}$ The suggestion that nutritional deficits cause fatigue in turn increases risk of injury to hamstring complex will be discussed with dehydration influences later on.

Some evidence-based hamstring complex rehabilitation programs propose fatigue prevention. To do so, there must be decreased work capacity, correction of fluid balance and ingestion of liquid carbohydrate drinks facilitating glycogen replenishment. ${ }^{5}$ Recommendations for carbohydrate intake is of 30-60 grams during each hour of practice to maintain blood glucose oxidation late in exercise and delay fatigue. ${ }^{5}$

Dehydration: Dehydration is not specifically mentioned in the literature as a causative factor for hamstring complex strains. As mentioned previously in the Fatigue section, nutritional deficit or fluid imbalance may cause an increase in fatigue. ${ }^{5,13,73-75}$ Therefore, if can be 
suggested that if dehydration is not monitored or corrected, fatigue will set in due to the imbalance and will have an increase on involvement or body's response to activity. More specifically, fatigue will have a greater affect on hamstring complex and increase risk of injury or re-injury.

De-Conditioning: De-conditioning as a causative factor for hamstring complex strains is not referenced in the literature. Within Division I athletics, prevention of detraining or deconditioning during recovery intervals is a key important factor and needs to be addressed in the literature.

Lumbar-pelvic region: The rationale for poor lumbar-pelvic region and postural involvement has been discussed previously. This section provides other reasoning as to why poor lumbar-pelvic posturing and function is a potential causative factor for hamstring complex strains.

Decrease in hip flexion and quadriceps flexibility increases the risk of the hamstring complex strain because lack of motion of the pelvis causes an anterior ilium tilt (sometimes unilateral) increasing tension on hamstring complex. ${ }^{15,34}$ This will also cause an increase in lumbar lordosis reinforcing hamstring complex tension and amplifying risk of injury. ${ }^{34}$

Another potential lumbar-pelvic risk is due to the lower crossed syndrome (pattern of muscle imbalances). Tight hip flexors and lumbar erector spinae and increased thoracic kyphosis inhibit gluteus maximus and abdominals to produce anterior pelvic tilt. ${ }^{34}$ However, the literature is unclear whether specifically addressing lumbar-pelvic region problems will decrease Hamstring complex risk of injury. ${ }^{34}$ 
Core stabilization: As discussed in lumbar-pelvic region section, weak abdominals can cause anterior pelvic tilt and increase stress, tension on hamstring complex. ${ }^{34}$ Nonetheless, similar to the use of flexibility exercises in rehabilitation protocols while research is inconclusive, is how core stabilization is approached. While core stabilization exercises are included in a large number of rehabilitation programs for hamstring complex, literature is lacking in providing evidence that weak core is a causative factors for hamstring complex strains.

Flexibility: The function of muscle flexibility is the ability to absorb forces, particularly at end range when the muscle becomes actively insufficient and passive non-contractile component (non-elastic tissue) increases its role. ${ }^{39}$ The main principle of flexibility is that vaseoelasticity properties of muscle can be changed by stretching, which will result in reduction in of load on MTJ at any given length. ${ }^{77}$ In spite of this, the literature contradicts the rationale.

In a study ${ }^{26}$ of 306 soccer players, flexibility of the hamstrings was evaluated by passive knee extension for which no significant results indicated a causative factor. There were several limitations to this study in which 249 of the 306 players only completed the flexibility test, however, results of the study did not specify if number of hamstring injuries that occurred involved the 249 participants. ${ }^{26}$ Nevertheless, outcomes of this study followed other evidencebased research, such as a study ${ }^{4}$ evaluating flexibility asymmetries of the lower limb with no significant results as a causative factor for hamstring complex strains. Another study ${ }^{14}$ tested flexibility with the sit and reach test and active knee extension test. The results found a significant correlation between increased hamstring complex injuries and increased or greater flexibility. ${ }^{14}$ The findings of this study clearly contradict the rationale for use flexibility exercise 
as rehabilitation and preventative measures. The contradiction continues with other research presenting significant correlation in the decreased flexibility after injury occurrence, yet it is unknown the relationship with re-injury rates. ${ }^{34,78,35}$

Similar to hamstring strength, evidence-based research has yet to verify the role of flexibility in the occurrence rate of hamstring complex strains. A suggestion is that rehabilitation programs put too much emphasis on hamstring complex stretching without actually decreasing the risk of re-injury. ${ }^{14}$ In addition, lacking and contradicting evidence could be due to the use of tests or instruments that have low reliability and validity in measuring muscle flexibility and in turn decrease any significance of results.

Dynamic stretching: Improper dynamic stretching is not specifically presented in the literature as a causative factor. Even with the purpose of dynamic stretching increase mobility or functional range of motion for a specific activity, it is increasing flexibility. ${ }^{34}$ As discussed previously, lack of flexibility has not been shown to be a causative factor in the literature, therefore, both need to be further evaluated. ${ }^{34,78,35}$

Rationale for inclusion of proper dynamic stretching is because the technique increased mobility and core body temperature via light intensity sports-specific exercises. ${ }^{34}$ As a result of the increased muscle temperature (core temperature) the MTJ increases in absorption of energy after dynamic stretching. ${ }^{6}$ Research ${ }^{5}$ indicates that MTJ is directly preoperational to both resting length of muscle and muscle temperature. Therefore, the dynamic stretching warm-up method is an unavoidable stage to activity initiating sport session. For it facilitates increases in connective tissue extensibility which is temperature dependent. ${ }^{5}$ 
Hamstring strength: There is insufficient evidence-based research to suggest that hamstring strength weakness is a causative factor for hamstring complex strains. ${ }^{34}$ However, hamstring strength differences have been found with athletes who have experienced recurrent hamstring complex strains, therefore, hamstring strength weakness may be postulated as a causative factor for re-injury. ${ }^{5,34}$

The literature ${ }^{95,10}$ evaluated mean peak torque of the hamstring tested isokinetically of the injured verse non-injured side. The results were not found to be significant, nor were there true differences bilaterally of only $6 \%{ }^{7}$ Torque-angle curves were also investigated; still results did not show this to be a causative factor for hamstring complex strains. ${ }^{7}$

A study ${ }^{4}$ was completed to evaluate the athletes' strength symmetry to see if asymmetry was a causative factor or predictor of hamstring complex strains. The study found that with eccentric isokinetic strength asymmetries greater than $15 \%$, functional leg length asymmetry greater than $1.8 \mathrm{~cm}$ and no prior history of hamstring injury, the athlete was at an increased risk of hamstring complex strains than without lower asymmetries and prior history. ${ }^{4}$ The reasoning for the significance of this study is that asymmetry may decrease capability to respond to maximum forces created by explosive contraction of knee extension during deceleration phase of later forward swing and thus causing a hamstring complex strain. ${ }^{4}$ In another isokinetic strength test, results showed injury history hamstrings have a short optimum angle for torque compared bilaterally. ${ }^{80}$ This follows the belief that muscles with shorter optimum angle are more likely to reinjure. ${ }^{80}$ This increased risk is as the muscle is stretched beyond optimum length within a myofibril, any sarcomere that is longer than others will preferentially take up the length changes until rising passive tension halts motion. ${ }^{24}$ 
Even though there is some significance between hamstring strength and injury, weakness is not the answer for higher rates. More significance is placed on prior history to be the determining factor. ${ }^{39}$ Conversely, a suggestion that hamstring strength is still a viable candidate because decreased strength of the hamstrings will produce insufficient force to counteract quads during knee extension of swing phase. ${ }^{12}$ Another suggestion is that current training regimens to target hamstring weakness may involve lower extremity strength generally and inadvertently put the hamstrings at greater risk by inducing excessive quadriceps strength. ${ }^{20}$ Finally, a reason why weakness may not be the primary causative factor, is that fatigue with activity has been shown to be causative factor and increased risk of injury and re-injury rate. ${ }^{55,}$ 81

Hamstrings-to-quadriceps ratio: Literature provides a multitude of optimal hamstringsto-quadriceps ratio, yet successful results remain unclear. ${ }^{34}$ The confusion is because strength imbalances are typically found after injury occurrence, therefore, unsure whether that was the reason for or result of the strain. ${ }^{34}$ An assumption that muscle strength asymmetries alter kinetic patterns of lower extremity and increase risk of muscle strains remains inconclusive.4 Eccentric strength: Not much background into whether eccentric hamstring strength weakness could be a causative factor has been provided in the literature. As discussed previously, eccentric contraction of the hamstring complex is a significant function within gait, therefore, it can be hypothesized that increased eccentric strength will increase control during the swing phase and overall decrease risk of injury. In concurring evidence, a study ${ }^{55}$ found eccentric weaknesses with prior history in previously injured leg as a risk for injury. The 
problem with this study is that the eccentric weaknesses were found post injury; therefore, it is unknown whether eccentric hamstring strength weaknesses were present prior to injury. ${ }^{55}$

A study ${ }^{54}$ appraised a preventative strength training program for elite soccer athletes with emphasis on eccentric hamstring complex overload to decrease risk of injury. The intervention included concentric and eccentric strength training over 16 sessions. ${ }^{53,54}$ The intervention increased max running speed as well as decreased the number of hamstring complex strains $3(20 \%, n=15)$ compared to the control group. Limitations with this study were the low number of subjects; therefore, results may not display population findings. In another study ${ }^{54,82}$ comparing hamstring curls verse Nordic hamstring training over 10 -week cycle. Hamstring curl group did not have a significant increase in strength, while Nordic hamstring group increased significantly in eccentric torque. Study did not follow-up on injury status of participant, therefore, it is unknown whether Nordic hamstring training decreased risk of injury. $^{54,82}$

Specific eccentric hamstring complex strengthening affect on the injury rate of acute hamstring injuries is inconsistent in the literature. 116 professional soccer athletes completed a 10-week training period during midseason break. ${ }^{54}$ The athletes were randomly split into two groups, intervention or control. The intervention group completed 27 sessions of Nordic hamstring exercises. The results confirmed prior research that the Nordic hamstring training does decrease injury and re-injury rates. ${ }^{54}$ Outcomes of the control group were 52 hamstring injuries with 1344 days absent from soccer training, while the intervention group only had 15 hamstring injuries with 454 days absent. Limitations to this study were results and compliance 
unknown beyond the 10 -week evaluation period. ${ }^{54}$ The study was also a non-blind study therefore, selection bias may have played a role in the outcome.

Observation of hamstring reaction to eccentric strength training may respond with delayed onset muscle soreness or injury due to the high intensity contractions. ${ }^{5}$ Eccentric exercise can cause soreness and stiffness within the following 24 hours. Research suggested this is because of the microscopic damage to muscle fibers, followed by a local inflammatory response. ${ }^{80}$ The eccentric hamstring contractions continually develop microscopic areas of damage and over time create a weak point in which an injury may occur. ${ }^{80}$

Sprint technique: Proper sprint technique was previously discussed in the Biomechanics of the Hamstring Complex section. Other points of poor sprint mechanics as a causative factor were previously discussed with fatigue and lumbar-pelvic posture subsections. This segment is to address the lack of literature in connection to hamstring complex strains.

Evidence-based research does provide two underlying principles for poor sprint mechanics and hamstring complex injuries. Research ${ }^{34,83}$ confirmed that maximum acceleration greater than 10 meters is a causative factor for hamstring complex strains. Another principle involved a mechanism of injury based on the positioning of the trunk during sprinting activities. An increased forward trunk lean while trying to maintain or increase speed with an overreaching of the lower leg that occurred simultaneously will cause a strain injury. ${ }^{24,34}$ Even though a forward trunk is counterproductive to performance, it is a very common adaptation due to poor sprint mechanics or fatigue. ${ }^{34}$ Another reason for over-reaching or over striding may be a result of gluteus maximus inhibition, which will increase forward lean and increase 
tension on the biarticulate hamstrings. ${ }^{34}$ Therefore, poor technique may be due to fatigue and/or increased workload of stabilizing biarticulate muscles surrounding the pelvis. ${ }^{5}$

During a sprint, the hamstring complex acts to transfer power between the knee and hip joint for forward propulsion. ${ }^{34}$ Therefore, when concentric contraction of the hamstring complex is required during gait, it is predominately for the hamstring complex to flex the knee, because gluteus maximus should be the primary hip extensor during the Stance Phase. As speed increased there is a decrease in the stance phase period, and an increase in lumbarpelvic control to decrease energy expenditure and increase efficiency ${ }^{34}$ When these simultaneous contractions properly transfer power, execution of the explosive movements in sprinting will increase performance. ${ }^{34,84,85}$ However, gluteus maximus is known to become inhibited due to lumbar-pelvic influences, therefore, the hamstring complex becomes the primary movers of hip extension and knee flexion. ${ }^{34,86}$ Once again, increasing the amount of tensile stress biarticulate hamstring muscles must withstand.

Functional activity: Functional activity is actions such as jumping, running and cutting at variable speed. ${ }^{6}$ Functional activity may also include sports specific drills such as the L-drill specifically for football. ${ }^{6}$ Petersen et. al. ${ }^{27}$ states that pain-free participation in sports specific activities is the best indicator for readiness to return to play or activity. However, it is not specifically noted or supported through evidence in the literature in reference to hamstring complex strains. Functional activity is related to rehabilitation programs and return to play decisions. If both are poorly managed, athlete may return to physical activity prematurely. ${ }^{34}$ Risk of re-injury: The risk of re-injury is very high. There is a $25 \%$ re-injury rate in American football athletes. ${ }^{55,56} \mathrm{In}$ the AFL (Australian Football League), hamstring re-injury rate 
is $34 \% .{ }^{31}$ Of the re-injury percentage from the AFL, one-third in-season re-injuries occurred within the first week after completion of rehabilitation of initial injury. ${ }^{24}$ In other sports, reinjury rate for sprinters is $17 \%$ and professional soccer athletes $12-16 \% .{ }^{11,53,68}$ A study $^{18,55}$ of 36 MRI positive hamstring strains found $30 \%$ re-injury rate during the same season. Another study $^{55,92}$ of 10 positive MRI hamstring injuries resulted in a $20 \%$ re-injury rate. Six of the athletes of the 10 (35\%) suffered re-injury after a successful rehabilitation and return to play completion. ${ }^{55}$ Evidence shows persistence of significant increased risk of re-injury, which lasted for many weeks after return to play. ${ }^{5}$

In an attempt to find causation for high risk neither length of muscle tear or CSA\% (cross-sectional area percentage of muscle tear) or recovery interval were accurate in predicting risk of re-injury. ${ }^{55}$ Suggestions of high rate are influence by management of rehabilitation, return to play protocol, or athlete's eagerness to return to play. ${ }^{58}$ Mismanagement of rehabilitation will encourage scar tissue and adhesion production with accumulation increase in risk of injury. ${ }^{34}$ Another suggestion is due to inability to assess severity of initial injury and premature return to play specifically during remodeling phase increase risk. $^{34}$

De-conditioning or reconditioning of the body

De-conditioning or detraining occurs when the cessation or decrease in anaerobic or aerobic training or reduction of frequency, volume, and intensity results in a decreased level of performance and loss of the physiological adaptations acquired from resistance training. ${ }^{41}$ The use of cardiovascular exercises during the rehabilitation process is common but never a focus. ${ }^{27,3} \mathrm{~A}$ balance between progressive rehabilitation of an injury and functional strength 
training without increase in over-training or risk of further injury needs to be addressed in the literature. One rehabilitation program does address cardiovascular exercise with examples of stationary bike, swimming or other controlled resistance activities to prevent de-conditioning. ${ }^{54}$ This is not enough to provide evidence-base research of the importance of prevention of deconditioning throughout the rehabilitation process.

Evidence-based hamstring complex rehabilitation programs

The design and duration of a rehabilitation program based on the location of the injury within the muscle may assist in the prediction of the recovery interval. With involvement of the distal MTJ or tendon, recovery interval is predicted to be a long process because the MTJ and tendon are avascular and will slow healing. ${ }^{34}$ Most rehabilitation programs are based on the tissue's theoretical healing process with the primary objective of restoration of function to the greatest possible degree in the shortest possible time. ${ }^{54}$ However, the literature is unclear as to whether those prediction measures do assist in the estimation of a recovery interval. Evidencebased research is also inconsistent with the inclusion criteria for a hamstring complex rehabilitation program. Often times programs contradict, yet still achieve successful significant results.

Table B1 presents eight hamstring rehabilitation programs that have been described in the literature. Holcomb et al.'s ${ }^{73}$ study was to evaluate an intervention program to prevent hamstring strains and increase strength of the hamstring muscles. The intervention worked in conjunction with off-season conditioning. Kilcoyne et al.'s ${ }^{74}$ study of Grade I and II hamstring strains and the response to a hamstring rehabilitation protocol. The hamstring rehabilitation was a three-day program with instructions on when to begin eccentric exercises, sprinting and 
plyometric exercises. ${ }^{74}$ One of the main focuses of the rehabilitation program was to stretch the hamstring between every drill completed on day $3 .{ }^{74}$ Forty-eight hamstring injuries completed the program. Three re-injuries occurred over the course of the study and the average return to play timeframe was eleven days. ${ }^{74}$

Malliaropoulas et al.'s $\mathrm{s}^{75}$ study was a randomized clinical trial of eighty male and female athletes. The participants were divided into two groups to complete a static stretching protocol forty-eight hours after the initial injury. The study evaluated knee extension bilaterally and return to play timeframe for significance of results. Group A took 7.3 days, where as, Group B took 5.6 days to return to play. ${ }^{75}$

Mjølsnes et al.'s ${ }^{37}$ randomized controlled trail of twenty-two competitive soccer players testing hamstring flexibility and strength between two 10 -week intervention programs. The participants had not experienced a recent hamstring strain at the beginning of the study. ${ }^{37}$ The Nordic hamstring group had a significant increase in hamstring-to-quadriceps strength ratio and maximal isometric torque compared to the hamstring curl group. ${ }^{37}$

Petersen et al.'s ${ }^{27}$ randomized controlled trail included fifty-four men's soccer teams with a total of 942 participants. The participants were divided into two groups, the intervention group completed a 10-week progress Nordic hamstring exercise program and the control group completed a usual training program. ${ }^{27}$ Intervention had fifteen acute hamstring injuries occur resulting in 454 days absent from soccer. ${ }^{27}$ Nine of the fifteen injuries occurred during the 10week training program. ${ }^{27}$ The control had fifty-one injuries occur missing 1344 days from soccer. ${ }^{27}$ Twelve of the fifty-one injuries from the control group occurred during the same 
training period as the intervention, therefore, participants had to complete the Nordic training program to decrease risk of injury. ${ }^{27}$

Sanfilippo et al.'s ${ }^{76}$ evaluated twenty-five recreational athletes who sustained an acute hamstring strain within ten days. The participants were tested for isokinetic strength and received Magnetic Resonance Imaging (MRI) at return to play and six months post return to play. ${ }^{76}$ The participants completed a rehabilitation program with a Physical Therapist three times a week for eight weeks. ${ }^{76}$ Return to play criteria was no significant pain with straight leg raise, full isometric strength against manual resistance, no tenderness to palpate and no apprehension during full effort sport specific movements. ${ }^{76}$ Average time away from physical activity was twenty-six days. At return to play, strength deficits were significant with peak torque and work. For the MRI at return to play, $20 \%$ of the cross-sectional area was still showing signs of injury. At six months post return to play, there was no deficit in strength; nevertheless, the MRI noted $4-5 \%$ atrophy bilaterally. ${ }^{76}$

Sherry et al.'s $\mathrm{s}^{33}$ randomized clinical trail evaluated rehabilitation protocols for time to return to play and re-injury rate during the first two weeks post return to play and one year post. ${ }^{33}$ The return to play protocol required five out of five strength with knee flexion, no point tender pain of posterior thigh, and subjective readiness after completing agility and running tests. Agility and running tests include hop for height, hop for distance, 4-hop crossover and 40yard sprint. ${ }^{33}$ The results found $54.4 \%$ of the Stretching and strengthening (STST) group and $0 \%$ of the Progressive agility and trunk stabilization (PATS) group suffered recurrent hamstring strains within the first sixteen days after return to play. ${ }^{33} 70 \%$ of the STST and $7.7 \%$ of the PATS 
suffered hamstring strains within the first year post return to play. No significance was found between groups for time to return to play. ${ }^{33}$

Verrall et al.'s ${ }^{77}$ prospective study was to evaluate four seasons of an Australian Rules football team with an average of seventy players per season. The purpose of the study was to assess the effect of an intervention program on the number of athletes having and the consequences of missing competition games due to hamstring strains. ${ }^{77}$ The first two seasons did not include the intervention program. The results showed hamstring injury incidence drop from 4.7 to 1.3 per 1000 playing hours during match play after the intervention. No significance was found with hamstring training injuries. ${ }^{77}$ Overall, there were fewer hamstring injuries and fewer competition games missed when compared to the first two seasons. ${ }^{77}$

Table B1. Evidence-Based Rehabilitation Program Trials

\begin{tabular}{|c|c|c|c|c|}
\hline Study & Purpose & Subjects & Rehabilitation Program & Results \\
\hline Holcomb et. al $_{73}$ & $\begin{array}{l}\text { Effectiveness of } \\
\text { resistance } \\
\text { training } \\
\text { emphasized } \\
\text { hamstrings on } \\
\text { the resulting } \\
\text { functional and } \\
\text { conventional } \mathrm{H}: \mathrm{Q} \\
\text { ratios }\end{array}$ & $\begin{array}{l}12 \text { female } \\
\text { collegiate } \\
\text { soccer players } \\
\text { (age 19-21) } \\
1 \text { year of } \\
\text { training }\end{array}$ & $\begin{array}{l}\text { Combination of speed, agility } \\
\text { exercises with upper body } \\
\text { resistance training } \\
\text { Endurance conditioning with } \\
\text { lower body resistance training } \\
\text { emphasizing hamstring } \\
\text { strengthening and functional } \\
\text { training. } \\
\text { Hamstring strength: } \\
\text { Single leg curls, straight leg } \\
\text { dead lifts, good morning } \\
\text { exercises, trunk } \\
\text { hyperextensions, resisted sled } \\
\text { walking, and exercise ball leg } \\
\text { curls. }\end{array}$ & $\begin{array}{l}\text { Max hamstring and } \\
\text { quadriceps muscle } \\
\text { strength obtained by } \\
\text { measuring peak torque } \\
\text { during isokinetic flexion } \\
\text { and extension. } \\
\text { Post-intervention } \\
\text { revealed increase in } \\
\text { functional } \\
\text { Hamstring:Quadriceps } \\
\text { ratio significantly } \\
\text { Post-intervention } \\
\text { revealed increase in } \\
\text { conventional } \\
\text { Hamstring:Quadriceps } \\
\text { ratio not significant. }\end{array}$ \\
\hline$\underset{74}{\text { Kilcoyne et. al }}$ & $\begin{array}{l}\text { Emphasizes early } \\
\text { motion and a } \\
\text { sustained static } \\
\text { elevated stretch } \\
\text { technique, with a }\end{array}$ & $\begin{array}{l}48 \text { Division I } \\
\text { athletes } \\
40 \text { men and } 8 \\
\text { women } \\
14 \text { sports - }\end{array}$ & $\begin{array}{l}\text { First } 48 \text { hours: compression } \\
\text { and knee immobilizer locked } \\
\text { in extension, placed on } \\
\text { NSAIDs } \\
\text { Day 2: athlete performed a }\end{array}$ & $\begin{array}{c}3 \text { of } 48 \text { athletes (6.2\%) } \\
\text { experienced re-injury } \\
\text { Average } 11.9 \text { days to } \\
\text { return to play } \\
\text { No variables were found }\end{array}$ \\
\hline
\end{tabular}




\begin{tabular}{|c|c|c|c|c|}
\hline & $\begin{array}{l}\text { return to sport } \\
\text { based on } \\
\text { painfree } \\
\text { completion of a } \\
\text { specific running } \\
\text { drill }\end{array}$ & $\begin{array}{l}\text { track:16 } \\
\text { hamstring } \\
\text { strains; } \\
\text { football: } 11 \\
\text { hamstring } \\
\text { strains. }\end{array}$ & $\begin{array}{c}\text { self-paced run until fatigue } \\
\text { (about } 1 \text { mile), ice applied for } \\
40 \text { minutes post. } \\
\text { Progressive static elevated } \\
\text { stretching technique held for } \\
60-90 \text { second after each drill } \\
\text { or exercises } \\
\text { Day 3: started run protocol } \\
\text { included plyometric exercises } \\
\text { and tuck jumps } \\
\text { Day 6: Eccentric exercises and } \\
\text { completed } 3 \text { times per week. } \\
2 \times 10 \text { repetitions } \\
\text { Isokinetic rehabilitation using } \\
2 \text { exercise techniques } \\
\text { Rolling start sprints initiated } \\
\text { when full sprint was painfree } \\
\text { or at } 90 \% \\
\text { Day } 7: \text { Unique running drill: } \\
\text { 10-yard build-up to speed and } \\
10 \text { yard coat to a jog. } \\
\text { Performed at } 90-95 \% \text { effort } \\
\text { After all sessions - athlete } \\
\text { iced for } 40 \text { minutes }\end{array}$ & significant \\
\hline $\begin{array}{l}\text { Malliaropoulos } \\
\text { et. al. }{ }^{75}\end{array}$ & $\begin{array}{l}\text { Evaluation of the } \\
\text { effects of } \\
\text { stretching on } \\
\text { injured } \\
\text { hamstring } \\
\text { muscles }\end{array}$ & $\begin{array}{l}52 \text { male and } \\
28 \text { female } \\
\text { Greek } \\
\text { athletes. } \\
\text { Randomly } \\
\text { assigned to } \\
\text { two groups }\end{array}$ & $\begin{array}{l}\text { First } 48 \text { hours: P.R.I.C.E. } \\
\text { protocol (protection, rest, ice, } \\
\text { compression, elevation) } \\
\text { Treatment: hamstring static } \\
\text { stretches held for } 30 \text { seconds, } \\
\text { repeated four times. } \\
\text { Group A: Completed one bout } \\
\text { of stretching daily } \\
\text { Group B: Completed four } \\
\text { bouts of stretching daily }\end{array}$ & $\begin{array}{l}\text { Group A: returned to } \\
\text { normal range of motion } \\
\text { of the knee in a mean } \\
\text { time of } 7.3 \text { days } \\
\text { Group B: returned to } \\
\text { normal range of motion } \\
\text { of the knee in a mean } \\
\text { time of } 5.6 \text { days. } \\
\text { Group A: took } 15 \text { days for } \\
\text { full, unrestricted athletic } \\
\text { activities } \\
\text { Group B: took } 13.3 \text { days } \\
\text { for full, unrestricted } \\
\text { athletic activities. }\end{array}$ \\
\hline$\underset{37}{\text { Mjølsnes et. al. }}$ & $\begin{array}{l}\text { Compare the } \\
\text { effect of Nordic } \\
\text { hamstring } \\
\text { exercises with } \\
\text { the most }\end{array}$ & $\begin{array}{l}22 \text { male } \\
\text { soccer players } \\
\text { Randomized } \\
\text { into two } \\
\text { groups: }\end{array}$ & $\begin{array}{c}\text { Hamstring curl group: } \\
\text { Week 1: } 1 \text { session per week, } \\
10 \text { repetitions max test } \\
\text { Week 2: } 2 \text { sessions per week, } \\
2 \text { sets of } 6 \text { repetitions at } 60 \%\end{array}$ & $\begin{array}{l}\text { Nordic hamstring group } \\
\text { developed eccentric } \\
\text { hamstring strength } \\
\text { measured isokinetically, } \\
\text { as well as acquiring a }\end{array}$ \\
\hline
\end{tabular}




\begin{tabular}{|c|c|c|c|c|}
\hline & $\begin{array}{l}\text { commonly used } \\
\text { concentric } \\
\text { strength training } \\
\text { exercise - } \\
\text { regular } \\
\text { hamstring curl }\end{array}$ & $\begin{array}{c}\text { Nordic } \\
\text { hamstring \& } \\
\text { Hamstring } \\
\text { curl }\end{array}$ & 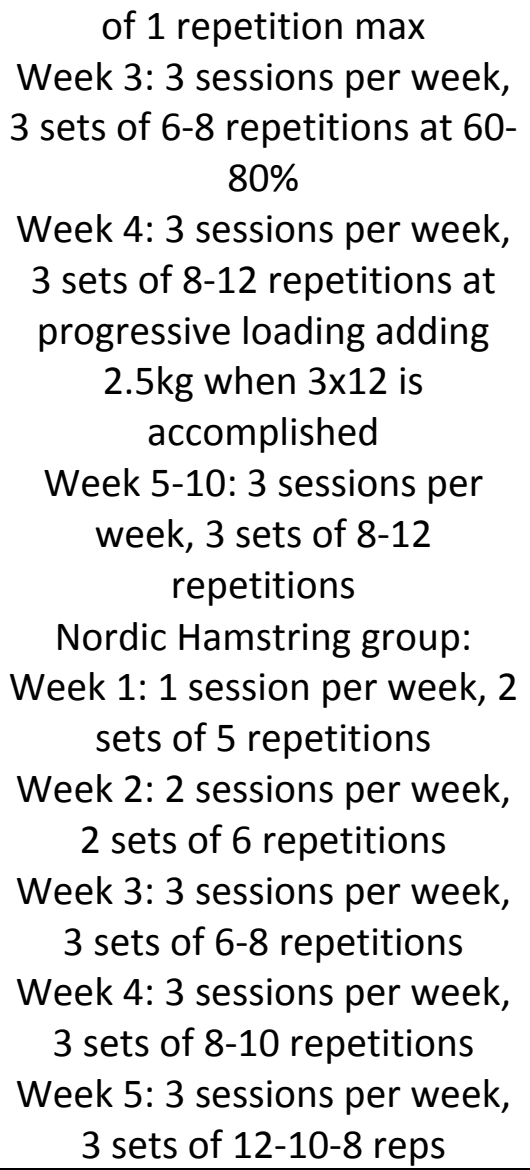 & $\begin{array}{l}\text { significant increase in } \\
\text { hamstring: quadriceps } \\
\text { ratio and maximal } \\
\text { isometric torque tested at } \\
\text { three knee angles. }\end{array}$ \\
\hline$\underset{27}{\text { Petersen et. al. }}$ & $\begin{array}{l}\text { Assess a } 10 \text { week } \\
\text { training program } \\
\text { using Nordic } \\
\text { hamstring } \\
\text { exercises could } \\
\text { lower the } \\
\text { incidence of new } \\
\text { and recurrent } \\
\text { acute hamstring } \\
\text { injuries in the } \\
\text { following soccer } \\
\text { season. }\end{array}$ & $\begin{array}{l}942 \text { male } \\
\text { Danish } \\
\text { professional } \\
\text { soccer players } \\
54 \text { teams } \\
\text { included and } \\
\text { randomly } \\
\text { assigned to a } \\
\text { intervention } \\
\text { or control } \\
\text { group. }\end{array}$ & $\begin{array}{c}\text { Intervention group: } \\
\text { Week 1: } 1 \text { session per week, } 2 \\
\text { sets with } 5 \text { repetitions of } \\
\text { Nordic hamstring exercise } \\
\text { Week } 2 \text { : } 2 \text { sessions per week, } \\
2 \text { sets of } 6 \text { repetitions } \\
\text { Week 3: } 3 \text { sessions per week, } \\
3 \text { sets of } 6-8 \text { repetitions } \\
\text { Week } 4: 3 \text { sessions per week, } \\
3 \text { sets of } 8-10 \text { repetitions } \\
\text { Week } 5 \text { to } 10: 3 \text { sessions per } \\
\text { week, } 3 \text { sets of } 12-10-8 \\
\text { repetitions } \\
\text { Week }+10: 1 \text { session per } \\
\text { week, } 3 \text { sets, } 12-10-8 \\
\text { repetitions of Nordic } \\
\text { hamstring exercises }\end{array}$ & $\begin{array}{c}\text { Total of } 67 \text { acute } \\
\text { hamstring injuries } \\
\text { occurred. } 44 \text { were new } \\
\text { and } 23 \text { were recurrent. } 15 \\
\text { hamstring injuries } \\
\text { occurred to the } \\
\text { intervention ( } 12 \text { new, } 3 \\
\text { recurrent); } 52 \text { occurred to } \\
\text { the control group ( } 32 \text { new } \\
\text { and } 20 \text { recurrent). } \\
\text { Intervention group had a } \\
\text { told of } 454 \text { days absent } \\
\text { from soccer; Control } \\
\text { group had } 1344 \text { days } \\
\text { absent from soccer. }\end{array}$ \\
\hline $\begin{array}{c}\text { Sanfilippo et. } \\
\text { al. }^{76}\end{array}$ & $\begin{array}{l}\text { Characterize } \\
\text { isokinetic } \\
\text { hamstring }\end{array}$ & $\begin{array}{c}25 \\
\text { recreational } \\
\text { athletes }\end{array}$ & Was not cited & $\begin{array}{c}\text { At RTP: injured limb } \\
\text { showed deficit } \\
\text { isokinetically }\end{array}$ \\
\hline
\end{tabular}




\begin{tabular}{|c|c|c|c|c|}
\hline & $\begin{array}{l}\text { strength and } \\
\text { morphology at } \\
\text { the time of } \\
\text { return to play } \\
\text { after a controlled } \\
\text { rehabilitation } \\
\text { program for } \\
\text { acute hamstring } \\
\text { injury - Grade I/II } \\
\text { strains }\end{array}$ & $\begin{array}{c}\text { 20-male } \\
5-\text { female } \\
\text { 15-33 years } \\
\text { old }\end{array}$ & & $\begin{array}{l}\text { MRI showed } 20 \% \text { of cross- } \\
\text { sectional area still injured. } \\
\text { At } 6 \text { months: strength } \\
\text { deficit resolved } \\
\text { MRI showed ST and BF of } \\
\text { both limbs atrophy } 4-5 \% \text {. }\end{array}$ \\
\hline Sherry et. al. ${ }^{33}$ & $\begin{array}{l}\text { Evaluate the } \\
\text { results of two } \\
\text { different types of } \\
\text { hamstring } \\
\text { rehabilitation } \\
\text { programs of } \\
\text { Grade I or II } \\
\text { strains }\end{array}$ & $\begin{array}{c}18 \text { - male } \\
6-\text { female } \\
\text { 14-49 years } \\
\text { old }\end{array}$ & $\begin{array}{l}\text { Group } 1 \text { - Static Stretching } \\
\text { and isolated progressive } \\
\text { resistance exercises group } \\
\text { Phase 1: static stretching and } \\
\text { isometric strengthening of } \\
\text { hamstring } \\
\text { Phase 2: dynamic stretching } \\
\text { with concentric and eccentric } \\
\text { hamstring strengthening } \\
\text { Group } 2 \text { - Progressive agility } \\
\text { and trunk stabilization } \\
\quad \text { exercises } \\
\text { Phase 1: progressive agility } \\
\text { movements in frontal and } \\
\text { transverse plane } \\
\text { Phase 2: agility movements in } \\
\text { transverse and sagittal plane }\end{array}$ & $\begin{array}{l}\text { Within first } 16 \text { days of } \\
\text { RTP: } \\
\text { Group } 1-6 \text { of } 11 \text { had a } \\
\text { recurrent hamstring strain } \\
\text { Group } 2-0 \text { of } 13 \\
\text { Within first year post RTP: } \\
\text { Group } 1-7 \text { of } 10 \text { had a } \\
\text { recurrent hamstring strain } \\
\text { Group } 2-1 \text { of } 13 \text { had a } \\
\text { recurrent hamstring strain }\end{array}$ \\
\hline Verrall et. al ${ }^{77}$ & $\begin{array}{l}\text { Assess effects of } \\
\text { an intervention } \\
\text { program on the } \\
\text { number of } \\
\text { athlete having } \\
\text { and } \\
\text { consequences of } \\
\text { hamstring } \\
\text { muscle strain } \\
\text { injuries. }\end{array}$ & $\begin{array}{c}\text { Australian } \\
\text { Rules Football } \\
\text { team (69-71 } \\
\text { players) } \\
\text { Male; Age: } \\
\text { Unknown } \\
\text { \# of games: } \\
23-26\end{array}$ & $\begin{array}{l}\text { High intensity anaerobic } \\
\text { interval running/acceleration } \\
\text { drills } \\
\text { Hamstring stretches: passive } \\
\text { isometric, performed when } \\
\text { degree of fatigue present; } \\
\text { hold for } 15 \text { second. } \\
\text { Specific Football training drills } \\
\text { for change in running speed } \\
\text { and trunk flexion training } \\
\text { performed for } 5 \text { minutes, two } \\
\text { times per week at the end of } \\
\text { practice. } \\
\text { Perform closed chain leg } \\
\text { weight lifting exercises only }\end{array}$ & $\begin{array}{c}8 \text { athletes completed } \\
\text { weight training; the rest } \\
\text { did not } \\
\text { Decrease in number of } \\
\text { hamstring strains (first } \\
\text { two years: } 27 \text { strains; post } \\
\text { intervention last two } \\
\text { years: } 8 \text { strains) } \\
\text { Missed games decreased } \\
\text { from first two years: } 69 ; \\
\text { last two years: } 21 \\
\text { Singe team: } 4.7 \text { injury rate } \\
\text { per } 1000 \text { playing hours } \\
\text { per intervention; Post } \\
\text { intervention } 1.3 \text { per } 1000 \\
\text { playing hours. }\end{array}$ \\
\hline
\end{tabular}


Despite the beneficial effects noted, there were also limitations in each study. In Holcomb et al., ${ }^{73}$ the limitation was the target of training. The goal was to increase hamstring strength, however, the exercises also have the potential to increase quadriceps strength, therefore, specificity was low. There was no control group for comparison and the primary research did not set limitation requirements for the participants as well as collecting selfreported information. Therefore, the likelihood of participants training outside of the intervention is present. A control group was not used for comparison and imaging was not completed to confirm injury and severity In the Kilcovne et al., ${ }^{\text {Kilcovne }}$ and Malliaropoulos et

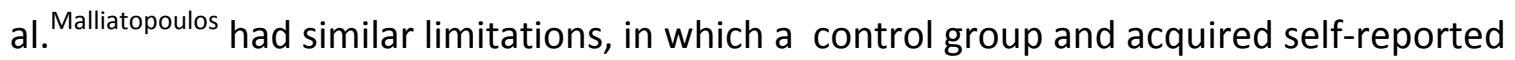
information and compliance were not included.

In Mjølsnes et al., ${ }^{37}$ concentric hamstring was not tested, therefore, it is unknown if the intervention can be applied to increased general strength of the hamstrings. Also post-testing was manipulated to conform to the needs of the participants due to their involvement with a professional team. Compliance and self-reported information was another limitation as well. Petersen et. al. ${ }^{27}$ had similar limitations specifically concerning compliance of the participants. Sanfilippo et al. ${ }^{76}$ was a not a randomized control trial nor was there a control group to compare strength changes and morphology at the return to play time frame and 6 month follow up. Other limitations included small sample size, and three dropouts from study due to suffering an injury. Two of those dropouts suffered another hamstring injury. The controlled rehabilitation program utilized in this study was not provided. 
Sherry et. al. ${ }^{33}$ evaluated two groups: PATS - hamstring progressive-resistance exercises and trunk stabilization and STST - hamstring stretch and strengthen. There were 0/13 reinjuries in the PATS group within the first 16 days post of completion of the rehabilitation protocol and one re-injury within that year. The STST group sustained a 70\% (10/11) re-injury rate the first 16 days. Overall, there was no significant difference between recovery intervals of the two groups. Limitations to the study were the small sample size. Other limitations were the large return to play period (10-95 days). Trunk neuromuscular control was not pre or post tested. There was also self-reports on exercise compliance, abstinence from therapeutic modalities and injury occurrence at 1-year follow-up. Therapist who completed pre and post testing were not blinded to the study.

The rehabilitation program in Verrall et al.$^{44}$ for effects of sport specific training on reducing hamstring focused on improved muscle conditioning, fatigue resistance and increased flexibility. ${ }^{44}$ The results were 4.7 hamstring injuries per 1000 playing hours. This was not seen as a significant finding because the percentages are consistent with non-intervention studies.

There were several other evidence-based rehabilitation programs utilized to generate the components and concepts for the questionnaire. These rehabilitation programs were strictly evidence-based understandings of the hamstring complex and were not randomized controlled trials to evaluate reliability and validity.

Table B2 provides the detailed information of evidence-based rehabilitation programs that were not conducted randomized control trials, instead are compiled techniques by previously completed research. Both Tables B1 and B2 provide valuable evidence-based 
research to utilize for the development of the questionnaire and generation of the final rehabilitation program.

Table B2 is in reference to the therapeutic exercises only. Heiderscheit et al. ${ }^{6}$ promotes neuromuscular control early in Phase 1 of a 3-phase program. The focus is on strengthening the lumbo-pelvic musculature progressing from light to moderate intensity. Heiderscheit et al. ${ }^{6}$ clearly states progression criteria for each phase. Phase 1 must have painfree walking prior to progression. Phase 2 has to return range of motion and avoid excessive lengthening or stretching of the muscle. Progression to Phase 3 must have full range of motion and strength. Phase 2 is when submaximal eccentrics are utilized. ${ }^{6}$ Phase 3 incorporates progression to return to play with agility and sport specific drills. Return to play criteria requires return to unrestricted sporting activities and functional activities without pain or stiffness and isokinetic tests should a $5 \%$ deficit or less bilaterally. ${ }^{6}$

Sherry et al.'s ${ }^{33}$ rehabilitation program is not broken down into phases for progression. It included dynamic warm-up drills, trunk stabilization and neuromuscular control exercises, as well as, eccentric training exercises. ${ }^{3}$

Petersen et al.'s ${ }^{27}$ five-phase program follows the healing cycle of injured tissue. The program includes the timeframe for each phase with the rehabilitation program lasting up to six months post initial onset. Phase 1 is focused on protection and early motion. ${ }^{27}$ Phase 2 aims to decrease atrophy, may begin activities to sustain cardiovascular fitness. ${ }^{27}$ Phase 3 incorporates flexibility and eccentric strengthening. Phase 4 begins the return to play process and Phase $\mathrm{V}$ focuses on maintaining stretching and strengthening of the hamstring. ${ }^{27}$ 
Schmitt et al's ${ }^{31}$ three-phase program has phase 1 protecting the injury and starting early painfree motion. The protocol does state criteria for progression to the next phase. Phase 1 must have normal gait before moving to phase $2 .{ }^{31}$ Phase 2 is to increase strength, achieve full range of motion painfree and begin neuromuscular control exercises specific to trunk and pelvis. The athlete must have full strength before progression to phase $3 .{ }^{31}$ Phase 3 begins lengthened-state eccentric exercises and integrates postural control into sport specific movements. Criteria for return to play, athlete must have full strength without pain, full range of motion without pain, equal bilateral peak torque strength and sports specific drills completed with speed and no symptoms. ${ }^{31}$

Table B2. Evidence-based Rehabilitation Protocol

\begin{tabular}{|c|c|}
\hline Authors & Evidence-Based Rehabilitation Protocol \\
\hline $\begin{array}{l}\text { Heiderscheit } \\
\text { et. al }\end{array}$ & $\begin{array}{l}\text { Phase 1: Protection - no excessive stretching of the hamstring; restricted motion encouraged } \\
\text { (short-stride ambulation), do not hold knee in flexion for periods of time; ice - } 3 \text { to } 5 \text { minutes } \\
\text { for ice cup, } 15 \text { to } 20 \text { minutes for ice bag; NSAIDs allowed; exercises to promote neuromuscular } \\
\text { control within protected ranges of motion: isometrics of lumbopelvic complex, single limb } \\
\text { balancing, short-stride frontal plane stepping drills. Avoid isolated resistance training of } \\
\text { injured hamstring. Performed without pain progress from light to moderate as tolerated. } \\
\text { Progression criteria - normal walking without pain, low-speed jogging without pain, and } \\
\text { painfree isometric contraction against submaximal (50-75\%) resistance during prone knee } \\
\text { flexion. } \\
\text { Phase 2: protection - no end range lengthening of hamstrings; ice performed after all activity; } \\
\text { NSAIDs - not warranted; Exercises - gradual increase in hamstring lengthening emphasizing } \\
\text { neuromuscular control, agility drills and trunk stabilization with progressive increase in speed } \\
\text { and intensity. Submaximal eccentric strengthening, anaerobic training and sports specific skills } \\
\text { may be initiated (nothing greater than } 50 \% \text { speed). Progression criteria - full strength (5/5), } \\
\text { without pain during a } 1 \text { rep max effort isometric MMT prone knee flexed to } 90 \text { degrees and } \\
\text { forward and backward jogging at } 50 \% \text { max speed painfree. } \\
\text { Phase } 3 \text { : Protection - range of motion is no longer protected. Sprinting and explosive } \\
\text { acceleration movements should be avoided until return to play criteria is met. Ice - completed } \\
\text { after all activity; Exercises - agility and sport-specific drills emphasized with quick direction } \\
\text { changes and technique training. Trunk stabilization challenging with transverse plane motions } \\
\text { and asymmetrical postures and functional movement patterns. Eccentric hamstring } \\
\text { strengthening full range of motion with increases in resistance. } \\
\text { Return to Sport criteria: full range of motion, strength, and functional abilities performed }\end{array}$ \\
\hline
\end{tabular}




\begin{tabular}{|c|c|}
\hline & $\begin{array}{l}\text { without pain or stiffness. Complete four consecutive pain-free repetitions of max effort } \\
\text { manual strength test in prone knee flexion at } 90 \text { and } 15 \text { degrees. Isokinetic testing: concentric } \\
\text { and eccentric actions - less than } 5 \% \text { deficit between eccentric hamstring to concentric } \\
\text { quadriceps. Functional testing similar to sports specific stressors. }\end{array}$ \\
\hline Sherry et. al. ${ }^{3}$ & $\begin{array}{l}\text { Dynamic Warm-up: A-March, A-skips, B-skips, short stride cariocas, side shuffles, leg cycling } \\
\text { and leg pawing, ankle pops, quick support running drills forward, falling running drills and } \\
\text { explosive starts. } \\
\text { Trunk stabilization and Neuromuscular Control exercises: Low to high wood chops and vice } \\
\text { versa, rotating core planks, physioball bridging with alternating leg holds and alternating hip } \\
\text { position, and single leg stand rotating reaches. } \\
\text { Eccentric Training exercises: eccentric box jumps, eccentric loaded lunge drops, eccentric } \\
\text { forward pulls, split-stance Zerchers, single-leg deadlifts. }\end{array}$ \\
\hline $\begin{array}{c}\text { Petersen et. } \\
\text { al. }^{27}\end{array}$ & $\begin{array}{l}\text { Phase } 1 \text { (acute): 1-7 days - R.I.C.E. protocol (rest, ice, compression, elevation); promote early } \\
\text { motion: painfree active knee flexion and extension exercises } \\
\text { Phase } 2 \text { (subacute): } 3->3 \text { weeks - concentric strength exercises after achieving full range of } \\
\text { motion without pain. Multiple joint angles, submaximal isometric contraction. Maintain } \\
\text { cardiovascular fitness with stationary bike riding, swimming or other controlled resistance } \\
\text { activities } \\
\text { Phase } 3 \text { (remodeling): } 1 \text { - } 6 \text { weeks - begin hamstring stretching; eccentric strengthening - } \\
\text { begin concentric before eccentric exercises are initiated. } \\
\text { Phase } 4 \text { (functional): } 2 \text { weeks - } 6 \text { months - progress hamstring flexibility and strength } \\
\text { appropriately return to normal values; painfree running progression (jogging at low intensity } \\
\text { to running and then sprinting); painfree participation in physical activity. } \\
\text { Phase } 5 \text { (return to competition): } 3 \text { weeks to } 6 \text { months - maintain stretching and } \\
\text { strengthening. }\end{array}$ \\
\hline $\begin{array}{c}\text { Schmitt et. } \\
\text { al. }^{31}\end{array}$ & $\begin{array}{l}\text { Phase 1: Acute stage - focus on protecting the injury and minimizing range of motion and } \\
\text { strength loss. Isometrics at } 90,60 \text { and } 30 \text { degrees, single leg balance, and progressive hip } \\
\text { strengthening } \\
\text { Goals: normalize gait, obtain knee flexion strength greater than } 50 \% \text { of uninjured leg upon } \\
\text { MMT at } 90 \text { degrees of knee flexion. } \\
\text { Phase 2: progressively regain strength throughout range of motion and improve } \\
\text { neuromuscular control of the hips and pelvis in preparation for sport specific movements. } \\
\text { Isokinetic eccentrics (non-lengthening), single leg stance with perturbation, Nordic hamstrings, } \\
\text { straight leg deadlifts, and single leg windmills } \\
\text { Goals: full strength MMT or within } 20 \% \text { deficit isokinetic testing. Able to jog forward and } \\
\text { backward without pain at moderate speed. } \\
\text { Phase 3: Functional movements and eccentric strengthening in the lengthened state. } \\
\text { Plyometric and sport specific training and advanced balance exercise. } \\
\text { Return to play criteria: full strength, full range of motion, and full strength in lengthened } \\
\text { hamstring position. } \\
\text { Dynamic straight leg raise flexibility test - "H-test"78 }\end{array}$ \\
\hline
\end{tabular}


Return to play for hamstring complex strains

Clarification and timing of a specific return to play protocol is lacking in the literature. The presentation in the literature only includes general terminology such as a progression of pain free walking to running program that varied pace. Progression must be painfree before initiating full speed activities with change in direction. ${ }^{55}$ Other suggestions include special tests, such as the Active Ballistic Hamstring Flexibility test. ${ }^{78}$ This test found significantly higher mean angular hip flexion velocities of uninjured (201 degrees/sec) compared to injured (175 degrees/sec). ${ }^{78}$ The suggestion is to use this test in conjunction with a return to play progression and clinical exam, however, the limitations of this study were a small sample size, performed by subject, and equipment not generally available. ${ }^{78}$

Nonetheless, the literature continues to present inconsistent information regarding a return to play progression. In a study ${ }^{53}$ evaluating return to play and recovery interval, there was no correlation found between return to play and pre-injury levels of hip flexibility and knee flexion strength. ${ }^{53}$ This suggested that even with pre- and post- measurements of strength and flexibility, the athlete may still be susceptible to re-injury. The use of MRIs in estimating recovery interval timeframe has been used, however, results were insufficient and contradicting. ${ }^{68}$ Three hamstring strains had a Grade I diagnosis and were found to take more than half of the absent days range. ${ }^{68}$ Whereas, 27 hamstring strains with a Grade 0 (no signal of injury was evident on MRI) had a mean recovery interval of 8 days. ${ }^{68}$

The most reliable suggestions for clinical evaluation and initiation of return to play progression is pain free palpation in sports specific activities as the best indicator of readiness. ${ }^{54}$ It is also important to have the correct timing of return to play, which should be based on 
normalized strength and flexibility with the ability to carry out sport specific activities without pain. It must be noted, the healing process after a hamstring complex strain may be slower than clinical findings would indicate. ${ }^{54}$ Therefore, research suggests full strength when manually resisting knee flexion in prone with hip in neutral extension with no point tender palpation, and completion of functional tests without pain. ${ }^{25}$ Functional tests include hop for height, hop for distance, 4-hop cross-over test and 40 yard sprint. ${ }^{25}$

Mixing evidence-based rehabilitation programs with the most commonly found causative factors to generate components and concepts that could potentially be incorporated in a complete hamstring complex rehabilitation program with a balance between the Athletic Trainer and Strength Specialist throughout the Recovery Process.

\section{SUMMARY}

Hamstring complex strains are the most common muscle injury occurring in high intensity sports. The hamstring complex muscles are biarticulate, therefore, increasing the stress applied during a sprint due to the lengthened position they are placed under during the late swing phase when the high is flexed and the knee is extended. The hamstring complex has to eccentrically contract to control knee extension and assist the gluteal muscles in decelerating hip flexion. The most common location of injury is to the Biceps Femoris. It is hypothesized that due to Biceps Femoris Long Head and Short Head having different innervations, a misfiring occurs. This misfiring is one of many possible causative factors. Others included prior history, lacking eccentric strength, hamstring-to-quadriceps strength ratio, fatigue, lack of flexibility, poor lumbo-pelvic control or dehydration. 
Several causative factors listed above lack evidence-based research in being a true mechanism of injury for the hamstring complex strain. Another possible causative factor could be poor rehabilitation or premature return to play. Several authors have presented positive results in reference to their rehabilitation programs. However, most are difficult to replicate with similar finds or the subject population was small, therefore, decreasing the significance of the findings. Literary findings also contradict themselves as seen in Table B1 and B2. These contradictions make it difficult for an ATC to design a rehabilitation program with inclusion of the most successful evidence-based information. Clarification and timing of a specific return to play protocol is lacking in the literature. Use of special tests and MRIs (Magnetic Resonance Imaging) have been proven useful in theory, however, there is still a lack in practicality and clinical application. Concern for re-injury is still high possibly due to the athlete not prepared to return to play or participant at pre-injury levels. Finally, the incorporation of conditioning into a rehabilitation program with a focus on the whole body and not just the injured tissue is a novel idea and requires the conduction of more research to generate successful results. 
APPENDIX C

ADDITIONAL METHODS

Table C1. Initial E-mail to Gauge Interest

April 1, 2013

Are you interested in research concerning the hamstrings?

You have been selected as a potential candidate to participate in this research study on hamstring rehabilitation. I, Caitlin McFadden, am a graduate student in athletic training at West Virginia University and in pursuit of completing my master's degree in athletic training. This research study's primary focus is the development of a complete hamstring complex rehabilitation program for NCAA Division I football players. The study will gather anecdotal and experienced-based knowledge from specific experts in the fields of athletic training, strength and conditioning and hamstring research. Your background has qualified you to be a potential expert for this study. I am contacting you in hopes that you will have interest in this designing a hamstring rehabilitation program and look forward to being on my expert panel.

The purpose of this research study is to combine evidence-based practice and best clinical experience to design a complete program to rehabilitate the hamstring complex and prevent de-conditioning of the entire body with involvement of hamstring researchers, strength and conditioning and athletic training professions. A secondary purpose is to determine the inclusion of concepts and components of a Five-Phase Recovery Process incorporated in the hamstring complex rehabilitation program specifically for National Collegiate Athletic Association Division I Football athletes. And I want you to be a part of its creation!

Your participation will include the completion of two rounds of a questionnaire. The first round will include questions on demographic information, as well as, hamstring complex related questions. You will return the first round electronically, and once results are analyzed, the second round questionnaire will be sent to you with the results included. Once you complete the second round you will once again submit it electronically. The first round should take about 30 minutes for completion, while the second round should only take 15 minutes. Participation in this study is voluntary and will not affect your employment status. You have the option to skip questions and your responses are completely confidential. West Virginia University IRB has approved this study and the approval is on file. If you are willing to participate please respond to this e-mail by including your email address.

I am looking forward to a favorable reply and I hope your interest is high. If so, please respond to this e-mail in reference to your interest. Thank you so much for your time and I look forward to designing a rehabilitation program with you. 
Sincerely,

\section{Caitlin McFadden, ATC, CSCS}

\section{Cmcfadd2@mix.wvu.edu}

*West Virginia University Institutional Review Board acknowledgment of this study is on file 
May 1, 2013

\section{Dear Selected Participant,}

Thank you for responding to the interest e-mail and I hope you are excited in providing your expertise to develop a complete hamstring complex rehabilitation program.

I will be conducting a study under the supervision of faculty member, Michelle A. Sandrey, PhD, ATC, to fulfill requirements for a Master's thesis and complete a Master's of Science degree in Athletic Training. Both are affiliated with West Virginia University. The study will take occur from April to May but will only require your participation in the completion of two rounds of questionnaires throughout that time period. The study design is following the Modified Delphi Method with an initial questionnaire asking about demographic information and your expertise on topics relating to hamstring injury, rehabilitation and strength training components using the Likert scale with 5 being "strongly agree" and 1 being "strongly disagree". There is also space available for additional comments on topics concerning hamstring complex rehabilitation. I am requesting for your critical evaluation of the information provided. This entire process will be completed electronically and the questionnaire should only take about 30 minutes to complete. Please go to the following website to take the survey:

http://www.surveymonkey.com/s/GWGK97L

This is a completely voluntary activity and all responses are guaranteed to be anonymous and confidential, a number system will be implemented so anonymity is secured. You are not required to answer every question and you have the right to withdraw any data you submit at any time. Your job status will not be affected by failure to participate. West Virginia University IRB has approved and the approval is on file. Please respond to the first round online questionnaire as soon as possible, with a deadline on May 15, 2013.

I greatly appreciate your time and participation throughout this study. I look forward to determining the results and the completion of the study on May 29, 2013. Once first round questionnaires have been submitted you will be contacted in reference to the next round. If you have any questions or concerns please contact Caitlin McFadden at (215) 498-2369 or cmcfadd2@mix.wvu.edu, or Dr. Michelle Sandrey, faculty supervisor and Graduate Athletic Training Program Director at West Virginia University, at (304) 293-0870 or msandrey@mail.wvu.edu.

Sincerely, Caitlin McFadden, ATC 
Table C3. First Round Questionnaire

\section{Hamstring Complex Rehabilitation Survey}

\section{Section 1. Demographic Information}

DIRECTIONS: Select the statement that best corresponds to the answer of the question unless otherwise specified.

1. Please indicate the highest educational degree you have attained:

Г Bachleor's Degree

Г Master's Degree

ГPh.D/ Ed. D/ Other Doctorate Degree

$\Gamma$ Other (please specify)

2. What credentials do you currently hold? (Select all that apply)

Г $\mathrm{ACT}$

$\Gamma \operatorname{cscs}$

$\Gamma \operatorname{scs}$

Г PES

$\Gamma \operatorname{sccc}$

$\Gamma$ Other (please specify)

3. How long have you been practicing as a Certified Athletic Trainer?

( $1-4$ years

( $5-10$ years

C $>10$ years

Not applicable

4. How long have you been practicing as a Strength and Conditioning Specialist?
1-4 years
5-10 years
C $>10$ years
Not applicable 


\section{Hamstring Complex Rehabilitation Survey}

5. How long have you been practicing as a Certified Athletic Trainer working primarily with NCAA Division I Football?

1-2 years

2-4 years

5-10 years

C $>10$ years

Not applicable

6. How long have you been practicing as a Strength and Conditioning Specialist working primarily with NCAA Division I Football?

(1-2 years

2-4 years

5-10 years

C $>10$ years

Not applicable

7. In what other settings do you work? (Select all that apply)

$\Gamma$ Academic

ए Athletic Training Room

ए Weight Room

$\Gamma$ Other (please specify)

8. How many presentations related to the hamstring complex have you given at professional meetings?
0
(1-2
( $3-4$
$5+$ 


\section{Hamstring Complex Rehabilitation Survey}

\section{How many of your research publications related to the hamstring complex or rehabilitation of the hamstring complex have appeared in peer reviewed journals?}

$$
\begin{array}{cc}
0 & 0 \\
6 & 1-2 \\
& 3-4 \\
& 5+
\end{array}
$$

\section{Section 2. Progression of a Complete Hamstring Rehabilitation Program}

A complete Hamstring rehabilitation program consists of hamstring complex rehabilitation and prevention of deconditioning of the entire body with the involvement of strength and conditioning and athletic training professionals.

Included in this section are questions about the concepts incorporated in every phase of the rehabilitation and treatment of Grade 1 and 2 hamstring complex strains during a Division I Football Season. The Recovery process has been broken down into five phases for the rehabilitation of hamstring complex each with specific aspects of involvement from the Athletic Trainer and Strength Specialist. There is also specific topics included in each section: Baseline of the Phase, Contraindications for Phase, Flexibility, Range of Motion/Strength, Core Strengthening, Strength \& Conditioning, and Progress to Next Phase.

Each item has a corresponding Likert scale, unless otherwise indicated. The scale selection ranges from strongly disagree (1) to strongly agree (5). After reading the concept, indicate your response with component being utilized.

Additional space is given for comments of each phase and at the end of the section. Please do not hesitate to critically evaluate the information provided with your responses. This will directly aid in the development of the hamstring complex rehabilitation program.

\section{Phase If Initial Assessment}

Acute Phase of a Grade I or II hamstring complex strain. The first phase includes observation and evaluation of the injury and functional ability of the athlete. At this point of the recovery process:

95\% involvement with ATC

$5 \%$ involvement with Strength Specialist

DIRECTIONS: Indicate your selection of each aspect that best corresponds to the answer of the question unless otherwise specified. If answer is not provided, please add additional information. 


\section{Hamstring Complex Rehabilitation Survey}

1. Typical presentation of an acute Grade I \& II hamstring complex strains:

$\begin{array}{lccccc} & \text { Strongly Disagree } & \text { Disagree } & \text { Neutral } & \text { Agree } & \text { Strongly Ag } \\ \text { Pain with knee flexion } & 0 & 0 & 0 & 0 & 0 \\ \begin{array}{l}\text { Decreased strength of } \\ \text { hamstring complex }\end{array} & 0 & 0 & 0 & 0 & 0 \\ \text { Ecchymosis } & 0 & 0 & 0 & 0 & 0 \\ \text { Minimal deformity/defect } & 0 & 0 & 0 & 0\end{array}$

Other (please specify)

\section{Typical mechanism of injury for grade I \& II hamstring complex strains:}

\begin{tabular}{lccccc} 
& Strongly Disagree & Disagree & Neutral & Agree & Strongly Agree \\
Eccentric contraction & 0 & 0 & 0 & 0 & 0 \\
Concentric contraction & 0 & 0 & 0 & 0 & 0 \\
$\begin{array}{l}\text { Over-reaching during a } \\
\text { sprint }\end{array}$ & 0 & 0 & 0 & 0 & 0 \\
Fatigue & 0 & 0 & 0 & 0 \\
Dehydration & 0 & 0 & & 0 \\
Other (please specify) & & & & \\
\hline
\end{tabular}

3. The rehabilitation exercises utilized in this phase will be dictated by:

$\begin{array}{lccccc} & \text { Strongly Disagree } & \text { Disagree } & \text { Neutral } & \text { Agree } & \text { Strongly Agree } \\ \begin{array}{l}\text { Prior history of hamstring } \\ \text { complex strains }\end{array} & 0 & 0 & 0 & 0 & 0 \\ \begin{array}{l}\text { Mechanism of Injury via } \\ \text { stretching }\end{array} & 0 & 0 & 0 & 0 & 0 \\ \begin{array}{l}\text { Mechanism of Injury via } \\ \text { sprinting }\end{array} & 0 & 0 & 0 & 0 & 0 \\ \begin{array}{l}\text { Ability to complete physical } \\ \text { activity immediately post } \\ \text { injury occurrence }\end{array} & 0 & 0 & & \\ \text { Other (please specify) } & & & & \\ \quad\end{array}$




\section{Hamstring Complex Rehabilitation Survey}

\section{Contraindications for this phase are:}

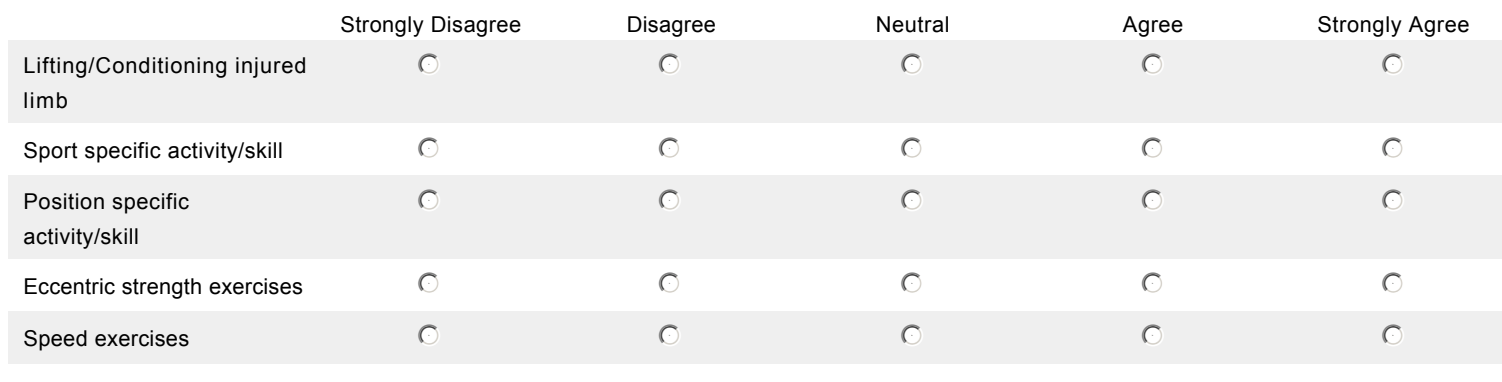

Other (please specify)

FLEXIBILITY FOCUS FOR PHASE I

5. Flexibility of the hamstring complex should be addressed during Phase $\mathbf{I}$.

Strongly Disagree

○
Disagree

0
Neutral

c
Agree

C
Strongly Agree

C

\section{Flexibility exercises for this phase should include:}

$\begin{array}{lccccc} & \text { Strongly Disagree } & \text { Disagree } & \text { Neutral } & \text { Agree } & 0 \\ \text { Static stretching exercises } & 0 & 0 & 0 & 0 & 0\end{array}$

exercises

Other (please specify)

\section{What should be used to increase total body flexibility:}

\begin{tabular}{|c|c|c|c|c|c|}
\hline & Strongly Disagree & Disagree & Neutral & Agree & Strongly Agree \\
\hline Multi-joint progression & O & O & O & O & O \\
\hline $\begin{array}{l}\text { Isolation or single joint } \\
\text { progression }\end{array}$ & $\mathrm{O}$ & $\mathrm{O}$ & 0 & O & 0 \\
\hline Manual Therapy & $\mathrm{O}$ & 0 & 0 & 0 & 0 \\
\hline
\end{tabular}

Other (please specify) 


\section{Hamstring Complex Rehabilitation Survey}

8. A sufficient static stretching protocol should include:

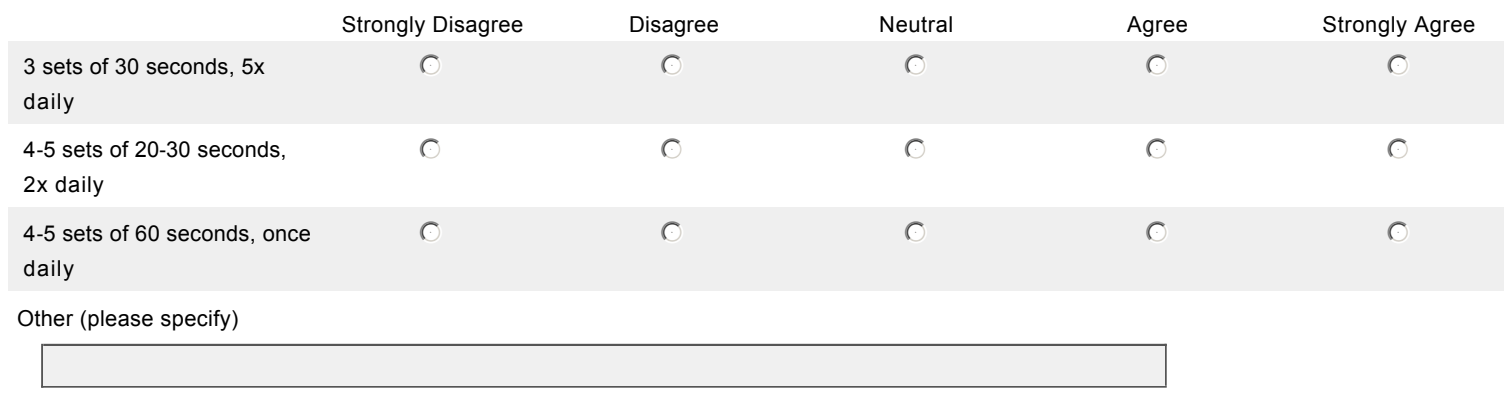

9. Flexibility exercises should focus on the entire lumbo-pelvic complex.
Strongly Disagree
Disagree
Neutral
Agree
Strongly Agree
C
○
○
(
$C$

\begin{abstract}
RANGE OF MOTION/STRENGTH FOR PHASE I
This aspect and corresponding questions is geared towards how the ATHLETIC TRAINER will conduct the rehabilitation program
\end{abstract} during Phase I.

10. Range of motion exercises should be completed during Phase $I$.
Strongly Disagree
Disagree
Neutral
Agree
Strongly Agree
○
c
C

11. Range of motion exercises for the hamstring should only be completed in a painfree range of motion.

Strongly Disagree

Disagree

Neutral

Agree

Strongly Agree

C

6

C

12. Range of motion exercises should also include the gluteal group.

Strongly Disagree

○
Disagree

○
Neutral

c
Agree

c
Strongly Agree

13. Functional activity should be carried out in a pool during Phase I of the rehabilitation program.

Strongly Disagree

0
Disagree

6
Neutral

(
Agree

$c$
Strongly Agree 


\section{Hamstring Complex Rehabilitation Survey}

14. Strengthening exercises for the hamstring complex should be focused on increasing:

$\begin{array}{lcc} & \text { Strongly Disagree } & \text { Disagree } \\ \text { Isometric Strength } & 0 & 0 \\ \text { Endurance } & 0 & 0 \\ \text { Concentric Strength } & 0 & 0 \\ \text { Eccentric Strength } & 0 & 0 \\ \text { Power } & 0 & 0\end{array}$

Other (please specify)

CORE STRENGTHENING FOR PHASE I

15. Core stabilization should be a focus during hamstring complex rehabilitation.

Strongly Disagree

O
Disagree

O

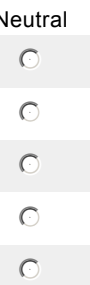

O

C

0

$C$
Agree

○

O

○

C

C
Strongly Agree

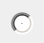

O

O

○

0

16. Core stability exercises should be more stabilization focused during Phase $\mathbf{I}$.

Strongly Disagree

O
Disagree

O
Neutral

C
Agree

C
Strongly Agree

C

STRENGTH \& CONDITIONING FOR PHASE I

This aspect and corresponding questions is geared towards how the STRENGTH SPECIALIST will conduct the rehabilitation program during Phase I.

17. Lifting and conditioning exercises should only be completed without involvement of injured limb.

Strongly Disagree

Disagree

Neutral

Agree

Strongly Agree

○

o

(

C

C

18. Lifting and conditioning progression should be normal for the rest of the body.

Strongly Disagree

O
Disagree

O
Neutral

o
Agree

C
Strongly Agree 


\section{Hamstring Complex Rehabilitation Survey}

19. Aerobic conditioning should be completed by:

$\begin{array}{lccccc} & \text { Strongly Disagree } & \text { Disagree } & \text { Neutral } & \text { Agree } & \text { Strongly Agree } \\ \begin{array}{l}\text { Stationary bike without } \\ \text { injured limb involvement }\end{array} & 0 & 0 & 0 & 0 & 0 \\ \begin{array}{l}\text { Upper Body Ergometer } \\ \text { sprints }\end{array} & 0 & 0 & 0 & 0 & 0 \\ \begin{array}{l}\text { Hydrotherapy running } \\ \text { Circuit training without } \\ \text { injured limb involvement }\end{array} & 0 & 0 & 0 & 0 & 0 \\ \text { Other (please specify) } & 0 & 0 & 0 & & 0 \\ \end{array}$

PROGRESS TO PHASE II 


\section{Hamstring Complex Rehabilitation Survey}

20. Prior to moving to Phase II of rehabilitation, athlete should:

\begin{tabular}{|c|c|c|c|c|c|}
\hline & Strongly Disagree & Disagree & Neutral & Agree & Strongly Agree \\
\hline $\begin{array}{l}\text { Perform activities of daily } \\
\text { living painfree }\end{array}$ & 0 & O & $\mathrm{O}$ & 0 & 0 \\
\hline Walking painfree & 0 & O & $\mathrm{O}$ & O & 0 \\
\hline $\begin{array}{l}\text { Be able to complete } \\
\text { lifting/workout of rest of the } \\
\text { body with team }\end{array}$ & O & O & 0 & 0 & 0 \\
\hline $\begin{array}{l}\text { Have full painfree range of } \\
\text { motion }\end{array}$ & 0 & O & 0 & 0 & 0 \\
\hline $\begin{array}{l}\text { Have no point tender } \\
\text { palpation }\end{array}$ & 0 & 0 & 0 & 0 & 0 \\
\hline $\begin{array}{l}\text { Have no spasm or mass felt } \\
\text { during palpation }\end{array}$ & $\mathrm{O}$ & 0 & O & $\mathrm{O}$ & 0 \\
\hline Have no discoloration & 0 & O & 0 & 0 & 0 \\
\hline Have no deformity noted & O & O & $\mathrm{O}$ & $\mathrm{O}$ & 0 \\
\hline $\begin{array}{l}\text { Have pain only during } \\
\text { hamstring stretch }\end{array}$ & O & O & 0 & 0 & O \\
\hline $\begin{array}{l}66 \% \text { difference Hamstring- } \\
\text { to-Quadriceps ratio }\end{array}$ & 0 & O & $\mathrm{O}$ & 0 & 0 \\
\hline $\begin{array}{l}50 \% \text { difference Hamstring- } \\
\text { to-Quadriceps ratio }\end{array}$ & 0 & 0 & 0 & 0 & 0 \\
\hline $\begin{array}{l}35 \% \text { difference Hamstring- } \\
\text { to-Quadriceps ratio }\end{array}$ & 0 & 0 & 0 & 0 & 0 \\
\hline $\begin{array}{l}25 \% \text { difference Hamstring- } \\
\text { to-Quadriceps ratio }\end{array}$ & 0 & O & 0 & 0 & 0 \\
\hline $\begin{array}{l}35 \% \text { difference eccentric } \\
\text { Hamstring-to-concentric } \\
\text { Quadriceps functional ratio }\end{array}$ & 0 & 0 & 0 & 0 & 0 \\
\hline When athlete feels ready & 0 & O & 0 & O & 0 \\
\hline \multicolumn{6}{|l|}{ Other (please specify) } \\
\hline & Strongly Disagree & Disagree & Neutral & Agree & Strongly Agree \\
\hline Prone curl painfree & 0 & O & O & O & 0 \\
\hline $\begin{array}{l}\text { Active straight leg raise to } \\
\text { max range of motion } \\
\text { painfree }\end{array}$ & $\mathrm{O}$ & 0 & 0 & O & 0 \\
\hline $\begin{array}{l}\text { Active ballistic hamstring } \\
\text { test results with low } \\
\text { insecurity and painfree } \\
\text { motion half of contralateral } \\
\text { limb range of motion }\end{array}$ & $\mathrm{O}$ & O & $\mathrm{O}$ & 0 & 0 \\
\hline Other (please specify) & & & & & \\
\hline
\end{tabular}




\section{Hamstring Complex Rehabilitation Survey}

\section{Additional Comments for Phase I of the rehabilitation program:}

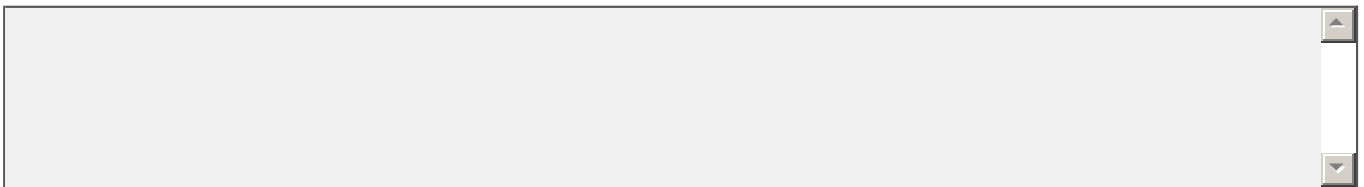

\section{Phase Il: Implementation of Functional Activity}

Sub-acute Phase of a Grade I or II hamstring complex strain. The second phase includes progression of the recovery process and functional activity incorporation. At this point of the recovery process:

85\% involvement with ATC

$15 \%$ involvement with Strength Specialist

DIRECTIONS: Indicate your selection of each aspect that best corresponds to the answer of the question unless otherwise specified. If answer is not provided, please add additional information.

BASELINE FOR PHASE II

\section{Prior to beginning Phase II, athlete should be able to complete:}

$\begin{array}{lcccc} & \text { Strongly Disagree } & \text { Disagree } & \text { Neutral } & \text { Agree } \\ \begin{array}{l}\text { Perform activities of daily } \\ \text { living pain free }\end{array} & 0 & 0 & 0 & 0 \\ \text { Walk painfree } & 0 & 0 & 0 & 0 \\ \text { Have full strength } & 0 & 0 & & 0 \\ \begin{array}{l}\text { Start functional activity with } \\ \text { minimal pain }\end{array} & 0 & & & 0 \\ \text { Other (please specify) } & & & \end{array}$




\section{Hamstring Complex Rehabilitation Survey}

2. Contraindications for Phase II are:

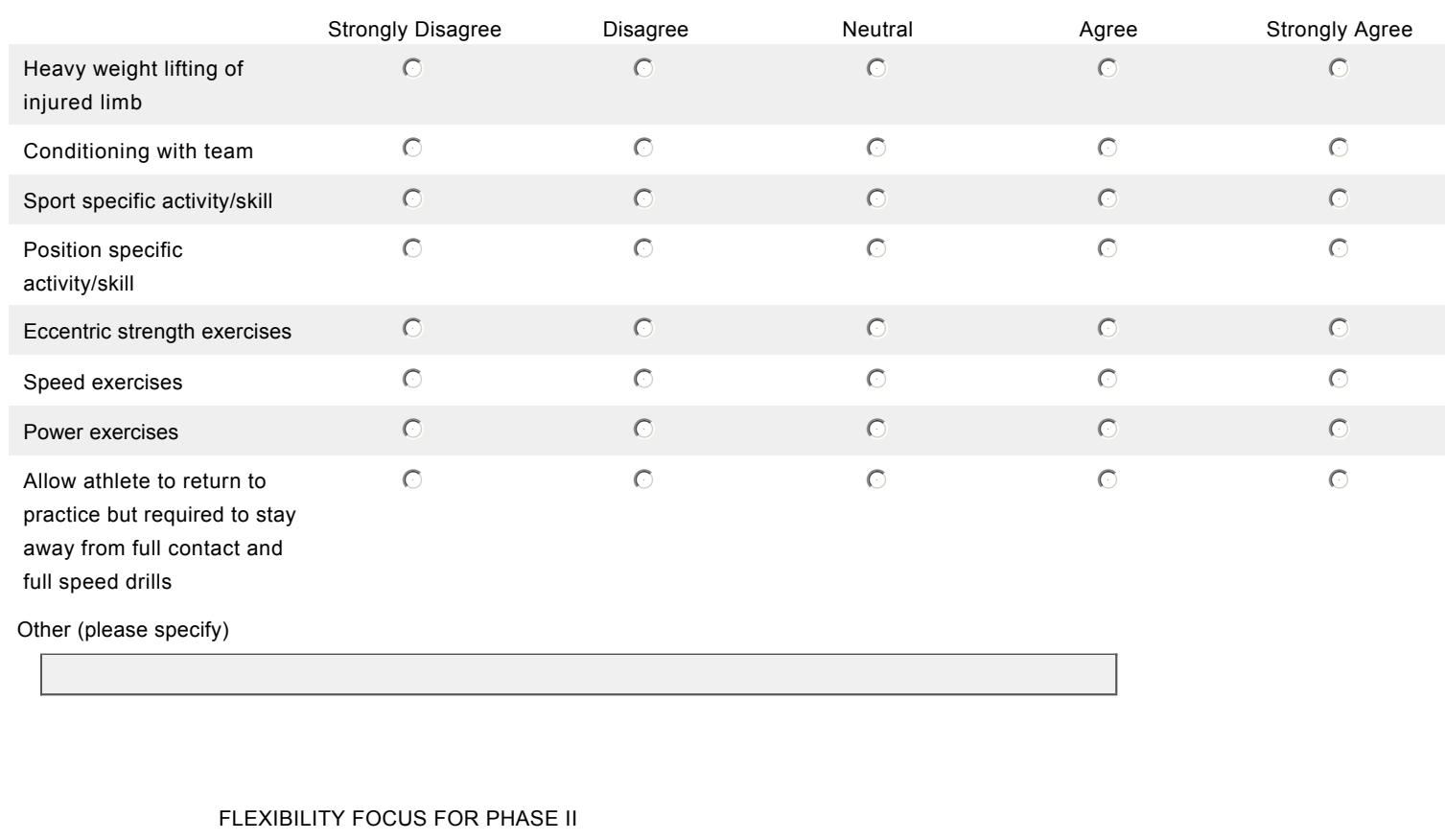

\section{Flexibility of the hamstring complex should be addressed during Phase II.}

Strongly Disagree

Disagree

Neutral

Agree

C

C

C

Strongly Agree

\section{Flexibility exercises for Phase II should include:}

$\begin{array}{lcccc} & \text { Strongly Disagree } & \text { Disagree } & \text { Neutral } & \text { Agree } \\ \text { Static stretching exercises } & 0 & 0 & 6 & 6 \\ \begin{array}{l}\text { Dynamic stretching } \\ \text { exercises }\end{array} & 0 & 0 & 0 \\ \text { Manual therapy techniques } & 0 & 0 & & 0 \\ \text { Other (please specify) } & & & \end{array}$

5. Flexibility exercises should be completed in a more aggressive form compared to Phase I of the rehabilitation program.

Strongly Disagree

Disagree

Neutral

Agree

Strongly Agree

O

C

o

C

O

6. Static stretches included in Phase II should utilize the PNF technique.

Strongly Disagree

Disagree

Neutral

Agree

O

O

C

O

Strongly Agree 


\section{Hamstring Complex Rehabilitation Survey}

RANGE OF MOTION/STRENGTH FOR PHASE II

This aspect and corresponding questions is geared towards how the ATHLETIC TRAINER will conduct the rehabilitation program during Phase II.

7. Range of motion exercises should be continued during Phase II.

Strongly Disagree

C
Disagree

C
Neutral

O
Agree
Strongly Agree

8. Strengthening exercises for the hamstring complex during Phase II should be focused on increasing:

$\begin{array}{lccccc} & \text { Strongly Disagree } & \text { Disagree } & \text { Neutral } & \text { Agree } \\ \text { Isometric Strength } & 0 & 0 & 0 & 0 & 0 \\ \text { Endurance } & 0 & 0 & 0 & 0 & 0 \\ \text { Concentric Strength } & 0 & 0 & 0 & 0 \\ \text { Eccentric Strength } & 0 & 0 & 0\end{array}$

Other (please specify)

9. Strengthening exercises included in Phase II should include exercises to increase strength of the low back.

Strongly Disagree

Disagree

Neutral

Agree

Strongly Agree

C

(

C

10. Strengthening exercises included in Phase II should include exercises to increase strength of the lumbo-pelvic complex.

Strongly Disagree

Disagree

C

Neutral

Agree

C

Strongly Agree

11. Eccentric exercises should be started during Phase II.

Strongly Disagree

Disagree

Neutral

Agree

Strongly Agree

O

O

O

12. Functional activity should be started:

Strongly Disagree

Disagree

Within the first phase of

rehabilitation program

Once painfree

Once point tender

palpation is resolved

Once equal bilatera

strength is achieved

Other (please specify) 


\title{
Hamstring Complex Rehabilitation Survey
}

13. Functional activity should continue to be carried out in a pool during Phase II.

Strongly Disagree

○
Disagree
Neutral
Agree
Strongly Agre

C

14. Functional activity during Phase II should include:

$\begin{array}{lcccc} & \text { Strongly Disagree } & \text { Disagree } & \text { Neutral } & \text { Agree } \\ \text { Walk/Jog progression } & 0 & 0 & 0 & \\ \text { Light intensity sprinting } & 0 & 0 & \\ \text { Aerobic training on a } & 0 & & \\ \text { weight bearing machine } & & & \\ \text { Other (please specify) } & & \end{array}$

CORE STRENGTHENING FOR PHASE II

15. Core stabilization should be a focus during Phase II.

Strongly Disagree

Disagree

Neutral

Agree

Strongly Agree

C

O

(

C

16. Core stability exercises should be more strength based with dynamic motions focused during Phase II.

Strongly Disagree

Disagree

Neutral

Agree

Strongly Agree

O

○

17. Core strengthening exercises should be performed in a multiplaner form.

Strongly Disagree

Disagree

Neutral

Agree

Strongly Agree

C

○

C

\begin{abstract}
STRENGTH \& CONDITIONING FOR PHASE II
This aspect and corresponding questions is geared towards how the STRENGTH SPECIALIST will conduct the rehabilitation program during Phase II.
\end{abstract}

18. Lifting and conditioning exercises should only be completed without involvement of injured limb during Phase II.

Strongly Disagree
Disagree

O
Neutral
Agree
Strongly Agree

O 


\section{Hamstring Complex Rehabilitation Survey}

19. Lifting and conditioning exercises may involve injured limb while:

\begin{tabular}{|c|c|c|c|c|c|}
\hline & Strongly Disagree & Disagree & Neutral & Agree & Strongly Agree \\
\hline Weight is light & 0 & 0 & 0 & 0 & 0 \\
\hline $\begin{array}{l}\text { Eccentric Strength is } \\
\text { utilized or focused on }\end{array}$ & 0 & 0 & 0 & 0 & 0 \\
\hline $\begin{array}{l}\text { Power exercises are } \\
\text { performed }\end{array}$ & 0 & 0 & 0 & 0 & 0 \\
\hline $\begin{array}{l}\text { No power exercises are } \\
\text { performed }\end{array}$ & 0 & 0 & 0 & 0 & 0 \\
\hline $\begin{array}{l}\text { Lift and conditioning } \\
\text { movements that cause pain } \\
\text { are not performed }\end{array}$ & 0 & 0 & 0 & 0 & 0 \\
\hline $\begin{array}{l}\text { Activity that caused original } \\
\text { injury cannot be performed }\end{array}$ & 0 & 0 & 0 & 0 & 0 \\
\hline
\end{tabular}

20. Lifting and conditioning progression should be normal for the rest of the body.

Strongly Disagree

○
Disagree

C
Neutral

C
Agree

C
Strongly Agree

O

21. Aerobic conditioning should be completed by:

Strongly Disagree

Disagree

Stationary bike without

injured limb involvement

Upper bike ergometer

sprints

Hydrotherapy running

Circuit training without

injured limb involvement

Other (please specify)
Neutral

○

O

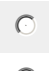

○
Agree

○

O

0

○
Strongly Agree

○

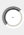

C

22. During Phase II, start with a dynamic warm and begin walk/job/run progression.

Strongly Disagree

O
Disagree

○
Neutral

C 


\section{Hamstring Complex Rehabilitation Survey}

\section{Prior to moving to Phase III of rehabilitation program, athlete should:}

Strongly Disagree

Able to completing

lifting/workout without

limitations

Have full strength equal

bilateral painfree

No pain during hamstring

stretch

$66 \%$ difference Hamstring-

to-Quadriceps ratio

$50 \%$ difference Hamstring-

to-Quadriceps ratio

$35 \%$ difference Hamstring-

to-Quadriceps ratio

$25 \%$ difference Hamstring-

to-Quadriceps ratio

$50 \%$ difference Eccentric

Hamstring -to-Concentric

Quadriceps functional ratio

When athlete feels ready

Walking lunges do not

cause pain with full range

of motion

When functional activity is

started

When $75 \%$ strength is

achieved

When $75 \%$ speed is

achieved

Other (please specify)
Disagree

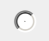

0

O

O

O

O

O

c

C

0

c

O

c

C

O

(

0

$C$

$C$

C

C

c

0

(1)

C

C
Neutral

o

C

Agree

C

$0 \quad 0 \quad 0$

O

6

○

C

C

o

O

C

o

O

C

O

C

(1)

(

0

0

0

0

0

O

0

O

O

0

0

O

O

0

0

O

○

○ 


\section{Hamstring Complex Rehabilitation Survey}

24. The following clinical tests or evaluations should be included to determine progression to Phase III of the rehabilitation program:

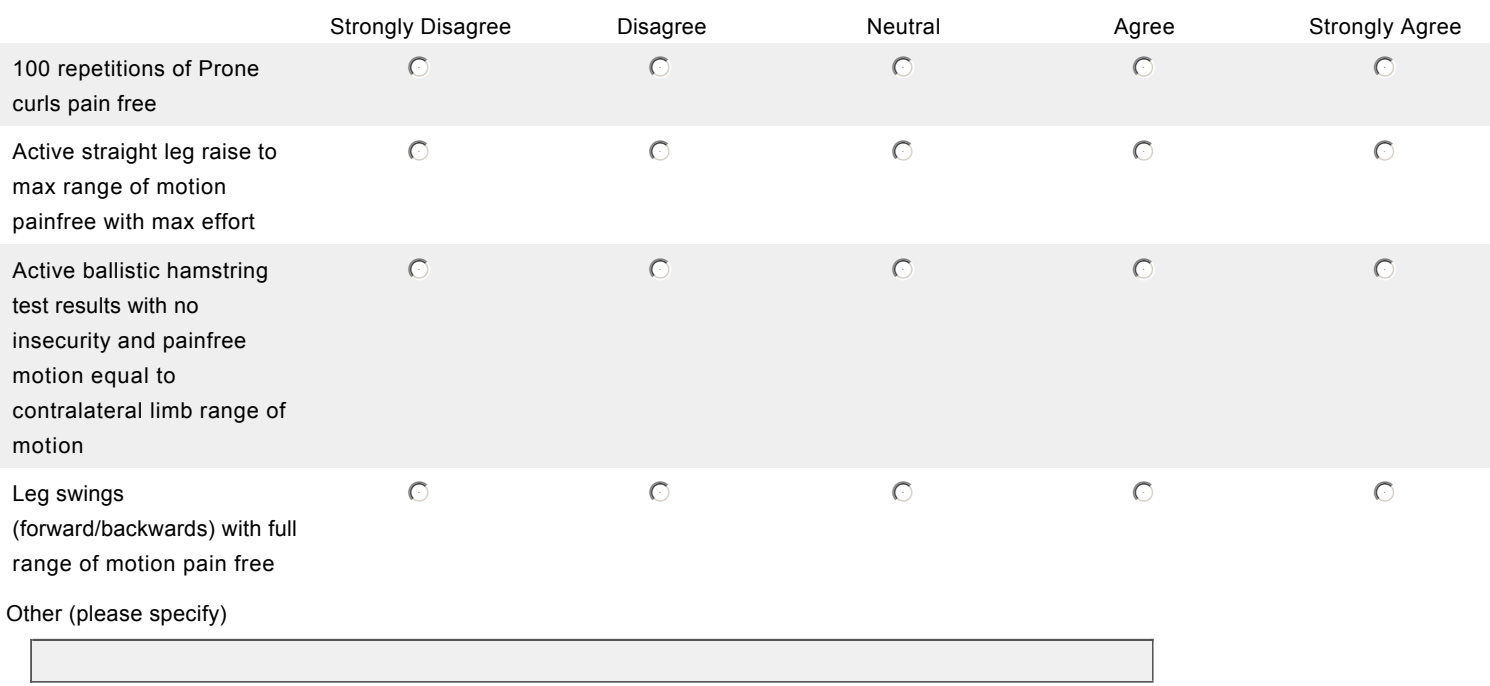

\section{Additional Comments for Phase II of the rehabilitation program:}

\section{Phase III: Re-education of the Fundamentals of Strength \& Conditioning}

Chronic Phase of a Grade I or II hamstring complex strain. The third phase includes progression of the recovery process and introduction/education of the fundamentals and skills required to perform strength and conditioning properly. At this point of the recovery process:

$50 \%$ involvement with ATC

$50 \%$ involvement with Strength Specialist

DIRECTIONS: Indicate your selection of each aspect that best corresponds to the answer of the question unless otherwise specified. If answer is not provided, please add additional information. 


\section{Hamstring Complex Rehabilitation Survey}

1. Prior to Beginning Phase III, athlete should be able to complete:

\begin{tabular}{|c|c|c|}
\hline & Strongly Disagree & Disagree \\
\hline $\begin{array}{l}\text { Perform functional activity } \\
\text { without pain }\end{array}$ & 0 & 0 \\
\hline $\begin{array}{l}\text { Perform functional activity } \\
\text { with minimal pain }\end{array}$ & $\mathrm{O}$ & 0 \\
\hline $\begin{array}{l}\text { Full strength compared } \\
\text { bilaterally }\end{array}$ & 0 & 0 \\
\hline $\begin{array}{l}\text { Start sprinting greater than } \\
85 \% \text { speed with minimal } \\
\text { pain }\end{array}$ & 0 & 0 \\
\hline
\end{tabular}

CONTRAINDICATIONS FOR PHASE III

\section{Contraindications for Phase III are:}

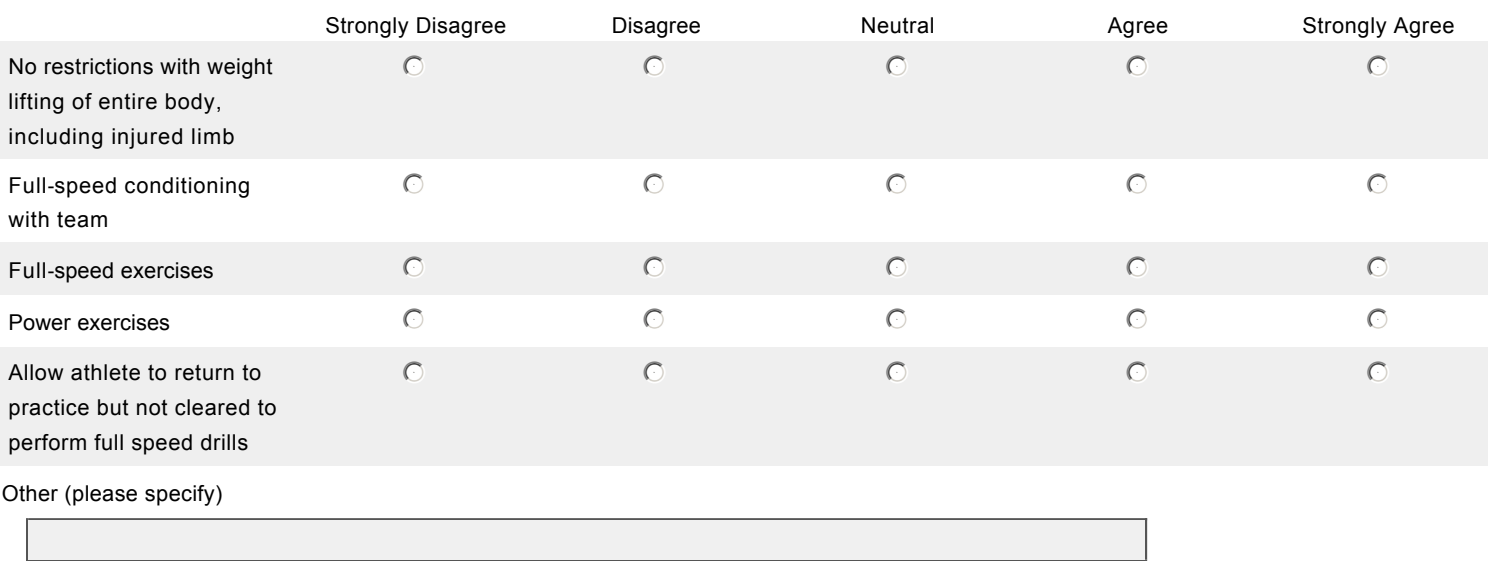

FLEXIBILITY FOCUS FOR PHASE III

3. Static exercises started in Phases I \& II of the rehabilitation program should be continued during Phase III.

Strongly Disagree

C
Disagree
Neutral

C
Agree
Strongly Agree

C

0

O

O

4. Dynamic stretching should be used to increase hamstring flexibility during Phase III of the rehabilitation program.

Strongly Disagree

O
Disagree

C
Neutral

O
Agree
Strongly Agree 


\section{Hamstring Complex Rehabilitation Survey}

RANGE OF MOTION/STRENGTH FOR PHASE III This aspect and corresponding questions is geared towards how the ATHLETIC TRAINER will conduct the rehabilitation
program during Phase III.

5. Range of motion exercises are not required for Phase III.

Strongly Disagree

Disagree

Neutral

Agree

Strongly Agree

O

C

6. Strengthening exercises for the hamstring complex during Phase III should be focused on increasing:

\begin{tabular}{|c|c|c|c|c|c|}
\hline & Strongly Disagree & Disagree & Neutral & Agree & Strongly Agree \\
\hline Endurance & 0 & 0 & 0 & 0 & 0 \\
\hline Concentric Strength & 0 & 0 & 0 & 0 & 0 \\
\hline Eccentric Strength & 0 & 0 & 0 & 0 & 0 \\
\hline Power & 0 & 0 & 0 & 0 & 0 \\
\hline
\end{tabular}

7. Eccentric exercises should increase in intensity and volume during this phase of the rehabilitation program.

Strongly Disagree

Disagree

C
Neutral

O
Agree
Strongly Agree

O

8. Strengthening exercises included in Phase III should include exercises to increase strength of the lumbo-pelvic complex.

Strongly Disagree Disagree

Neutral

Agree

Strongly Agree

C

$\mathrm{O}$

C

9. What percentage of strengthening exercises should be for hamstring complex versus lumbo-pelvic complex during Phase III:

$95 \%$ vs. $5 \%$
$75 \%$ vs. $25 \%$
$50 \%$ vs. $50 \%$
$25 \%$ vs. $75 \%$
$5 \%$ vs. $95 \%$

Strongly Disagree

Disagree

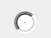

O

Neutral

Agree

Strongly Agree

Other (please specify) 


\section{Hamstring Complex Rehabilitation Survey}

16. Lifting and conditioning exercises may involve injured limb while:

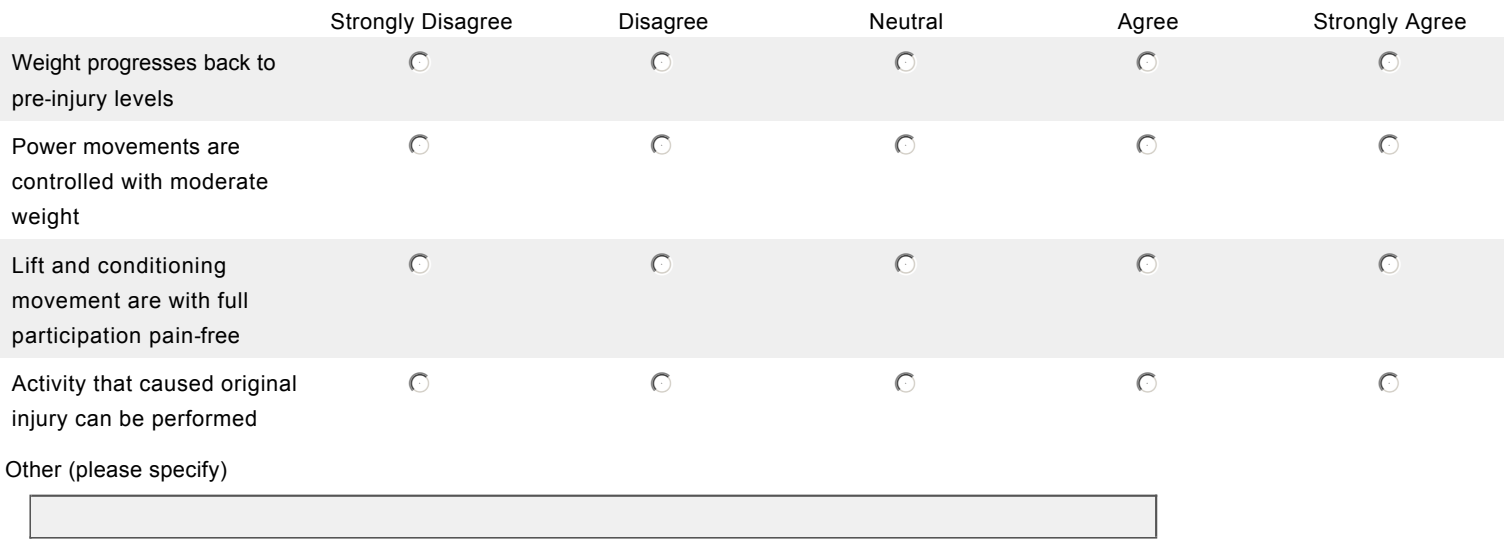

17. Lifting and conditioning progression should be in conjunction with team progression.

Strongly Disagree

○
Disagree

○
Neutral

○
Agree

○
Strongly Agree

O

18. Aerobic/Anaerobic conditioning should be completed with team while:

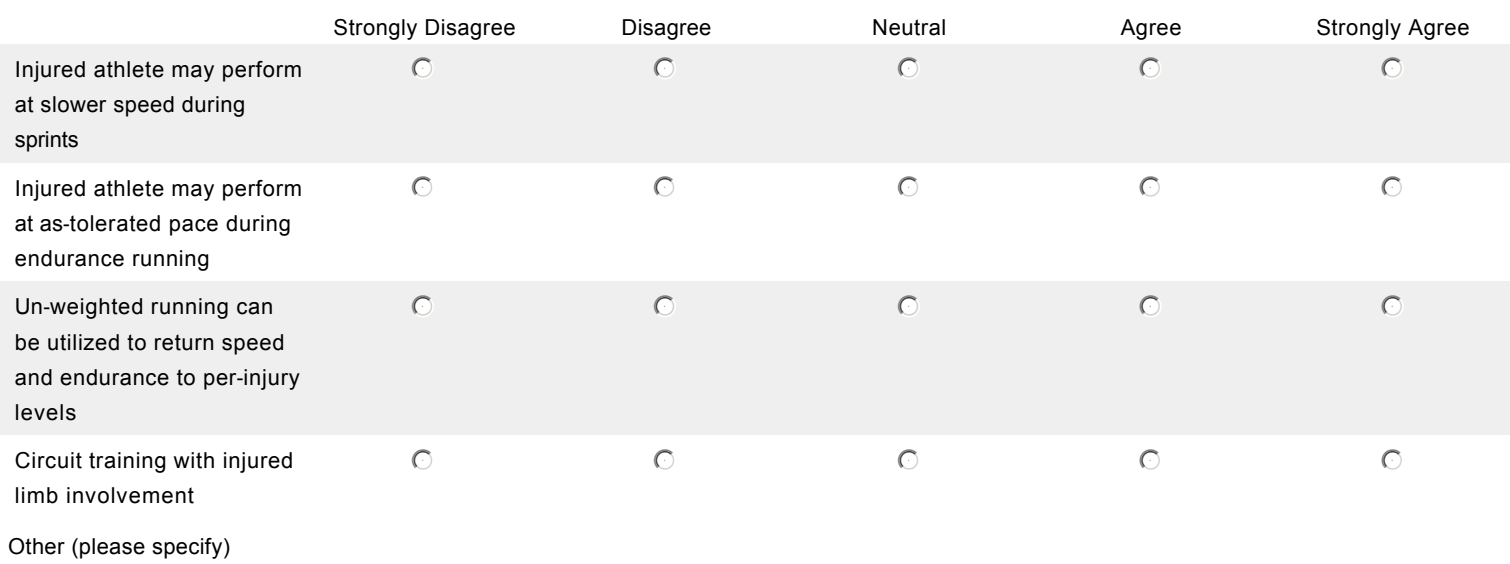

19. During Phase III, full dynamic warm-up may be complete with team.

Strongly Disagree

○
Disagree

c
Neutral

6
Agree

c
Strongly Agree

○

20. During Phase III, athlete should be fully participating in skill, individual and agility drills with team.

Strongly Disagree
Disagree

○
Neutral
Agree

○
Strongly Agree 


\section{Hamstring Complex Rehabilitation Survey}

21. Athletic Trainer and Strength Specialist should be concerned of re-injury to hamstring complex within the first two-weeks post returning to full participation.

Strongly Disagree

C
Disagree

C
Neutral

c
Agree

○
Strongly Agree

O

22. The following clinical tests or evaluations should be included to determine return to full participation:

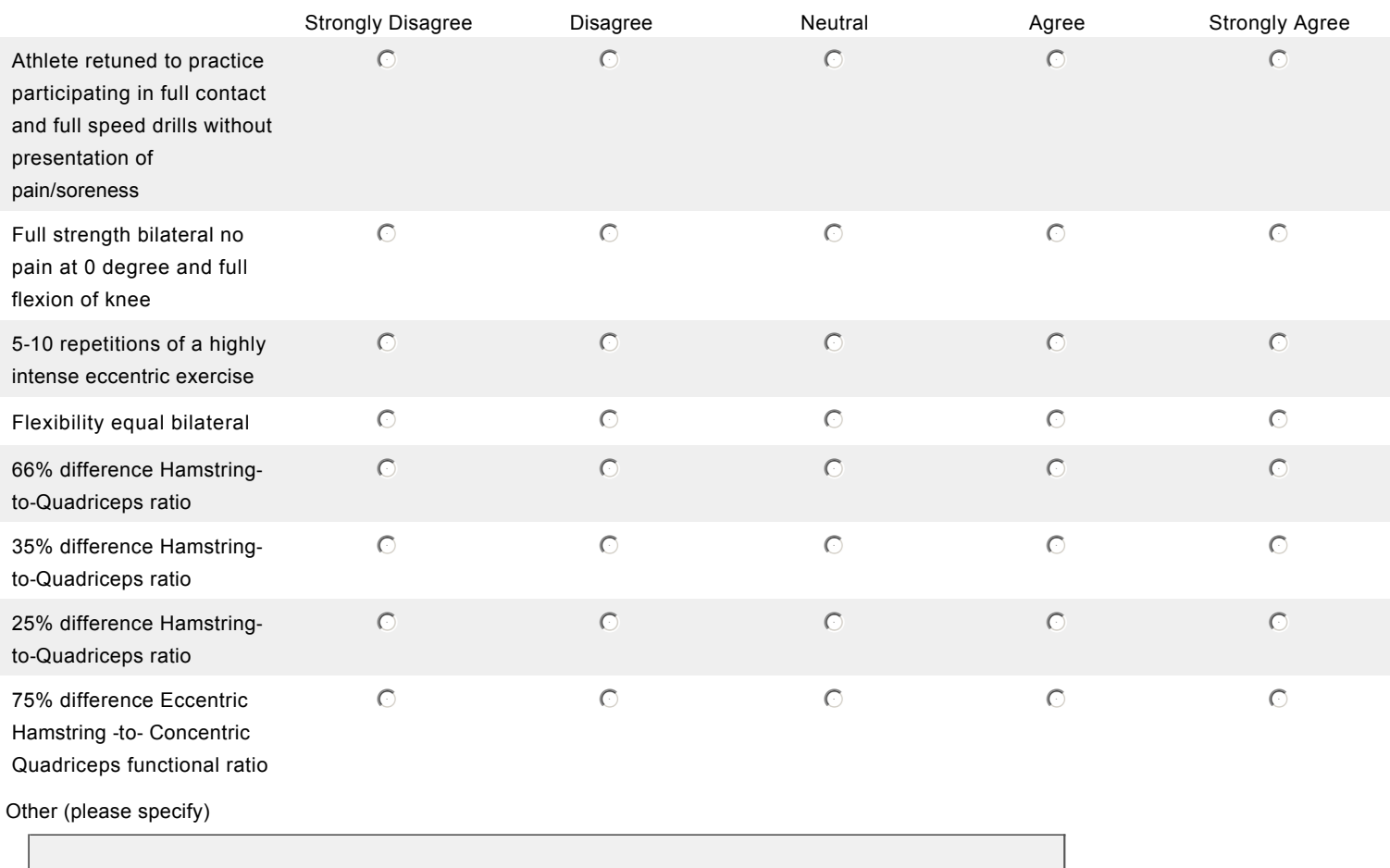

\section{Additional Comments for Phase III of the rehabilitation program:}

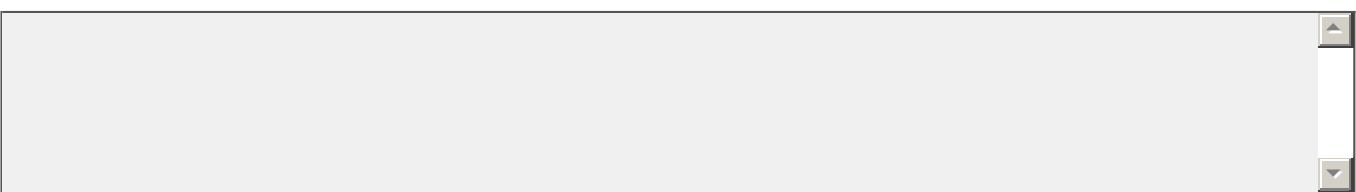

\section{Phase IV: Re-conditioning the Body}

Return to Play Phase of a Grade I or II hamstring complex strain. The fourth phase includes return to play progression and re-conditioning of the athlete. At this point of the recovery process:

$15 \%$ involvement with ATC

$85 \%$ involvement with Strength Specialist

DIRECTIONS: Indicate your selection of each aspect that best corresponds to the answer of the question unless 


\section{Hamstring Complex Rehabilitation Survey}

otherwise specified. If answer is not provided, please add additional information.

BASELINE FOR PHASE IV

\section{Prior to Phase IV, athlete should be able to complete:}

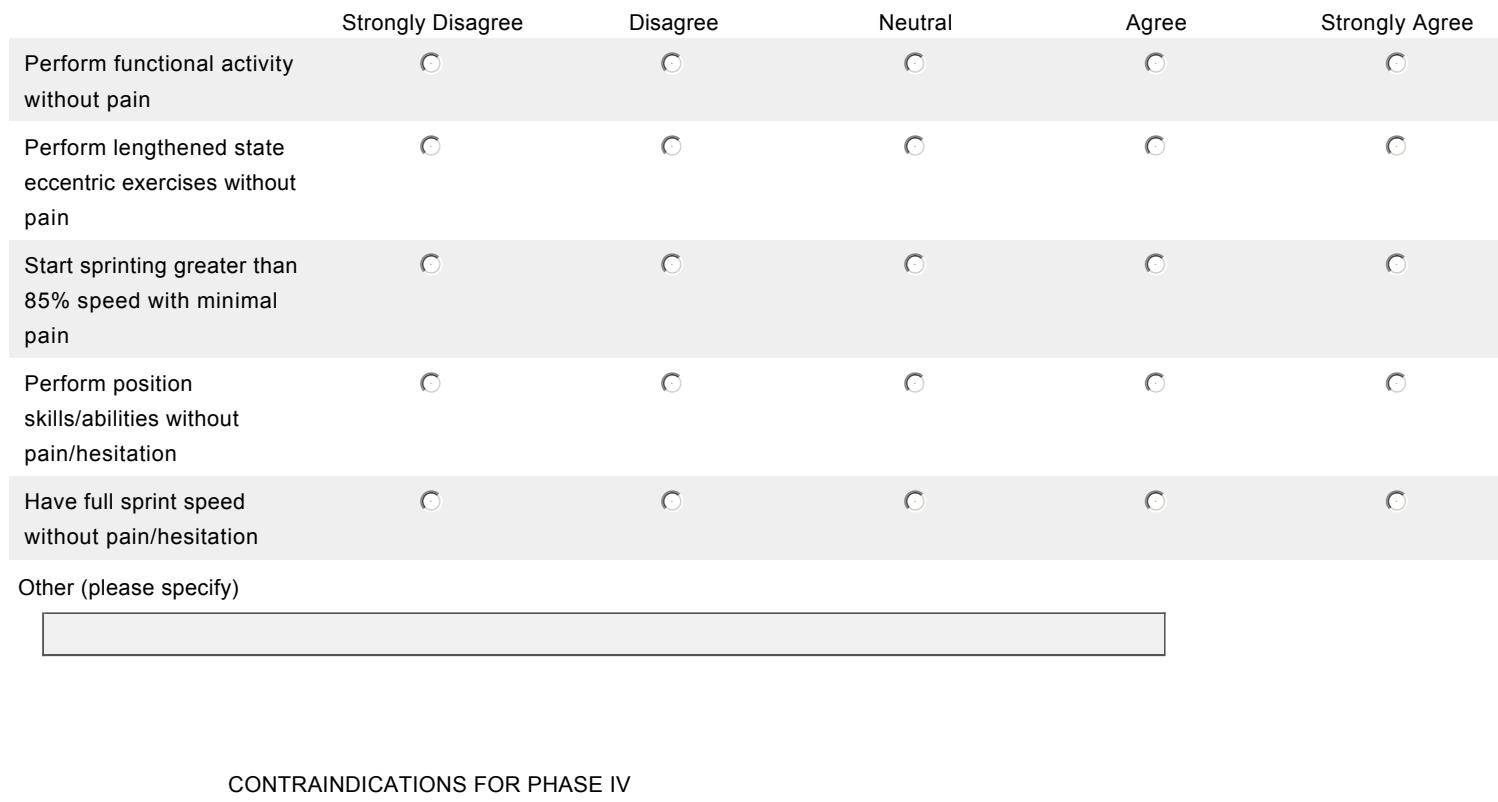

2. There are no contraindications for Phase III of the rehabilitation program.

Strongly Disagree

0
Disagree

○
Neutral

○
Agree

C
Strongly Agree

FLEXIBILITY FOCUS FOR PHASE IV

3. Static exercises started in PhaseS I, II \& III of the rehabilitation program should be continued during Phase IV.

Strongly Disagree

C
Disagree

○
Neutral

○
Agree

C

Agree

C

Strongly Agree

O

\section{All dynamic stretching should be completed with team.}

Strongly Disagree

Disagree

Neutral

C

C

C

5. Flexibility exercises are completed as needed.

Strongly Disagree

O
Disagree

o
Neutra

C
Agree

○
Strongly Agree

O 


\section{Hamstring Complex Rehabilitation Survey \\ RANGE OF MOTION/STRENGTH FOR PHASE IV \\ This aspect and corresponding questions is geared towards how the ATHLETIC TRAINER will conduct the rehabilitation program during Phase IV.}

6. Strengthening exercises for the hamstring complex during Phase IV should be focused on:

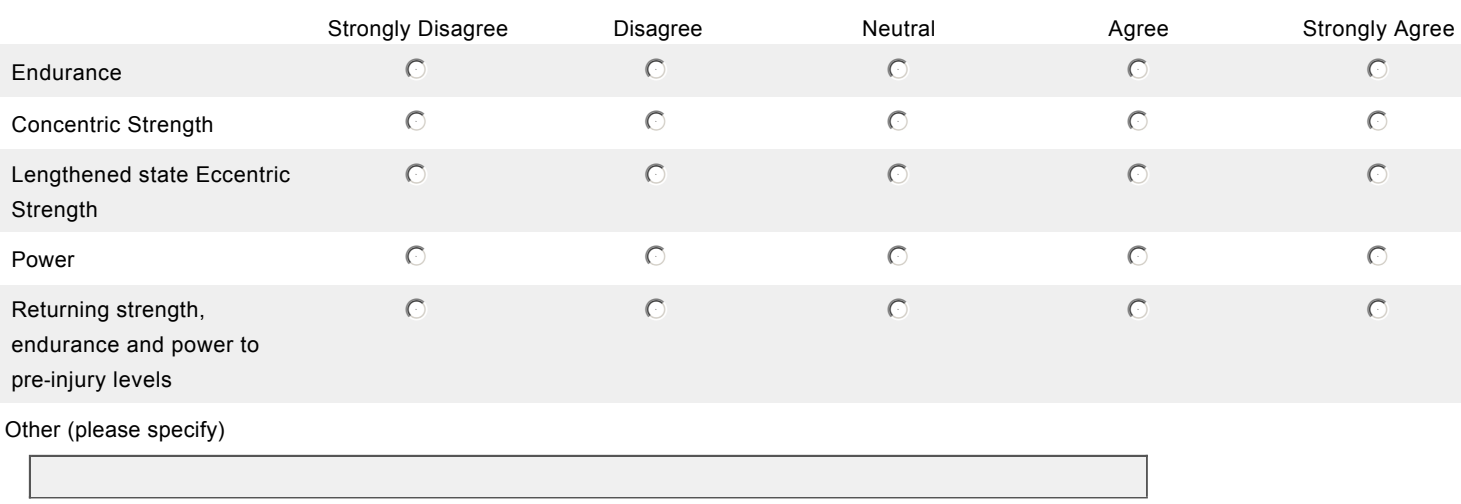

7. Strengthening exercises included in Phase IV should include exercises to increase strength of the lumbo-pelvic complex with proprioceptive challenges.
Strongly Disagree
Disagree
Neutral
Agree
Strongly Agree
C
c
C

C

$c$

8. Lower extremity plyometric exercises should be included during Phase IV.
Strongly Disagree
Disagree
Neutral
Agree
c
Strongly Agree
C
r
C

9. Rehabilitation exercises included in Phase IV should be focused on maintaining correct hamstring complex function.
Strongly Disagree
Disagree
Neutral
Agree
Strongly Agree
C
○

10. Lengthened-state Eccentric exercises should only be completed if weight lifting is not including exercises in team program.
Strongly Disagree
Disagree
Neutral
Agree
Strongly Agree

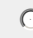
c
$C$

11. During Phase IV, athlete should complete hamstring complex rehabilitation 2-3 days per week, in unison with weight lifting schedule.
Strongly Disagree
Disagree
Neutral
Agree
Strongly Agree
C
c
6

12. All functional activity should be completed with team agilities and conditioning. 


\section{Hamstring Complex Rehabilitation Survey}

CORE STRENGTHENING FOR PHASE IV

13. Core exercises are completed during team weight lifting and are not a focus during Phase IV.

Strongly Disagree

C
Disagree

C
Neutral

C
Agree
Strongly Agree

STRENGTH \& CONDITIONING FOR PHASE IV

This aspect and corresponding questions is geared towards how the STRENGTH SPECIALIST will conduct the rehabilitation program during Phase IV.

14. Sprinting technique exercises should be completed during Phase IV.

Strongly Disagree
Disagree

(
Neutral
Agree

C
Strongly Agree

15. Power lifting exercises with progression to weight prior to injury should be included in Phase IV.

Strongly Disagree Disagree

Neutral

Agree

Strongly Agree

C

C

C

16. Lifting and conditioning exercises should be completed without limitation of athlete during Phase IV.

Strongly Disagree Disagree

Neutral Agree
C

\section{C}

17. During Phase IV, athlete should be fully participating in all aspects of the sport of football including skill, agility and contact requirements. 


\section{Hamstring Complex Rehabilitation Survey}

18. The following clinical tests or evaluations should be included to determine progression to Phase $V$ and no concern or fear of re-injury:

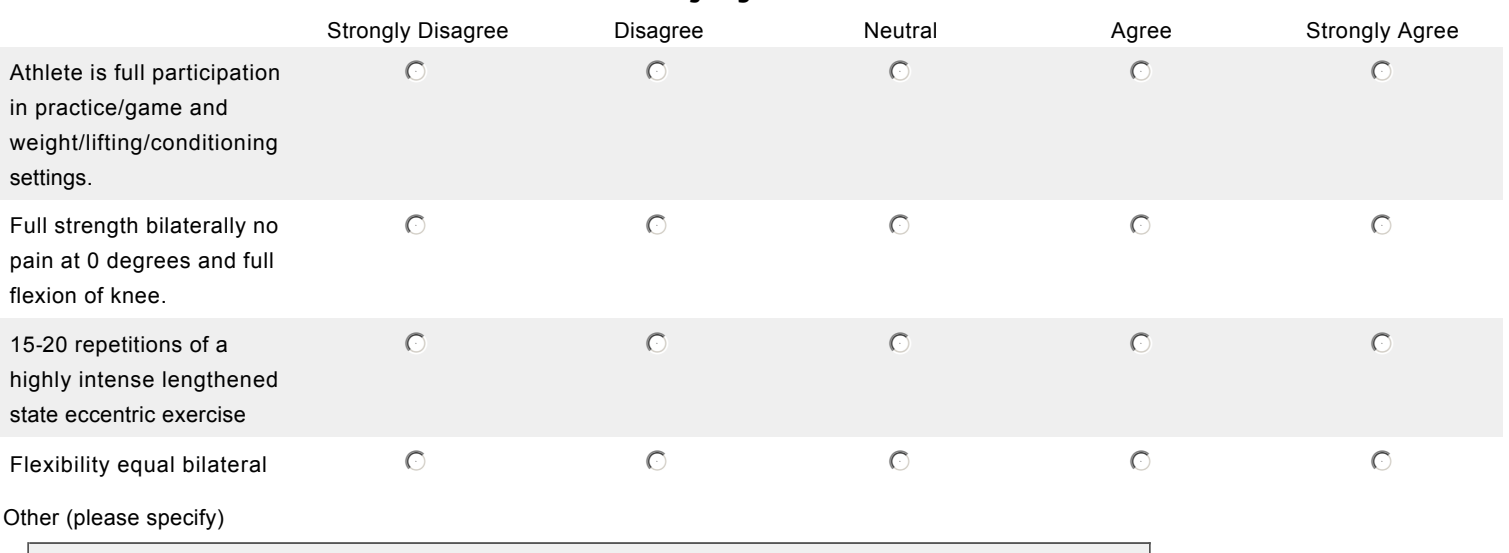

19. Additional Comments for Phase IV of the rehabilitation program:

Phase V: Reintroduction of Physical and Positional Demands

Maintenance Phase of a Grade I or II hamstring complex strain. The fifth phase includes continued rehabilitation of healed injured and full participation of athlete. At this point of the recovery process:

$5 \%$ involvement with ATC

95\% involvement with Strength Specialist

DIRECTIONS: Indication your selection of each aspect that best corresponds to the answer of the question unless otherwise specified. If answer is not provided, please add additional information.

BASELINE FOR PHASE V 


\section{Hamstring Complex Rehabilitation Survey}

1. Prior to beginning Phase $V$, athlete should be able to complete:

\begin{tabular}{|c|c|c|c|c|c|}
\hline & Strongly Disagree & Disagree & Neutral & Agree & Strongly Agree \\
\hline $\begin{array}{l}\text { All physical activity without } \\
\text { pain/hesitation }\end{array}$ & 0 & O & 0 & $\mathrm{O}$ & C \\
\hline $\begin{array}{l}\text { Perform position } \\
\text { skills/abilities without } \\
\text { pain/hesitation }\end{array}$ & $\mathrm{O}$ & $\mathrm{O}$ & $\mathrm{O}$ & o & O \\
\hline $\begin{array}{l}\text { Have full sprint speed } \\
\text { without pain/hesitation }\end{array}$ & 0 & 0 & $\mathrm{O}$ & $\mathrm{O}$ & O \\
\hline Other (please specify) & & & & & \\
\hline
\end{tabular}

CONTRAINDICATIONS FOR PHASE V

2. There are no contraindications for Phase $\mathbf{V}$ of the rehabilitation program.

Strongly Disagree

○
Disagree
Neutral

○
Agree
Strongly Agree

FLEXIBILITY FOCUS FOR PHASE V

3. Static flexibility exercises should be completed by athlete three times per week.

Strongly Disagree

O
Disagree

C
Neutral

(
Agree
Strongly Agree

\section{RANGE OF MOTION/STRENGTH FOR PHASE V}

This aspect and corresponding questions is geared towards how the ATHLETIC TRAINER will conduct the rehabilitation program during Phase $\mathrm{V}$.

4. Athlete should complete endurance exercises for the hamstring complex during Phase V three times per week.

Strongly Disagree

(
Disagree

C
Neutral

○
Agree
Strongly Agree

\section{No modified exercises required for athlete to perform during Phase $\mathbf{V}$.}

Strongly Disagree

C
Disagree

○
Neutral

C
Agree
Strongly Agree

STRENGTH \& CONDITIONING FOR PHASE V

This aspect and corresponding questions is geared towards how the STRENGTH SPECIALIST will conduct the rehabilitation program during Phase $\mathrm{V}$. 


\section{Hamstring Complex Rehabilitation Survey}

6. The athlete is fully returned and will continue team weight lifting/conditioning program as seen by the Strength Specialist.

Strongly Disagree

C
Disagree

○
Neutral

c
Agree

C
Strongly Agree

C

7. Athlete should be performing all strength and speed requirements at pre-injury level.

Strongly Disagree

O
Disagree

0
Neutral
Agree
Strongly Agree

\section{CONTINUED MAINTENANCE}

8. Athlete must be instructed to continue maintenance program to decrease risk of reinjury to the hamstring complex.

Strongly Disagree

Disagree

Neutral

C

(

C

Agree

Strongly Agree

O

\section{Additional Comments for Phase V of the rehabilitation program:}

\section{Thank you for completing the Questionnaire.}

If you are satisfied with your responses please submit questionnaire. Once data is collected, you will be notified for your reviewal of the panel responses and completion of the second round.

Once again, thank you. 
May 12, 2013

Dear Participant,

Just sending a quick reminder in reference to your participation and the completion of the first round questionnaire for the design of a complete hamstring complex rehabilitation program may be completed by May 15, 2013.

This is an outstanding opportunity for you to take part in the development of a hamstring complex rehabilitation program for Division I Football athletes. I will be conducting this research study with Michelle A. Sandrey PhD, ATC, as the faculty supervisor, to fulfill requirements for a Master's thesis and to complete an MS degree in Athletic Training.

For those of you who have already submitted your responses or are in the process, I apologize for this interruption and thank you for your participation. The questionnaire should only take about 30 minutes to complete. For those of you, who no longer have the original information, please go to the following website to take the survey:

http://www.surveymonkey.com/s.aspx

This is a completely voluntary activity and all responses are guaranteed to be anonymous and confidential, as a number system will be instituted so anonymity is secured. You have the option to skip questions, with the right to withdraw any data you submit at any time. Your job status will not be affected by failure to participate. West Virginia University IRB has approved the study and the approval is on file. Once again please respond to the online questionnaire by May 15, 2013.

If you have any questions or concerns please contact Caitlin McFadden at (215) 4982369 or by e-mail: cmcfadd2@mix.wvu.edu. You may also contact Dr. Michelle Sandrey, faculty supervisor and Graduate Athletic Training Program Director at West Virginia University, at (304) 293-0870 or at msandrey@mail.wvu.edu.

Thank you for your participation in this study and I greatly appreciate your time and commitment.

Sincerely,

Caitlin McFadden, ATC, CSCS 
If you would not like to participate in this study please click the following link. http://www.surveymonkey.com/optout.aspx 
May 24, 2013

Dear Participant,

Thank you for your participation in the study and providing your expertise for the development a complete hamstring complex rehabilitation program.

Your first round responses were very informative and beneficial in completing this research. The second round questionnaire will be the final step for the completion of the program for Division I Football athletes. This is your opportunity to view the results, as well as rate and comment on the new components from the first round questionnaire. Your final responses are very important and will directly assist athletic trainers and strength specialist when challenged with rehabilitating a hamstring complex injury. I will be conducting this study under the faculty supervision of Michelle A. Sandrey PhD, ATC to fulfill requirements for a Master's thesis and to complete a Master's of Science degree in Athletic Training from West Virginia University.

This final round should only take about 30 minutes to complete. Please go to the following website to take the survey:

http://www.surveymonkey.com/s.aspx

This is a completely voluntary activity and all responses are guaranteed to be anonymous and confidential, a number system will be implemented so anonymity is secured. You have the option to skip questions and you have the right to withdraw any data you submit at any time. Your job status will not be affected by failure to participate. West Virginia University IRB has approved the study and the approval is on file. Please respond to the online questionnaire as soon as possible, with the deadline on June 7, 2013.

I greatly appreciate your time and participation throughout this study. If you have any questions or concerns please contact Caitlin McFadden at (215) 498-2369 or by e-mail: cmcfadd2@mix.wvu.edu. You may also contact Dr. Michelle Sandrey, faculty supervisor and Graduate Athletic Training Program Director at West Virginia University, at (304) 293-0870 or msandrey@mail.wvu.edu.

Sincerely,

Caitlin McFadden, ATC 


\section{Table C6. Second Round Questionnaire}

\section{Ham Rehab Survey}

\section{Round 2. Design and Finalization of a Complete Hamstring Rehabilitation Pro...}

Included in this questionnaire are concepts to be considered in the development of a rehabilitation program for NCAA Division I Football athletes with the statistical (means and percentages of participants) results from the First Round. The concepts presented are those asked during the First Round followed by a series of numbers. The numbers represent the frequency and number of responses from the First Round.

For Example:

Pain with knee flexion: $0.0 \%(0), 0.0 \%(0), 0.0 \%(0), 50 \%(2), 50 \%(2)$. The number order represent the statistics, respectively: Strongly Disagree, Disagree, Neutral, Agree, Strongly Agree, followed by the rating average and response count. Please take these numbers into consideration as you rate each concept again.

The additional comments from the First Round are also provided following the concepts in each Phase. Please rate these responses as well as providing any additional feedback in the comment box.

\section{Phase It Initial Assessment}

Acute Phase of a Grade I or II hamstring complex strain. The first phase includes observation and evaluation of the injury and functional ability of the athlete. At this point of the recovery process:

95\% involvement with ATC

$5 \%$ involvement with Strength Specialist

DIRECTIONS: Indicate your selection of each aspect that best corresponds to the answer of the question unless otherwise specified. If answer is not provided, please add additional information.

*REMINDER: The numbers represent the frequency and number of responses from First Round. 


\section{Ham Rehab Survey}

\section{Typical presentation of an acute Grade I \& II hamstring complex strains:}

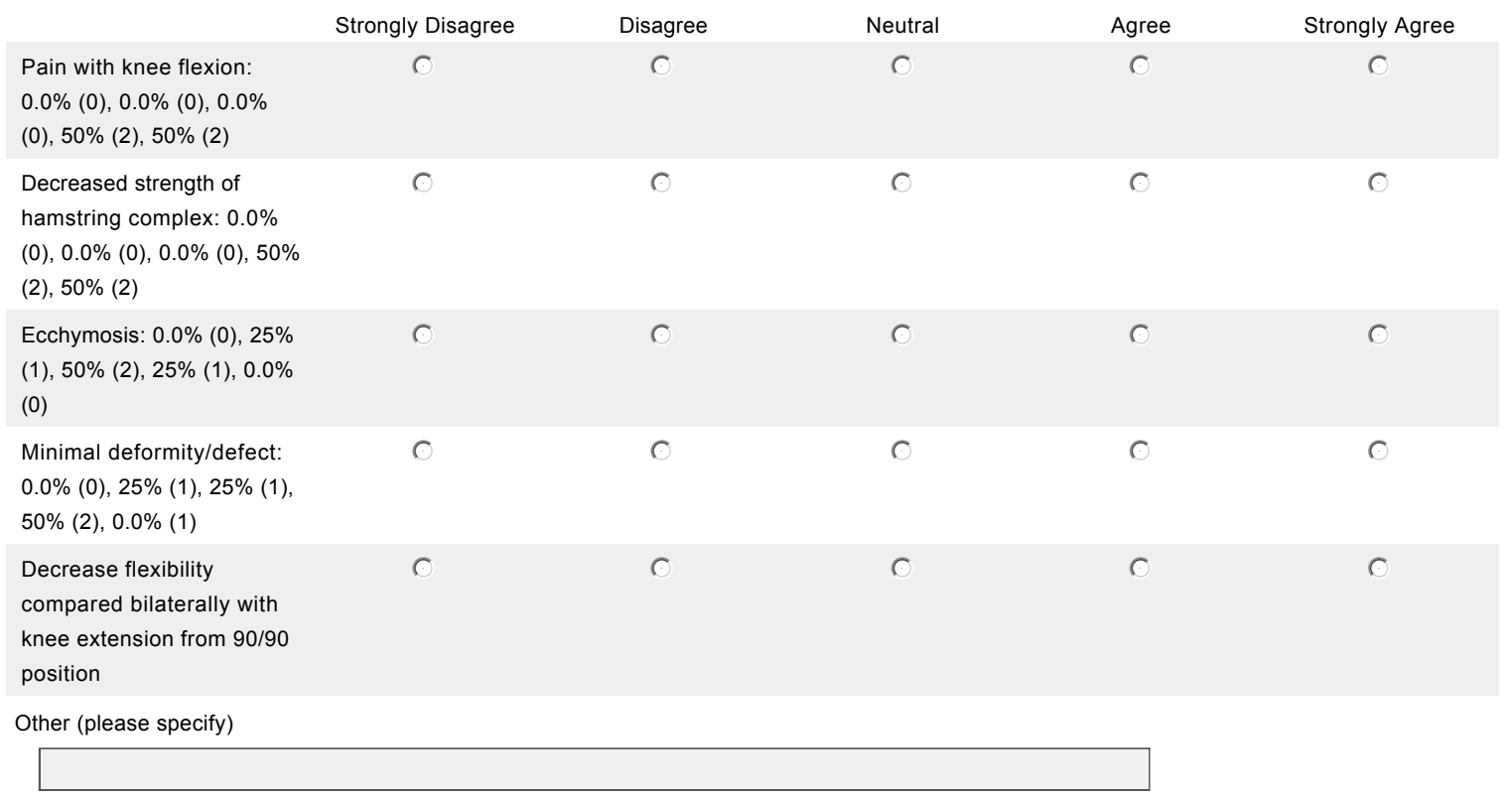

\section{Typical mechanism of injury for grade I \& II hamstring complex strains:}

\begin{tabular}{|c|c|c|c|c|c|}
\hline & Strongly Disagree & Disagree & Neutral & Agree & Strongly Agree \\
\hline $\begin{array}{l}\text { Eccentric contraction: } 0.0 \% \\
(0), 0.0 \%(0), 0.0 \%(0), 50 \% \\
(2), 50 \%(2)\end{array}$ & 0 & 0 & 0 & O & O \\
\hline $\begin{array}{l}\text { Concentric contraction: } \\
0.0 \%(0), 50 \%(2), 50 \%(2) \text {, } \\
0.0 \%(0), 0.0 \%(0)\end{array}$ & 0 & 0 & 0 & 0 & 0 \\
\hline $\begin{array}{l}\text { Over-reaching during a } \\
\text { sprint: } 0.0 \%(0), 0.0 \%(0) \text {, } \\
25 \%(1), 50 \%(2), 25 \%(1)\end{array}$ & 0 & 0 & 0 & 0 & 0 \\
\hline $\begin{array}{l}\text { Fatigue: } 0.0 \%(0), 0.0 \%(0) \text {, } \\
50 \%(2), 50 \%(2), 0.0 \%(0)\end{array}$ & 0 & 0 & 0 & 0 & 0 \\
\hline $\begin{array}{l}\text { Dehydration: } 25 \%(1), 0.0 \% \\
(0), 0.0 \%(0), 75 \%(3), 0.0 \% \\
(0)\end{array}$ & 0 & $\mathrm{O}$ & 0 & 0 & 0 \\
\hline $\begin{array}{l}\text { Somatic dysfunction of } \\
\text { Pelvis }\end{array}$ & 0 & 0 & 0 & 0 & 0 \\
\hline Other (please specify) & & & & & \\
\hline
\end{tabular}




\section{Ham Rehab Survey}

3. The rehabilitation exercises utilized in this phase will be dictated by:

$\begin{array}{lccccc} & \text { Strongly Disagree } & \text { Disagree } & \text { Neutral } & \text { Agree } & \text { Strongly Agree } \\ \text { Prior history of hamstring } & 0 & 0 & 0 & 0 & \\ \text { complex strains: } 0.0 \%(0), & & & & \\ 0.0 \%(0), 50 \%(2), 50 \%(2), & & & 0 & 0 & 0 \\ 0.0 \%(0) & 0 & 0 & 0\end{array}$

Mechanism of Injury via stretching: $0.0 \%(0), 0.0 \%$

(0), $50 \%(2), 50 \%(2), 0.0 \%$

(0)

Mechanism of Injury via sprinting: $0.0 \%(0), 25 \%(1)$

$50 \%(2), 25 \%(1), 0.0 \%(0)$

Ability to complete physical activity immediately post

injury occurrence: $0.0 \%(0)$ $0.0 \%(0), 25 \%(1), 50 \%(2)$,

$25 \%(1)$

Area of Injury

(Proximal/Middle/Distal)

Hamstring muscle Involved

Degree of Injury

C

C

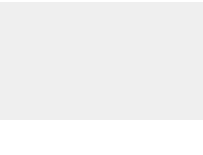

○

O

C

Other (please specify) 


\section{Ham Rehab Survey}

4. Contraindications for this phase are:

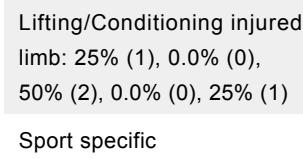

O

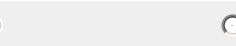

C

○

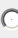

C
C

Neutral

C
Agree

O

O
O

C

O

0

○

FLEXIBILITY FOCUS FOR PHASE I

5. Flexibility of the hamstring complex should be addressed during Phase I: $\mathbf{0 . 0} \%(0), 50 \%$ (2), $25 \%(1), 25 \%(1), 0.0 \%(0)$

Strongly Disagree Disagree

0

Neutral

c
Agree

C
Strongly Agree

O

\section{Flexibility exercises for this phase should include:}

Strongly Disagree

Static stretching exercises:

$25 \%$ (1), $0.0 \%$ (0), $50 \%$ (2),

$25 \%(1), 0.0 \%(0)$

Dynamic stretching exercises: $25 \%$ (1), $25 \%$ (1) $25 \%$ (1), $25 \%$ (1), $0.0 \%$ (0) Nothing to elicit pain for Phase I (first three days) No stretch of muscle within first 48 hours

Other (please specify)

O
Disagree

O

Neutral

0

0

O

c

o

Strongly Agree

C

$\begin{array}{lll}0 & 0 & 6 \\ 0 & 0 & 0\end{array}$

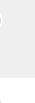




\section{Ham Rehab Survey}

7. What should be used to increase total body flexibility:

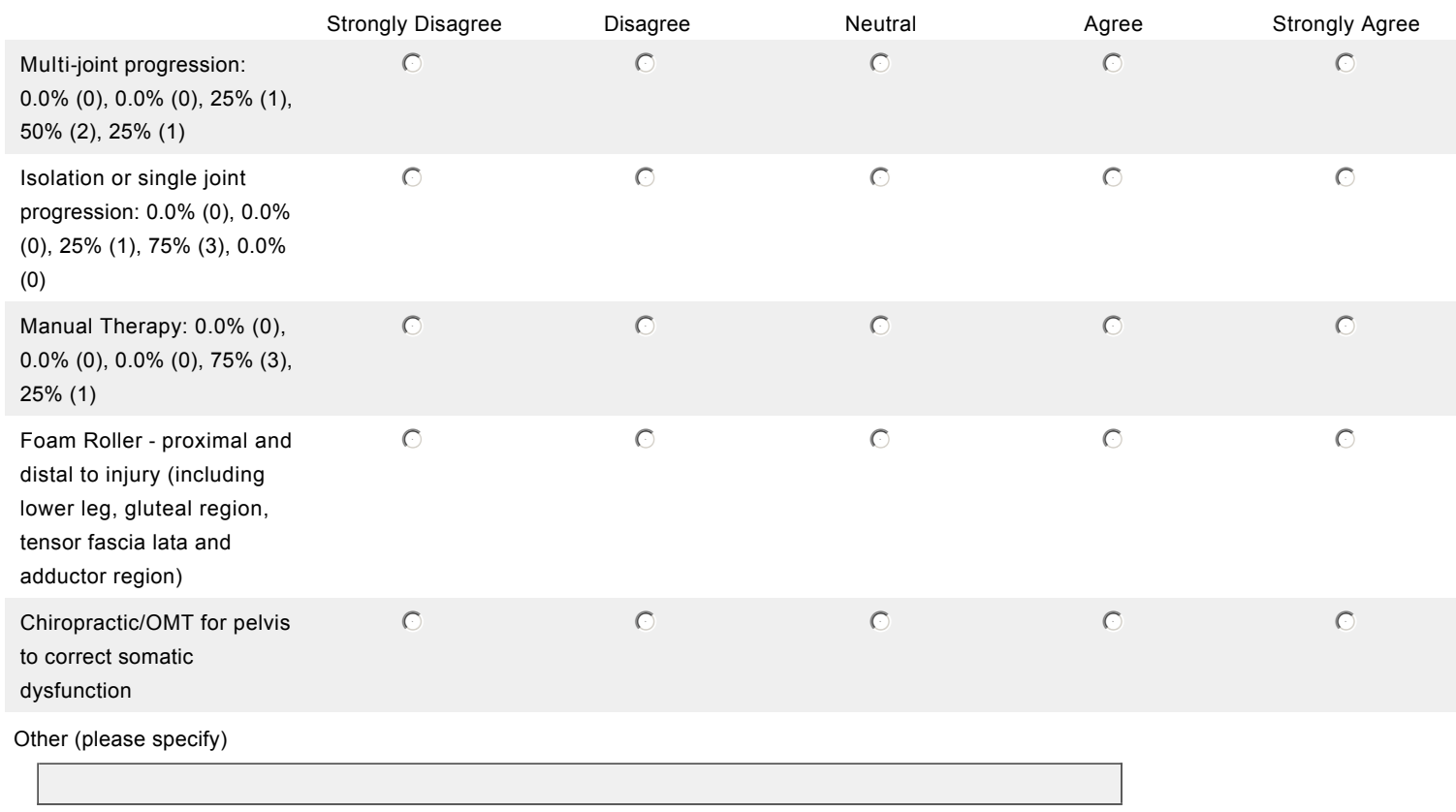

\section{A sufficient static stretching protocol should include:}

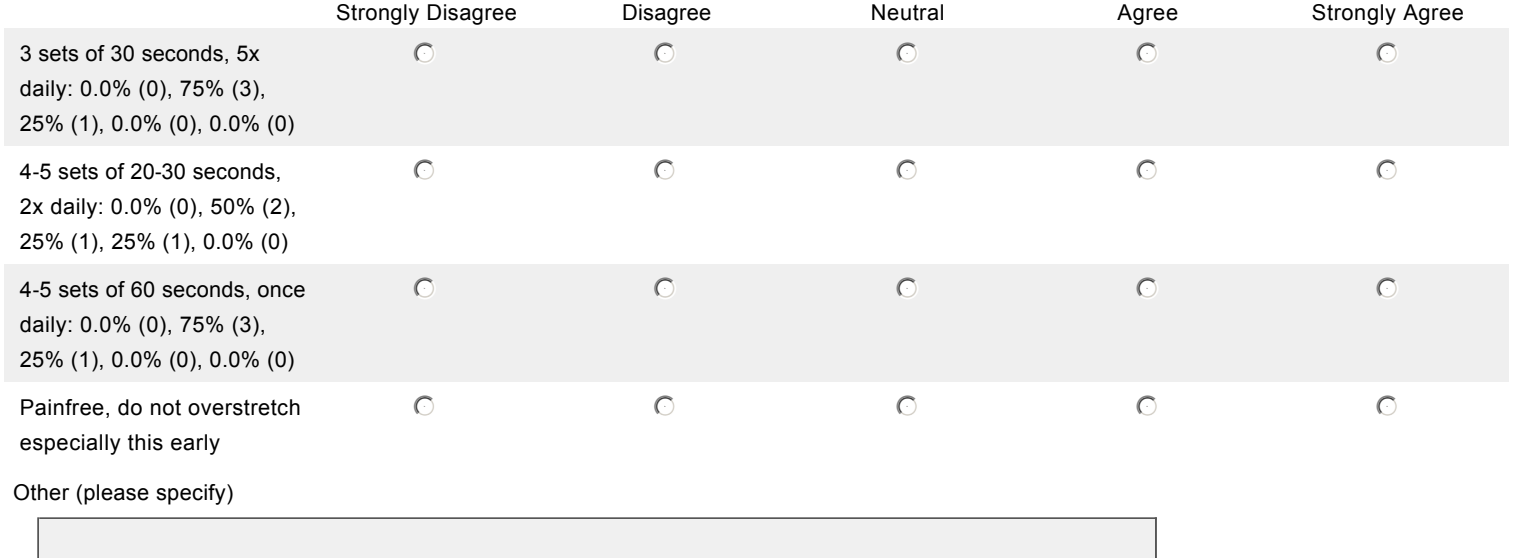

9. Flexibility exercises should focus on the entire lumbo-pelvic complex: $0.0 \%(0), 0.0 \%(0)$, $25 \%$ (1), 25\% (1), $50 \%$ (2)

Strongly Disagree

0
Disagree

c
Neutral
Agree

Strongly Agree

\section{RANGE OF MOTION/STRENGTH FOR PHASE I}

This aspect and corresponding questions is geared towards how the ATHLETIC TRAINER will conduct the rehabilitation program during Phase I. 


\section{Ham Rehab Survey}

10. Range of motion exercises should be completed during Phase I: $0.0 \%(0), 0.0 \%(0)$, $0.0 \%(0), 75 \%(3), 25 \%(1)$

Strongly Disagree

C
Disagree

O
Neutral

○
Agree

C
Strongly Agree

O

11. Range of motion exercises for the hamstring should only be completed in a painfree range of motion: $\mathbf{0 . 0 \% ( 0 ) , 0 . 0 \% ( 0 ) , 0 . 0 \% ( 0 ) , 5 0 \% ( 2 ) , 5 0 \% ( 2 ) ~}$

Strongly Disagree

○
Disagree

(O
Neutral

C
Agree
Strongly Agree

12. Range of motion exercises should also include the gluteal group: $0.0 \%(0), 0.0 \%(0)$, $25 \%(1), 0.0 \%(0), 75 \%(3)$

Strongly Disagree

Disagree

Neutral

Agree

Strongly Agree

C

O

13. Functional activity should be carried out in a pool during Phase $I$ of the rehabilitation program: $0.0 \%(0), 25 \%(1), 25 \%(1), 25 \%(1), 25 \%(1)$

Strongly Disagree

Disagree

Neutral

Agree

Strongly Agree

C

C

6

C

14. Strengthening exercises for the hamstring complex should be focused on increasing:

Strongly Disagree

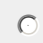

Isometric Strength: $0.0 \%$

(0), $0.0 \%(0), 0.0 \%(0), 50 \%$

(2), $50 \%(2)$

Endurance: $0.0 \%(0), 25 \%$

(1), $25 \%$ (1), $0.0 \%$ (0), $50 \%$

(2)

Concentric Strength: $0.0 \%$

(0), $25 \%$ (1), $25 \%$ (1), $25 \%$

(1), $25 \%$ (1)

Eccentric Strength: $25 \%$ (1)

$25 \%$ (1), $0.0 \%(0), 0.0 \%(0)$,

$50 \%(2)$

Power: 25\% (1), 25\% (1),

$0.0 \%(0), 0.0 \%(0), 50 \%(2)$

Other (please specify)
Disagree

C

Neutra

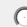

O

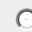

C
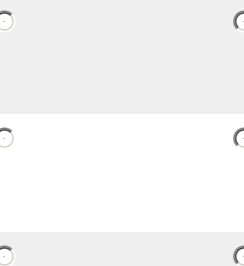

Agree

C

O

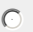

O

0

CORE STRENGTHENING FOR PHASE I

15. Core stabilization should be a focus during hamstring complex rehabilitation: $0.0 \%(0)$, $0.0 \%(0), 0.0 \%(0), 25 \%(1), 75 \%(3)$

Strongly Disagree

O
Disagree

O
Neutral

o
Agree

○
Strongly Agree 


\section{Ham Rehab Survey}

16. Core stability exercises should be more stabilization focused during Phase l: $\mathbf{0 . 0 \%}(0)$, $0.0 \%(0), 0.0 \%(0), 25 \%(1), 75 \%(3)$

Strongly Disagree

O
Disagree
Neutral

C
Agree

6
Strongly Agree

\section{STRENGTH \& CONDITIONING FOR PHASE I \\ This aspect and corresponding questions is geared towards how the STRENGTH SPECIALIST will conduct the rehabilitation program during Phase I.}

17. Lifting and conditioning exercises should only be completed without involvement of injured limb: $0.0 \%$ (0), $50 \%$ (2), 25\% (1), 25\% (1), $0.0 \%$ (0)

Strongly Disagree

Disagree

Neutral

C

Agree

Strongly Agree

18. Lifting and conditioning progression should be normal for the rest of the body: $0.0 \%$ (0), $0.0 \%(0), 0.0 \%(0), 25 \%(1), 75 \%(3)$

Strongly Disagree

Disagree

C

Neutral

c

Agree

Strongly Agree

19. Aerobic conditioning should be completed by:

Strongly Disagree

Disagree

Stationary bike without

Neutral

Agree

injured limb involvement:

$25 \%$ (1), $25 \%$ (1), $25 \%(1)$

$25 \%$ (1), $0.0 \%(0)$

Upper Body Ergometer sprints: $0.0 \%(0), 0.0 \%(0)$

$25 \%$ (1), $25 \%$ (1), $50 \%$ (2)

Hydrotherapy running: $0.0 \%$

(0), $25 \%$ (1), $0.0 \%$ (0), $50 \%$

(2), $25 \%$ (1)

Circuit training without

injured limb involvement:

$25 \%(1), 0.0 \%(0), 25 \%$ (1)

$50 \%(2), 0.0 \%(0)$

Stationary bike with both

limbs - Only if painfree

Other (please specify) 


\section{Ham Rehab Survey}

\section{Prior to moving to Phase II of rehabilitation, athlete should:}

Perform activities of daily Strongly Disagree

living painfree: $0.0 \%(0)$,

$0.0 \%(0), 0.0 \%(0), 50 \%(2)$,

$50 \%(2)$

Walking painfree: $0.0 \%(0)$, $0.0 \%(0), 0.0 \%(0), 25 \%(1)$, $75 \%$ (3)

\section{Be able to complete}

lifting/workout of rest of the body with team: $0.0 \%(0)$, $25 \%$ (1), $25 \%$ (1), $25 \%$ (1), $25 \%$ (1)

Have full painfree range of motion: $0.0 \%(0), 0.0 \%(0)$, $0.0 \%(0), 75 \%$ (3), $25 \%$ (1)

Have no point tender palpation: $0.0 \%(0), 0.0 \%$ (1), $25 \%$ (1), $75 \%$ (3), $0.0 \%$ (0)

Have no spasm or mass felt during palpation: $0.0 \%(0)$, $0.0 \%(0), 50 \%(2), 25 \%(1)$ $25 \%$ (1)

Have no discoloration: $0.0 \%(0), 25 \%$ (1), $50 \%$ (2), $25 \%(1), 0.0 \%(0)$

Have no deformity noted: $0.0 \%(0), 25 \%(1), 25 \%(1)$ $50 \%(2), 0.0 \%(0)$

Have pain only during hamstring stretch: $0.0 \%(0)$ $25 \%$ (1), $50 \%$ (2), $25 \%$ (1), $0.0 \%(0)$

$66 \%$ difference Hamstringto-Quadriceps ratio: $0.0 \%$

(0), $75 \%$ (3), $25 \%$ (1), $0.0 \%$ (0), $0.0 \%(0)$

$50 \%$ difference Hamstringto-Quadriceps ratio: $0.0 \%$

(0), $75 \%$ (3), $25 \%$ (1), $0.0 \%$ (0), $0.0 \%(0)$

$35 \%$ difference Hamstringto-Quadriceps ratio: $0.0 \%$

(0), $50 \%$ (2), $50 \%$ (2), $0.0 \%$ (0), $0.0 \%(0)$

$25 \%$ difference Hamstringto-Quadriceps ratio: $0.0 \%$

(0), $50 \%$ (2), $50 \%$ (2), $0.0 \%$

(0), $0.0 \%(0)$

Disagree

O

c

Neutral

O

Agree

O

Strongly Agree

O

C

c

C

c

0

C

0

C

(

○

0

C

6

6

c

0

C

C

C

0

$35 \%$ difference eccentric 


\section{Ham Rehab Survey}

Hamstring-to-concentric

Quadriceps functional ratio:

$0.0 \%(0), 50 \%(2), 25 \%(1)$,

$25 \%(1), 0.0 \%(0)$

When athlete feels ready:

$0.0 \%(0), 25 \%(1), 75 \%(3)$,

$0.0 \%(0), 0.0 \%(0)$

Other (please specify)

21. The following clinical tests or evaluations should be included to determine progression to next phase of the rehabilitation program:

Strongly Disagree

Prone curl painfree: : $0.0 \%$

(0), $25 \%$ (1), $0.0 \%$ (0), $25 \%$

O

(1), $50 \%$ (2)

Active straight leg raise to

max range of motion

painfree: : $0.0 \%(0), 0.0 \%$

(0), $25 \%$ (1), $50 \%$ (2), $25 \%$

(1)

\section{Active ballistic hamstring}

test results with low

insecurity and painfree

motion half of contralateral

limb range of motion: :

$0.0 \%$ (0), $50 \%$ (2), $25 \%$ (1),

$25 \%(1), 0.0 \%(0)$

Other (please specify)

c

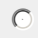

Disagree

C

Neutral

C

Agree

C

Strongly Agree

C

$$
\text { C }
$$$$
\text { O }
$$

C

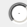

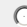

22. Additional comment for Phase I of the rehabilitation program from first round questionnaire:

No pain should occur from rehabilitation technique/exercises during Phase $I$.

Strongly Disagree

O
Disagree

o
Neutral

c
Agree

C
Strongly Agree

O

\section{Additional Comments for Phase I of the rehabilitation program:}

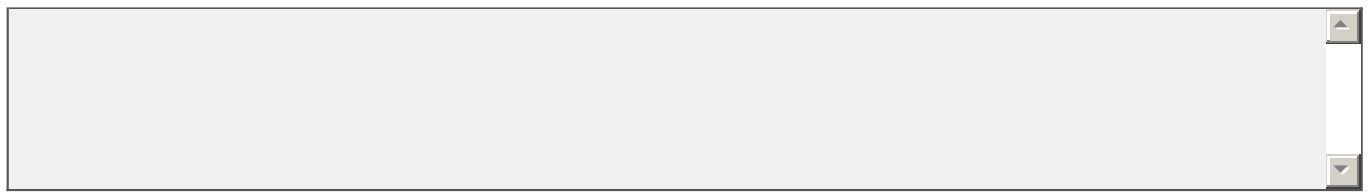

\section{Phase Il: Implementation of Functional Activity}

Sub-acute Phase of a Grade I or II hamstring complex strain. The second phase includes progression of the recovery process and functional activity incorporation. At this point of the recovery process:

$85 \%$ involvement with ATC 


\section{Ham Rehab Survey}

$15 \%$ involvement with Strength Specialist

DIRECTIONS: Indicate your selection of each aspect that best corresponds to the answer of the question unless otherwise specified. If answer is not provided, please add additional information.

${ }^{*}$ REMINDER: The numbers represent the frequency and number of responses from First Round.

BASELINE FOR PHASE II

\section{Prior to beginning Phase II, athlete should be able to complete:}

\begin{tabular}{|c|c|c|c|c|c|}
\hline & Strongly Disagree & Disagree & Neutral & Agree & Strongly Agree \\
\hline $\begin{array}{l}\text { Perform activities of daily } \\
\text { living pain free: } 0.0 \%(0) \text {, } \\
0.0 \%(0), 0.0 \%(0), 0.0 \% \\
(0), 100 \%(4)\end{array}$ & 0 & 0 & 0 & 0 & 0 \\
\hline $\begin{array}{l}\text { Walk painfree: } 0.0 \%(0) \text {, } \\
0.0 \%(0), 0.0 \%(0), 0.0 \% \\
(0), 100 \%(4)\end{array}$ & 0 & 0 & 0 & 0 & 0 \\
\hline $\begin{array}{l}\text { Have full strength: } 0.0 \%(0) \text {, } \\
25 \%(1), 25 \%(1), 50 \%(2) \\
0.0 \%(0)\end{array}$ & 0 & 0 & 0 & 0 & 0 \\
\hline $\begin{array}{l}\text { Start functional activity with } \\
\text { minimal pain: } 0.0 \%(0) \text {, } \\
0.0 \%(0), 0.0 \%(0), 75 \%(3) \text {, } \\
25 \%(1)\end{array}$ & 0 & 0 & 0 & 0 & 0 \\
\hline Other (please specify) & & & & & \\
\hline
\end{tabular}




\section{Ham Rehab Survey}

\section{Contraindications for Phase II are:}

Strongly Disagree

Heavy weight lifting of

injured limb: $0.0 \%(0), 50 \%$

(2), $0.0 \%(0), 50 \%(2), 25 \%$

(1)

Conditioning with team:

$0.0 \%(0), 25 \%(1), 75 \%(3)$

$0.0 \%(0), 0.0 \%(0)$

Sport specific activity/skill:

$0.0 \%(0), 25 \%$ (1), $50 \%$ (2)

$0.0 \%(0), 25 \%(1)$

Position specific

activity/skill: $0.0 \%(0), 50 \%$

(2), $0.0 \%(0), 0.0 \%(0), 50 \%$

(2)

Eccentric strength exercises: $25 \%$ (1), $25 \%$ (1), $25 \%$ (1),

$0.0 \%(0), 25 \%$ (1)

Speed exercises: $25 \%$ (1)

$25 \%$ (1), 25\% (1), 0.0\% (0),

$25 \%(1)$

Power exercises: $0.0 \%(0)$,

$50 \%(2), 0.0 \%(0), 25 \%(1)$

$25 \%$ (1)

Allow athlete to return to

practice but required to stay

away from full contact and

full speed drills: $0.0 \%(0)$,

$25 \%$ (1), $50 \%$ (2), $25 \%$ (1),

$0.0 \%(0)$

Other (please specify)
Disagre

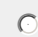

0

\begin{abstract}
0
\end{abstract}
O

c

O

C
O

c

6

Neutral

O

O

C

0

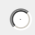

O

C

0
Agree

C

Strongly Agree

O

\section{FLEXIBILITY FOCUS FOR PHASE II}

3. Flexibility of the hamstring complex should be addressed during Phase II: $\mathbf{0 . 0 \%}(0)$, $0.0 \%(0), 0.0 \%(0), 75 \%(3), 25 \%(1)$

Strongly Disagree

C
Disagree

O
Neutral

O
Agree

C
Strongly Agree

$\mathrm{C}$ 


\section{Ham Rehab Survey}

4. Flexibility exercises for Phase II should include:

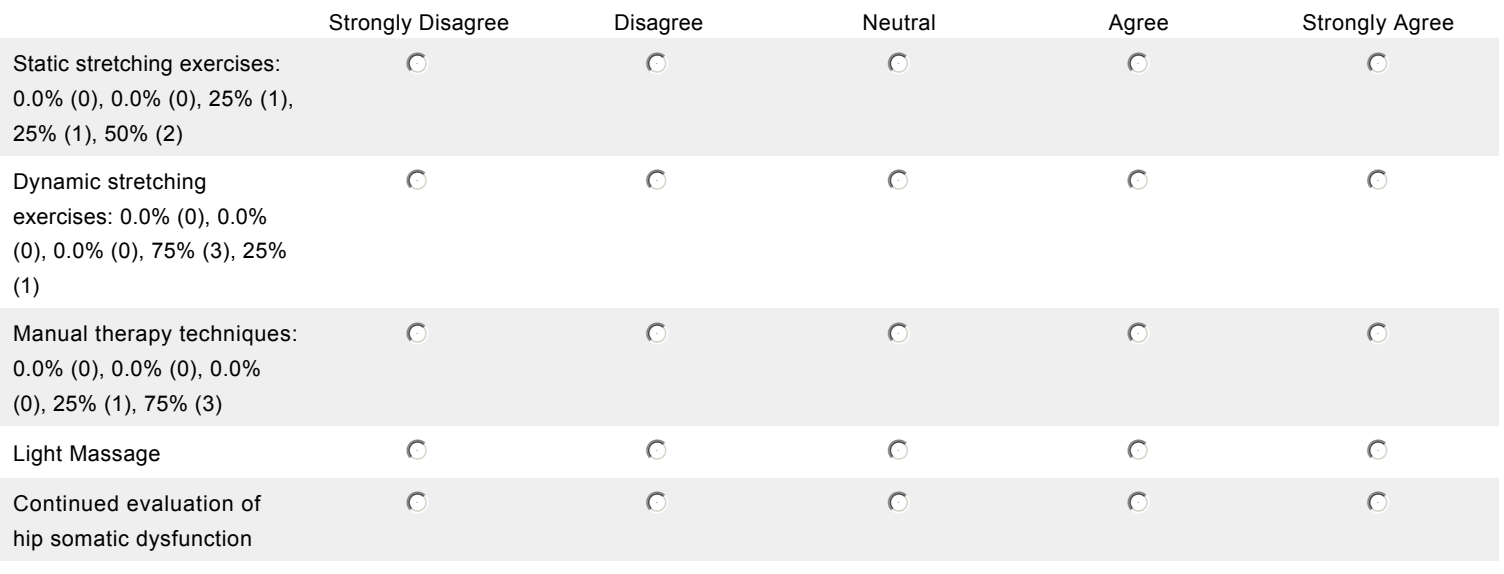

Other (please specify)

5. Flexibility exercises should be completed in a more aggressive form compared to Phase I of the rehabilitation program: $0.0 \%(0), 0.0 \%(0), 25 \%(1), 50 \%(2), 25 \%(1)$

Strongly Disagree

Disagree

Neutral

Agree

Strongly Agree

C

O

○

C

6. Static stretches included in Phase II should utilize the PNF technique: $0.0 \%(0), 0.0 \%(0)$, $25 \%$ (1), $50 \%$ (2), $25 \%$ (1)

Strongly Disagree

Disagree

Neutral

Agree

Strongly Agree

C

O

c

C

RANGE OF MOTION/STRENGTH FOR PHASE II

This aspect and corresponding questions is geared towards how the ATHLETIC TRAINER will conduct the rehabilitation program during Phase II.

7. Range of motion exercises should be continued during Phase II: $0.0 \%(0), 0.0 \%(0), 0.0 \%$ (0), $25 \%$ (1), $75 \%$ (3)

Strongly Disagree

Disagree

Neutral

C

Agree

Strongly Agree

C 


\section{Ham Rehab Survey}

8. Strengthening exercises for the hamstring complex during Phase II should be focused on increasing:

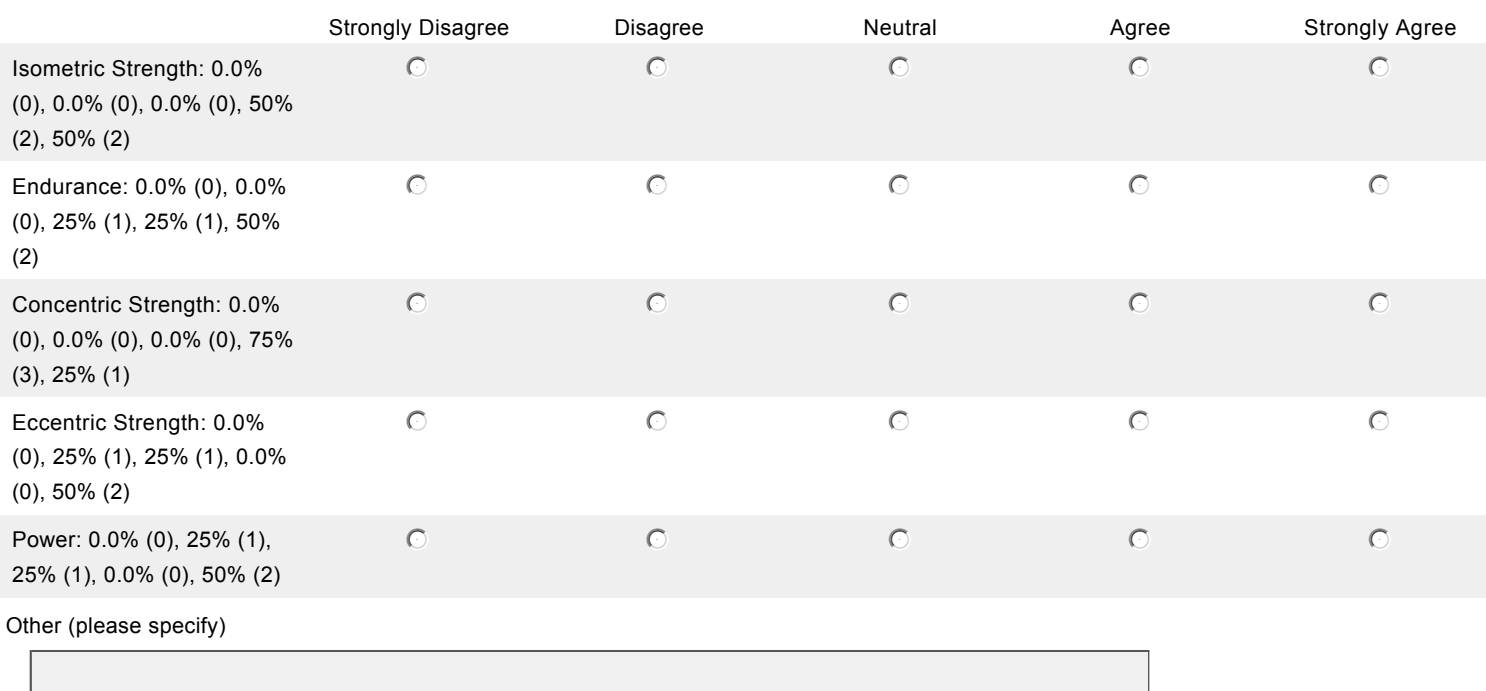

9. Strengthening exercises included in Phase II should include exercises to increase strength of the low back: $0.0 \%(0), 0.0 \%(0), 0.0 \%(0), 75 \%(3), 25 \%(1)$

Strongly Disagree Disagree Neutral

Agree Strongly Agree C r

C C

10. Strengthening exercises included in Phase II should include exercises to increase strength of the lumbo-pelvic complex: : $0.0 \%(0), 0.0 \%(0), 0.0 \%(0), 25 \%(1), 75 \%(3)$

Strongly Disagree O
Disagree

C
Neutral

(
Agree
Strongly Agre

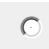

11. Eccentric exercises should be started during Phase Il: $0.0 \%(0), 25 \%(1), 0.0 \%(0), 50 \%$ (2), $25 \%$ (1)

Strongly Disagree

C
Disagree

O
Neutral

○
Agree

C
Strongly Agree 


\section{Ham Rehab Survey}

12. Functional activity should be started:

Strongly Disagree

Disagree

Within the first phase of

rehabilitation program:

$0.0 \%$ (0), $25 \%$ (1), $25 \%$ (1),

$25 \%(1), 25 \%(1)$

Once painfree: $0.0 \%(0)$,

$0.0 \%$ (0), $25 \%(1), 50 \%$ (2),

$25 \%$ (1)

Once point tender

palpation is resolved: $0.0 \%$

(0), $0.0 \%$ (0), $75 \%$ (3), $25 \%$

(1), $0.0 \%(0)$

Once equal bilateral

strength is achieved: $0.0 \%$

(0), $25 \%$ (1), $50 \%$ (2), $25 \%$

(1), $0.0 \%(0)$

Other (please specify)

13. Functional activity should continue to be carried out in a pool during Phase Il: $0.0 \%(0)$, $0.0 \%(0), 0.0 \%(0), 75 \%(3), 25 \%(1)$

Strongly Disagree

C

Disagree

C

Neutral

Agree

Strongly Agree

\section{Functional activity during Phase II should include:}

Strongly Disagree

Walk/Jog progression: $0.0 \%$

(0), $0.0 \%(0), 0.0 \%(0), 25 \%$

(1), $75 \%(3)$

Light intensity sprinting:

$25 \%(1), 0.0 \%(0), 75 \%(3)$,

$0.0 \%(0), 0.0 \%(0)$

Aerobic training on a

weight bearing machine:

$0.0 \%(0), 0.0 \%(0), 25 \%(1)$

$25 \%$ (1), 50\% (2)

Other (please specify)

CORE STRENGTHENING FOR PHASE II

15. Core stabilization should be a focus during Phase II: $0.0 \%(0), 0.0 \%(0), 0.0 \%(0), 50 \%$

(2), $50 \%$ (2)

Strongly Disagree

O
Disagree

O

C

eutra

C

0

O

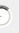

Agree

0

O

0

C

ngly Agree

○ 


\section{Ham Rehab Survey}

16. Core stability exercises should be more strength based with dynamic motions focused during Phase II: $0.0 \%(0), 0.0 \%(0), 0.0 \%(0), 25 \%(1), 75 \%(3)$

Strongly Disagree

○
Disagree

○
Neutral

(
Agree

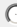

Strongly Agree

$C$

17. Core strengthening exercises should be performed in a multiplaner form: $0.0 \%(0)$, $0.0 \%(0), 0.0 \%(0), 50 \%(2), 50 \%(2)$

Strongly Disagree

O
Disagree

o
Neutral

o
Agree

C
Strongly Agree

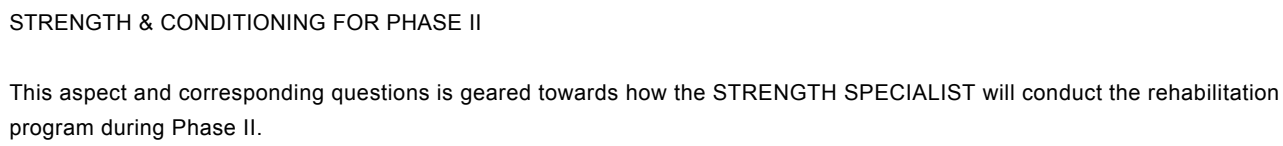

This aspect and corresponding questions is geared towards how the STRENGTH SPECIALIST will conduct the rehabilitation program during Phase II.

18. Lifting and conditioning exercises should only be completed without involvement of injured limb during Phase II: $0.0 \%(0), 50 \%$ (2), 25\% (1), 25\% (1), 0.0\% (0) 


\section{Ham Rehab Survey}

19. Lifting and conditioning exercises may involve injured limb while:

$\begin{array}{lccccc} & \text { Strongly Disagree } & \text { Disagree } & \text { Neutral } & \text { Agree } & \text { Strongly Agree } \\ \text { Weight is light: } 0.0 \%(0), & 0 & 0 & 0 & 0 & 0 \\ 0.0 \%(0), 25 \%(1), 50 \%(2), & & & & \\ 25 \%(1) & & & & \end{array}$

Eccentric Strength is

$6-6$

utilized or focused on: $0.0 \%$

(0), $50 \%(2), 0.0 \%(0), 25 \%$

(1), $25 \%$ (1)

Power exercises are

performed: $0.0 \%(0), 75 \%$

(3), $25 \%(1), 0.0 \%(0), 0.0 \%$

(0)

No power exercises are

performed: $0.0 \%(0), 0.0 \%$

(0), $25 \%$ (1), $50 \%(2), 25 \%$

(1)

Lift and conditioning

movements that cause pain

are not performed: $0.0 \%$

(0), $0.0 \%(0), 0.0 \%(0), 50 \%$

(2), $25 \%$ (1)

Activity that caused original injury cannot be performed: $0.0 \%(0), 0.0 \%(0), 50 \%(2)$,

$50 \%(2), 0.0 \%(0)$

Through painfree range of

motion

With limited range of

motion, Romanian

Deadlifts (RDL) completed

before hamstring curls

Other (please specify)

20. Lifting and conditioning progression should be normal for the rest of the body: $0.0 \%$ (0), $0.0 \%(0), 0.0 \%(0), 25 \%(1), 75 \%(3)$

Strongly Disagree

O
Disagree

○
Neutral

○
Agree

c
Strongly Agree 
Ham Rehab Survey

21. Aerobic conditioning should be completed by:

Stationary bike without

injured limb involvement:

$0.0 \%(0), 25 \%(1), 0.0 \%(0)$,

$50 \%(2), 25 \%$ (1)

Upper bike ergometer sprints: $0.0 \%(0), 25 \%(1)$,

$0.0 \%(0), 25 \%(1), 50 \%(2)$

Hydrotherapy running: $0.0 \%$

(0), $0.0 \%(0), 25 \%(1), 50 \%$

(2), $25 \%$ (1)

Circuit training without injured limb involvement:

$0.0 \%(0), 25 \%(1), 0.0 \%(0)$,

$75 \%$ (3), 0.0\% (0)

StairMaster may be tolerated

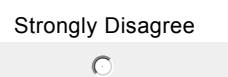

Disagree

O

C

C

O

O

C

C

O

C

O

Other (please specify)
Neutral o

C

C
Agree O
Strongly Agree

O

22. During Phase II, start with a dynamic warm and begin walk/job/run progression: $\mathbf{0 . 0} \%$ (0), $0.0 \%(0), 0.0 \%(0), 75 \%(3), 25 \%(1)$

Strongly Disagree

Disagree

Neutral

Agree

Strongly Agree

O

O

O

C

O

PROGRESS TO PHASE III

153 


\section{Ham Rehab Survey}

23. Prior to moving to Phase III of rehabilitation program, athlete should:

Strongly Disagree

Able to completing

lifting/workout without

limitations: $0.0 \%(0), 0.0 \%$

(0), $50 \%(2), 25 \%(1), 25 \%$

(1)

Have full strength equal bilateral painfree: $0.0 \%(0)$, $50 \%$ (2), $0.0 \%$ (0), $25 \%$ (1), $25 \%(1)$

No pain during hamstring stretch: $0.0 \%(0), 0.0 \%(0)$ $25 \%$ (1), $50 \%$ (2), $25 \%$ (1)

$66 \%$ difference Hamstring to-Quadriceps ratio: $0.0 \%$

(0), $50 \%$ (2), $50 \%$ (2), $0.0 \%$ (0), $0.0 \%(0)$

$50 \%$ difference Hamstring to-Quadriceps ratio: $0.0 \%$

(0), $25 \%$ (1), $75 \%$ (3), $0.0 \%$ (0), $0.0 \%(0)$

$35 \%$ difference Hamstringto-Quadriceps ratio: $0.0 \%$

(0), $50 \%$ (2), $50 \%$ (2), $0.0 \%$ (0), $0.0 \%(0)$

$25 \%$ difference Hamstring to-Quadriceps ratio: $0.0 \%$

(0), $50 \%$ (2), $50 \%$ (2), $0.0 \%$ (0), $0.0 \%(0)$

$50 \%$ difference Eccentric Hamstring -to-Concentric Quadriceps functional ratio: $0.0 \%(0), 50 \%(2), 50 \%(2)$, $0.0 \%(0), 0.0 \%(0)$

When athlete feels ready: $0.0 \%(0), 0.0 \%(0), 25 \%$ (1), $75 \%$ (3), $0.0 \%$ (0)

Walking lunges do not cause pain with full range of motion: $0.0 \%(0), 0.0 \%$ (0), $0.0 \%(0), 100 \%(4)$, $0.0 \%(0)$

When functional activity is started: $0.0 \%(0), 0.0 \%(0)$ $0.0 \%(0), 100 \%(4), 0.0 \%$

When $75 \%$ strength is achieved: $0.0 \%(0), 25 \%$ (1), $50 \%$ (2), $25 \%$ (1), $0.0 \%$ (0)

When $75 \%$ speed is

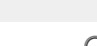

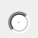

C

O

C

○

C

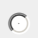

○
Disagree

c

O

Neutral

O

Agree

C

Strongly Agree

C
C

$C$

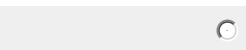

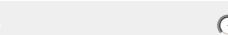

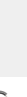

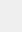
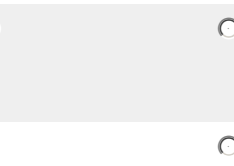


\section{Ham Rehab Survey}

achieved: $0.0 \%(0), 25 \%$

(1), $50 \%(2), 25 \%(1), 0.0 \%$

(0)

Other (please specify)

24. The following clinical tests or evaluations should be included to determine progression to Phase III of the rehabilitation program:

100 repetitions of Prone

Strongly Disagree

Disagree

curls pain free: $25 \%(1)$

$0.0 \%(0), 50 \%(2), 25 \%(1)$,

$0.0 \%(0)$

Active straight leg raise to

max range of motion

painfree with max effort:

$0.0 \%(0), 0.0 \%(0), 50 \%(2)$,

$50 \%(2), 0.0 \%(0)$

Active ballistic hamstring

test results with no

insecurity and painfree

motion equal to

contralateral limb range of

motion: $25 \%(1), 0.0 \%(0)$,

$25 \%(1), 50 \%$ (2), $0.0 \%(0)$

Leg swings

(forward/backwards) with full

range of motion painfree:

$0.0 \%(0), 0.0 \%(0), 25 \%(1)$,

$75 \%(3), 0.0 \%(0)$

Equal flexibility bilaterally

No point tenderness

○

C

Neutral

C

Agre

C

O

○

C

C

C

C

Other (please specify)

\section{Additional Comments for Phase II of the rehabilitation program: Active Release}

Technique should be implemented early in Phase II to determine texture of tissue and for constant re-evaluation purposes, many steps could be skipped or more attention can be given based on assessments.

Strongly Disagree

O
Disagree

(
Neutral

O
Agree

(
Strongly Agree

26. Additional Comments for Phase II of the rehabilitation program: 


\section{Ham Rehab Survey}

\section{Phase III: Re-education of the Fundamentals of Strength \& Conditioning}

Chronic Phase of a Grade I or II hamstring complex strain. The third phase includes progression of the recovery process and introduction/education of the fundamentals and skills required to perform strength and conditioning properly. At this point of the recovery process:

$50 \%$ involvement with ATC

$50 \%$ involvement with Strength Specialist

DIRECTIONS: Indicate your selection of each aspect that best corresponds to the answer of the question unless otherwise specified. If answer is not provided, please add additional information.

${ }^{*}$ REMINDER: The numbers represent the frequency and number of responses from First Round.

BASELINE FOR PHASE II

\section{Prior to Beginning Phase III, athlete should be able to complete:}

Perform functional activity
without pain: $0.0 \%(0)$,
Full strength compared
bilaterally: $0.0 \%(0), 0.0 \%$
(0), $50 \%(2), 50 \%(2), 0.0 \%$ (0)

Start sprinting greater than $85 \%$ speed with minimal pain: $0.0 \%(0), 25 \%(1)$ $50 \%$ (2), $25 \%$ (1), $0.0 \%(0)$

Other (please specify) 


\section{Ham Rehab Survey}

\section{Contraindications for Phase III are:}

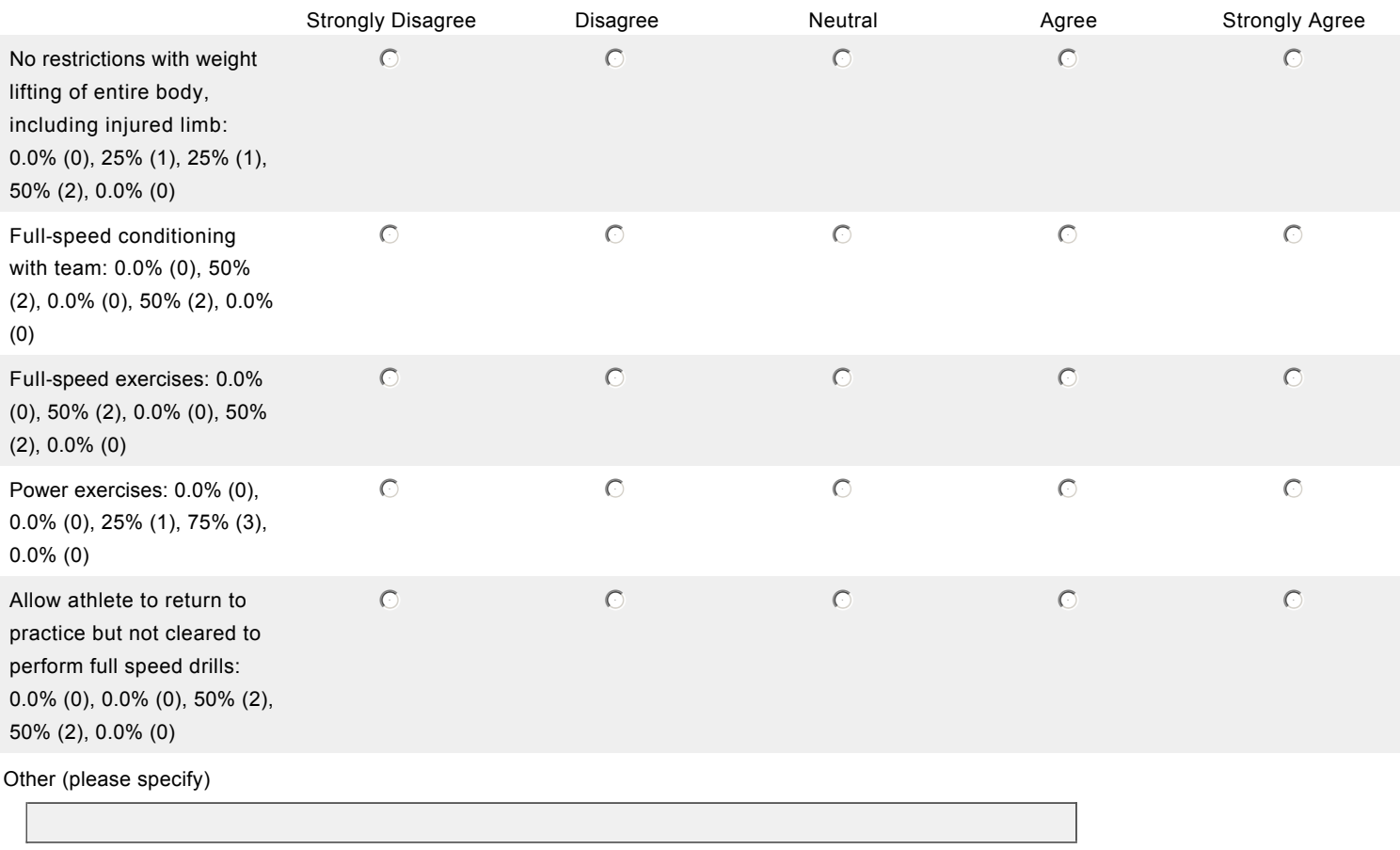

FLEXIBILITY FOCUS FOR PHASE II

3. Static exercises started in Phases I \& II of the rehabilitation program should be continued during Phase III: $0.0 \%(0), 0.0 \%(0), 50 \%(2), 50 \%(2), 0.0 \%(0)$

Strongly Disagree

C
Disagree

C
Neutral
Agree
Strongly Agree

C

4. Dynamic stretching should be used to increase hamstring flexibility during Phase III of the rehabilitation program: $0.0 \%(0), 0.0 \%(0), 0.0 \%(0), 75 \%(3), 25 \%(1)$

Strongly Disagree

O
Disagree

O
Neutral

C

\section{RANGE OF MOTION/STRENGTH FOR PHASE III}

This aspect and corresponding questions is geared towards how the ATHLETIC TRAINER will conduct the rehabilitation program during Phase III.

5. Range of motion exercises are not required for Phase III: $\mathbf{0 . 0 \%}(0), 50 \%(2), 0.0 \%(0), 50 \%$ (2), $0.0 \%$ (0)

Strongly Disagree

C
Disagree

O
Neutral

c
Agree

C
Strongly Agree 


\section{Ham Rehab Survey}

6. Strengthening exercises for the hamstring complex during Phase III should be focused on increasing:

Endurance: $0.0 \%(0), 0.0 \%$
$(0), 0.0 \%(0), 50 \%(2), 50 \%$

Strongly Disagree

C

Disagree

C

C

Concentric Strength: $0.0 \%$

(0), $0.0 \%(0), 0.0 \%(0), 50 \%$

(2), $50 \%(2)$

Eccentric Strength: $0.0 \%$

(0), $25 \%$ (1), $0.0 \%$ (0), $25 \%$

(1), $50 \%(2)$

Power: $0.0 \%(0), 0.0 \%(0)$

$50 \%$ (2), $25 \%$ (1), $25 \%$ (1)

Other (please specify)

7. Eccentric exercises should increase in intensity and volume during this phase of the rehabilitation program: $0.0 \%(0), 25 \%(1), 0.0 \%(0), 50 \%(2), 25 \%(1)$

Strongly Disagree

Disagree

C
Neutral

C
Agree
Agree Strongly Agree

O

O

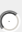

Strongly Agree

C

8. Strengthening exercises included in Phase III should include exercises to increase strength of the lumbo-pelvic complex: $0.0 \%(0), 0.0 \%(0), 0.0 \%(0), 50 \%(2), 50 \%(2)$

Strongly Disagree
Disagree

C
Neutral

C
Agree
Strongly Agree

9. What percentage of strengthening exercises should be for hamstring complex versus lumbo-pelvic complex during Phase III:

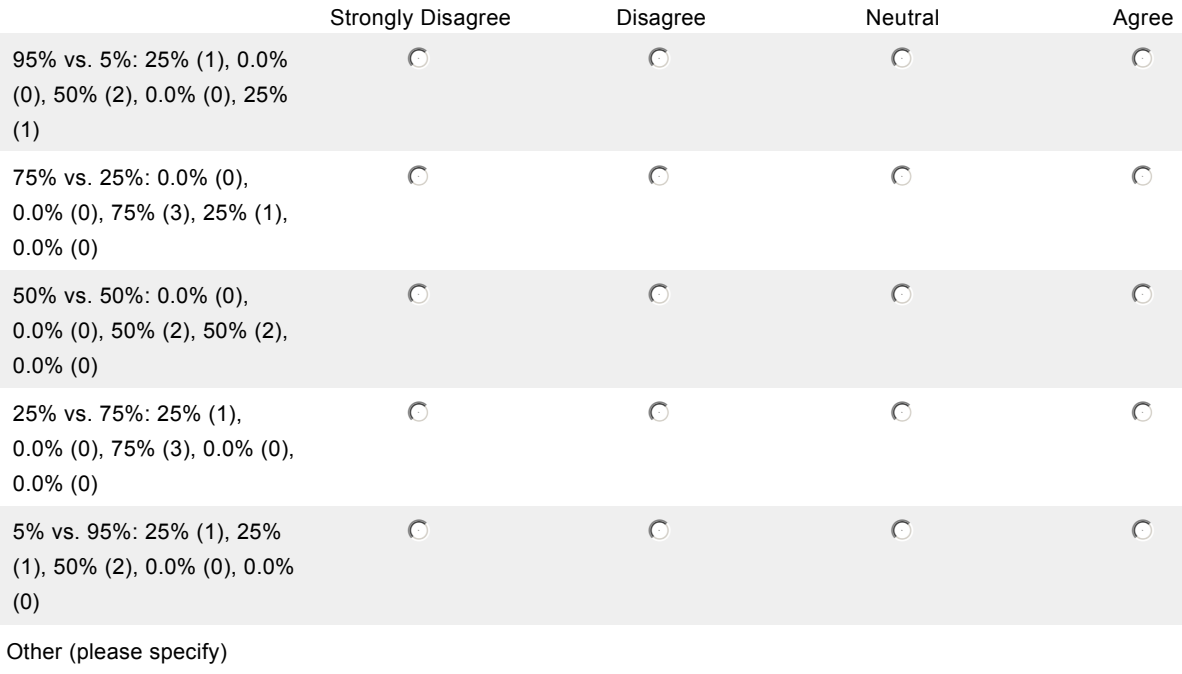

Disagree

C

eutral

O

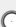

Agree

C

O 


\section{Ham Rehab Survey}

10. Functional activity during Phase III should include:

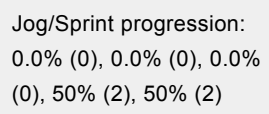

Other (please specify)
Strongly Disagree Disagree Neut

O

O

Agree

O

6

C

O

O

6

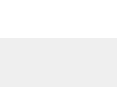




\section{Ham Rehab Survey}

15. Lifting and conditioning exercises should be completed without limitation of athlete during Phase III: $0.0 \%(0), 0.0 \%(0), 25 \%(1), 75 \%(3), 0.0 \%(0)$

Strongly Disagree

O
Disagree

o
Neutral

C
Agree

○
Strongly Agree

O

16. Lifting and conditioning exercises may involve injured limb while:

Strongly Disagree

Weight progresses back to pre-injury levels: $0.0 \%(0)$, $0.0 \%(0), 25 \%(1), 50 \%(2)$, 25\% (1)

Power movements are controlled with moderate weight: $0.0 \%(0), 0.0 \%(0)$, $25 \%$ (1), $50 \%$ (2), $25 \%$ (1)

Lift and conditioning movement are with full participation pain-free: $0.0 \%(0), 0.0 \%(0), 0.0 \%$ (0), $75 \%$ (3), $25 \%$ (1)

Activity that caused original injury can be performed: $0.0 \%(0), 25 \%(1), 25 \%(1)$, $25 \%$ (1), $25 \%$ (1)

Other (please specify)
Disagree$$
\text { C }
$$

O

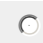

O

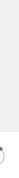

Neutral

O

O

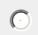

O
0
Agree

C

0

O 0
Strongly Agree

O

O

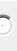

17. Lifting and conditioning progression should be in conjunction with team progression: $0.0 \%(0), 25 \%(1), 25 \%(1), 50 \%(2), 0.0 \%(0)$

Strongly Disagree Disagree Neutral Agree Strongly Agree O 


\section{Ham Rehab Survey}

18. Aerobic/Anaerobic conditioning should be completed with team while:

Strongly Disagree

Injured athlete may perform at slower speed during sprints: $0.0 \%(0), 0.0 \%(0)$, $0.0 \%(0), 75 \%$ (3), $25 \%$ (1)

Injured athlete may perform at as-tolerated pace during endurance running: $0.0 \%$

(0), $0.0 \%$ (0), $25 \%$ (1), $25 \%$

(1), $50 \%$ (2)

Un-weighted running can be utilized to return speed and endurance to per-injury levels: $0.0 \%(0), 0.0 \%(0)$, $0.0 \%(0), 75 \%$ (3), $25 \%$ (1)

Circuit training with injured limb involvement: $0.0 \%(0)$ $0.0 \%(0), 0.0 \%(0), 100 \%$

(4), $0.0 \%(0)$
Disagree

C

Agree

C

Strongly Agree

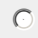

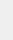

0

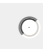

(

c
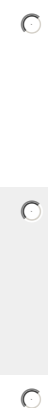

C

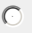

Other (please specify)

19. During Phase III, full dynamic warm-up may be complete with team: $0.0 \%(0), 0.0 \%(0)$, $25 \%(1), 25 \%(1), 50 \%(2)$

Strongly Disagree

Disagree

Neutral

Agree

Strongly Agree

C

C

20. During Phase III, athlete should be fully participating in skill, individual and agility drills with team: $0.0 \%(0), 0.0 \%(0), 25 \%(1), 50 \%(2), 25 \%(1)$

Strongly Disagree

Disagree

Neutral

Agree

Strongly Agree

PROGRESS TO PHASE IV

21. Athletic Trainer and Strength Specialist should be concerned of re-injury to hamstring complex within the first two-weeks post returning to full participation: $0.0 \%(0), 0.0 \%(0)$, $0.0 \%(0), 50 \%(2), 50 \%(2)$

Strongly Disagree

C
Disagree

C
Neutral

c
Agree
Strongly Agree 


\section{Ham Rehab Survey}

22. The following clinical tests or evaluations should be included to determine return to full participation:

Athlete retuned to practice

Strongly Disagree

Disagree

Neutral

Agree

Strongly Agree

participating in full contact

O

O

○

○

O

and full speed drills without

presentation of

pain/soreness: $0.0 \%(0)$,

$0.0 \%(0), 0.0 \%(0), 50 \%(2)$,

$50 \%(2)$

Full strength bilateral no pain at 0 degree and full flexion of knee: $0.0 \%(0)$, $0.0 \%$ (0), $25 \%$ (1), $25 \%$ (1), $50 \%(2)$

5-10 repetitions of a highly intense eccentric exercise: $0.0 \%(0), 0.0 \%(0), 0.0 \%$ (0), $75 \%$ (3), $25 \%$ (1)

Flexibility equal bilateral: $0.0 \%(0), 0.0 \%(0), 0.0 \%$ (0), $75 \%$ (3), $25 \%$ (1) $66 \%$ difference Hamstringto-Quadriceps ratio: $0.0 \%$

(0), $50 \%(2), 50 \%(2), 0.0 \%$ (0), $0.0 \%(0)$

$35 \%$ difference Hamstringto-Quadriceps ratio: $0.0 \%$

(0), $50 \%(2), 50 \%(2), 0.0 \%$

(0), $0.0 \%(0)$

$25 \%$ difference Hamstringto-Quadriceps ratio: $0.0 \%$

(0), $25 \%(1), 50 \%(2), 25 \%$

(1), $0.0 \%(0)$

$75 \%$ difference Eccentric Hamstring -to- Concentric

Quadriceps functional ratio:

$0.0 \%(0), 25 \%(1), 75 \%(3)$,

$0.0 \%(0), 0.0 \%(0)$

Other (please specify)

23. Additional Comments for Phase III of the rehabilitation program: Large variation in strength tests/measures depending on location of hamstring complex strain. Therefore, isokinetic values are not warranted to determine returning to full participation.

Strongly Disagree

C
Disagree

C
Neutral

C
Agree

O
Strongly Agree 


\section{Ham Rehab Survey}

\section{Additional Comments for Phase III of the rehabilitation program:}

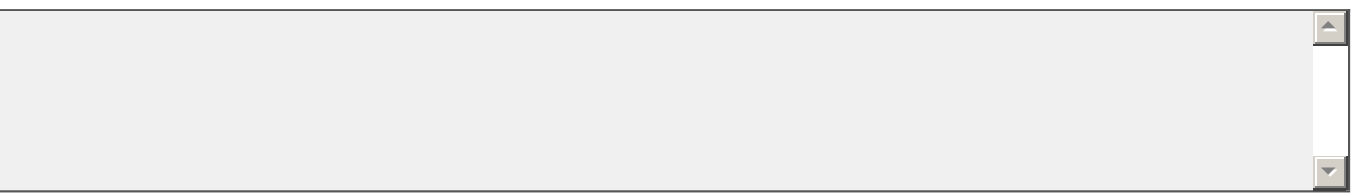

\section{Phase IV: Re-conditioning the Body}

Return to Play Phase of a Grade I or II hamstring complex strain. The fourth phase includes return to play progression and re-conditioning of the athlete. At this point of the recovery process:

$15 \%$ involvement with ATC

$85 \%$ involvement with Strength Specialist

DIRECTIONS: Indicate your selection of each aspect that best corresponds to the answer of the question unless otherwise specified. If answer is not provided, please add additional information.

*REMINDER: The numbers represent the frequency and number of responses from First Round.

BASELINE FOR PHASE IV

\section{Prior to Phase IV, athlete should be able to complete:}

\begin{tabular}{|c|c|c|c|c|c|}
\hline & Strongly Disagree & Disagree & Neutral & Agree & Strongly Agree \\
\hline $\begin{array}{l}\text { Perform functional activity } \\
\text { without pain: } 0.0 \%(0) \text {, } \\
0.0 \%(0), 0.0 \%(0), 25 \%(1) \text {, } \\
75 \% \text { (3) }\end{array}$ & 0 & 0 & 0 & 0 & 0 \\
\hline $\begin{array}{l}\text { Perform lengthened state } \\
\text { eccentric exercises without } \\
\text { pain: } 0.0 \%(0), 0.0 \%(0) \text {, } \\
0.0 \%(0), 50 \%(2), 50 \%(2)\end{array}$ & 0 & 0 & 0 & 0 & 0 \\
\hline $\begin{array}{l}\text { Start sprinting greater than } \\
85 \% \text { speed with minimal } \\
\text { pain: } 0.0 \%(0), 0.0 \%(0) \text {, } \\
0.0 \%(0), 75 \%(3), 25 \%(1)\end{array}$ & 0 & 0 & 0 & 0 & 0 \\
\hline $\begin{array}{l}\text { Perform position } \\
\text { skills/abilities without } \\
\text { pain/hesitation: } 0.0 \%(0) \text {, } \\
0.0 \%(0), 0.0 \%(0), 75 \%(3) \text {, } \\
25 \%(1)\end{array}$ & 0 & 0 & 0 & 0 & 0 \\
\hline $\begin{array}{l}\text { Have full sprint speed } \\
\text { without pain/hesitation: } \\
0.0 \%(0), 0.0 \%(0), 0.0 \% \\
(0), 75 \%(3), 25 \% \text { (1) }\end{array}$ & 0 & 0 & 0 & 0 & 0 \\
\hline Other (please specify) & & & & & \\
\hline
\end{tabular}




\section{Ham Rehab Survey}

CONTRAINDICATIONS FOR PHASE IV

2. There are no contraindications for Phase III of the rehabilitation program: $0.0 \%(0), 0.0 \%$ (0), $25 \%$ (1), $50 \%$ (2), $25 \%$ (1)

Strongly Disagree

C

Disagree

Neutral

Agree

Strongly Agree

○

(

FLEXIBILITY FOCUS FOR PHASE IV

3. Static exercises started in PhaseS I, II \& III of the rehabilitation program should be continued during Phase IV: $0.0 \%(0), 25 \%(1), 50 \%(2), 25 \%(1), 0.0 \%(0)$

Strongly Disagree

Disagree

Neutral

Agree

Strongly Agree

C

O

(

O

4. All dynamic stretching should be completed with team: $0.0 \%(0), 0.0 \%(0), 0.0 \%(0), 50 \%$ (2), $50 \%$ (2)

Strongly Disagree

Disagree

Neutral

Agree

Strongly Agree

C

$\mathrm{O}$

C

5. Flexibility exercises are completed as needed: $0.0 \%(0), 0.0 \%(0), 25 \%(1), 25 \%(1), 50 \%$

(2)

Strongly Disagree

C

Disagree

Neutral

Agree

Strongly Agree

C

(

C

RANGE OF MOTION/STRENGTH FOR PHASE IV

This aspect and corresponding questions is geared towards how the ATHLETIC TRAINER will conduct the rehabilitation program during Phase IV. 


\section{Ham Rehab Survey}

6. Strengthening exercises for the hamstring complex during Phase IV should be focused on:

Endurance: $0.0 \%(0), 0.0 \%$

Strongly Disagree

Disagree

Neutral

Agree

Strongly Agree

(0), $0.0 \%$ (0), $25 \%$ (1), $75 \%$

O

O

O

○

C

(3)

Concentric Strength: 0.0\%

(0), $0.0 \%(0), 0.0 \%(0), 75 \%$

(3), $25 \%$ (1)

Lengthened state Eccentric

Strength: $0.0 \%(0), 0.0 \%$

(0), $25 \%$ (1), $50 \%$ (2), $25 \%$

(1)

Power: $0.0 \%(0), 0.0 \%(0)$, $0.0 \%$ (0), $50 \%$ (2), $50 \%$ (2)

Returning strength,

endurance and power to

pre-injury levels: $0.0 \%(0)$,

$0.0 \%(0), 0.0 \%(0), 50 \%(2)$

$50 \%(2)$

Other (please specify)

7. Strengthening exercises included in Phase IV should include exercises to increase strength of the lumbo-pelvic complex with proprioceptive challenges: $0.0 \%(0), 0.0 \%(0)$, $25 \%(1), 25 \%(1), 50 \%(2)$

Strongly Disagree

Disagree

Neutral

Agree

Strongly Agree

C

O

O

C

C

8. Lower extremity plyometric exercises should be included during Phase IV: $0.0 \%(0)$, $0.0 \%(0), 0.0 \%(0), 50 \%(2), 50 \%(2)$

Strongly Disagree

C
Disagree

O
Neutral

c
Agree

(
Strongly Agree

C

9. Rehabilitation exercises included in Phase IV should be focused on maintaining correct hamstring complex function: $0.0 \%(0), 0.0 \%(0), 0.0 \%(0), 50 \%(2), 50 \%(2)$

Strongly Disagree

C
Disagree

O
Neutral

O
Agree

6
Strongly Agree

$\mathrm{C}$

10. Lengthened-state Eccentric exercises should only be completed if weight lifting is not including exercises in team program: $0.0 \%(0), 0.0 \%(0), 50 \%(2), 25 \%(1), 25 \%(1)$

Strongly Disagree

O
Disagree

O
Neutral

○
Agree

○
Strongly Agree 


\title{
Ham Rehab Survey
}

11. During Phase IV, athlete should complete hamstring complex rehabilitation 2-3 days per week, in unison with weight lifting schedule: $0.0 \%(0), 0.0 \%(0), 0.0 \%(0), 0.0 \%(0)$, $100 \%(4)$

Strongly Disagree C Disagree

Neutral

C

Agree

Strongly Agree

12. All functional activity should be completed with team agilities and conditioning: $0.0 \%$ (0), $0.0 \%(0), 0.0 \%(0), 50 \%(2), 50 \%(2)$
Strongly Disagree
Disagree
Agree
Strongly Agree
(
C
C

CORE STRENGTHENING FOR PHASE IV

13. Core exercises are completed during team weight lifting and are not a focus during Phase IV: $0.0 \%(0), 0.0 \%(0), 25 \%(1), 75 \%(3), 0.0 \%(0)$
Strongly Disagree
Disagree
Neutral
Agree
Strongly Agree
O
O
C
C
C

\begin{abstract}
STRENGTH \& CONDITIONING FOR PHASE IV
This aspect and corresponding questions is geared towards how the STRENGTH SPECIALIST will conduct the rehabilitation program during Phase IV.
\end{abstract}

14. Sprinting technique exercises should be completed during Phase IV: $0.0 \%(0), 0.0 \%$ (0), $0.0 \%(0), 75 \%(3), 25 \%(1)$
Strongly Disagree
Disagree
Neutral
Agree
Strongly Agree
(
C

15. Power lifting exercises with progression to weight prior to injury should be included in Phase IV: 0.0\% (0), 0.0\% (0), 0.0\% (0), 75\% (3), 25\% (1)
Strongly Disagree
Disagree
Neutral
Agree
Strongly Agree
C

16. Lifting and conditioning exercises should be completed without limitation of athlete during Phase IV: $0.0 \%(0), 0.0 \%(0), 0.0 \%(0), 75 \%(3), 25 \%$ (1)
Strongly Disagree
Disagree
Neutral
Agree
Strongly Agree

17. During Phase IV, athlete should be fully participating in all aspects of the sport of football including skill, agility and contact requirements: $0.0 \%(0), 0.0 \%(0), 0.0 \%(0), 50 \%$ (2), $50 \%(2)$

Strongly Disagree

C
Disagree

O
Neutral

C
Agree 


\section{Ham Rehab Survey}

PROGRESS TO PHASE V

\section{The following clinical tests or evaluations should be included to determine progression} to Phase $V$ and no concern or fear of re-injury:

Strongly Disagree

C

Athlete is full participation

in practice/game and

weight/lifting/conditioning

settings: $0.0 \%(0), 0.0 \%(0)$,

$0.0 \%(0), 25 \%(1), 75 \%$ (3)

Full strength bilaterally no pain at 0 degrees and full

flexion of knee: $0.0 \%(0)$,

$0.0 \%(0), 0.0 \%(0), 25 \%(1)$,

$75 \%(3)$

\begin{abstract}
15-20 repetitions of a
\end{abstract}
highly intense lengthened

state eccentric exercise:

$0.0 \%(0), 0.0 \%$ (0), $25 \%$ (1),

$25 \%$ (1), $50 \%$ (2)

Flexibility equal bilateral:

$0.0 \%(0), 25 \%$ (1), $0.0 \%(0)$,

$25 \%(1), 50 \%$ (2)

Other (please specify)
Disagree

C

Neutral

O

○

C gly Agree

19. Additional Comments for Phase IV of the rehabilitation program:

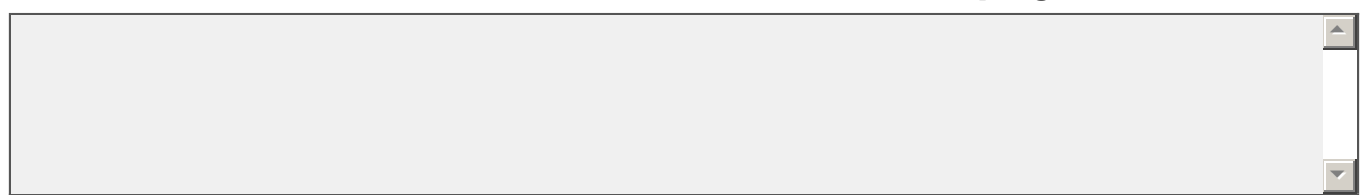

\section{Phase V: Reintroduction of Physical and Positional Demands}

Maintenance Phase of a Grade I or II hamstring complex strain. The fifth phase includes continued rehabilitation of healed injured and full participation of athlete. At this point of the recovery process:

$5 \%$ involvement with ATC

95\% involvement with Strength Specialist

DIRECTIONS: Indication your selection of each aspect that best corresponds to the answer of the question unless otherwise specified. If answer is not provided, please add additional information.

*REMINDER: The numbers represent the frequency and number of responses from First Round. 


\section{Ham Rehab Survey}

BASELINE FOR PHASE V

\section{Prior to beginning Phase $V$, athlete should be able to complete:}

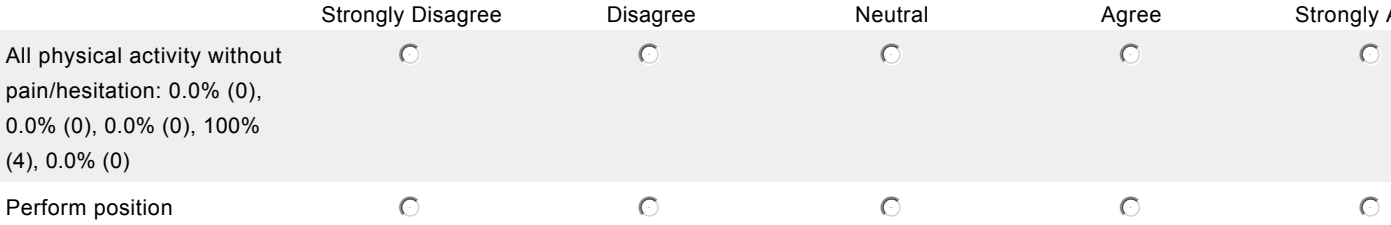

skills/abilities without

pain/hesitation: $0.0 \%(0)$,

$0.0 \%(0), 0.0 \%(0), 100 \%$

(4), $0.0 \%(0)$

Have full sprint speed

without pain/hesitation:

$0.0 \%(0), 0.0 \%(0), 25 \%(1)$

$75 \%$ (3), $0.0 \%(0)$

Other (please specify)

CONTRAINDICATIONS FOR PHASE $V$

2. There are no contraindications for Phase $V$ of the rehabilitation program: $0.0 \%(0), 0.0 \%$ (0), $0.0 \%(0), 50 \%(2), 50 \%(2)$

Strongly Disagree Disagree

○

Neutral

Agree

Strongly Agree

FLEXIBILITY FOCUS FOR PHASE $V$

3. Static flexibility exercises should be completed by athlete three times per week: $0.0 \%$ (0), $0.0 \%(0), 25 \%(1), 50 \%(2), 25 \%(1)$

Strongly Disagree

○
Disagree
Neutral
Agree
Strongly Agree

\section{RANGE OF MOTION/STRENGTH FOR PHASE V}

This aspect and corresponding questions is geared towards how the ATHLETIC TRAINER will conduct the rehabilitation program during Phase $\mathrm{V}$.

4. Athlete should complete endurance exercises for the hamstring complex during Phase V three times per week: $0.0 \%(0), 0.0 \%(0), 0.0 \%(0), 75 \%(3), 25 \%(1)$

Neutral

Agree

Strongly Agree 


\section{Ham Rehab Survey}

5. No modified exercises required for athlete to perform during Phase V: $0.0 \%(0), 0.0 \%(0)$, $50 \%(2), 0.0 \%(0), 50 \%(2)$

Strongly Disagree

Disagree

Neutral

Agree

Strongly Agree

C

STRENGTH \& CONDITIONING FOR PHASE V

This aspect and corresponding questions is geared towards how the STRENGTH SPECIALIST will conduct the rehabilitation program during Phase $\mathrm{V}$.

6. The athlete is fully returned and will continue team weight lifting/conditioning program as seen by the Strength Specialist: $0.0 \%(0), 0.0 \%(0), 0.0 \%(0), 25 \%(1), 75 \%(3)$

Strongly Disagree

Disagree

Neutral

Agree

Strongly Agree

7. Athlete should be performing all strength and speed requirements at pre-injury level: $0.0 \%(0), 0.0 \%(0), 0.0 \%(0), 50 \%(2), 50 \%(2)$

Strongly Disagree

Disagree

Neutral

Agree

Strongly Agree

6

C

CONTINUED MAINTENANCE

8. Athlete must be instructed to continue maintenance program to decrease risk of reinjury to the hamstring complex: $0.0 \%(0), 0.0 \%(0), 0.0 \%(0), 25 \%(1), 75 \%(3)$

Strongly Disagree

Disagree

Neutral

Agree

Strongly Agree

\section{Additional Comments for Phase V of the rehabilitation program:}

\section{Thank you for completing the Questionnaire.}

Your participation in this study is now complete, please submit the questionnaire once you are satisfied with your responses.

Thank you for Completing the Second Round Questionnaire for the design of a Complete Hamstring Complex Rehabilitation Program. You time throughout this study is greatly appreciated!!! 
May 31, 2013

Dear Participant,

Just sending a quick reminder in reference to the second round questionnaire for the development of a complete hamstring complex rehabilitation program can be completed by June 7, 2013 for your participation.

The second round questionnaire will be the final step for the completion of the program for Division I Football athletes. This stage provides the results from the all participants and the opportunity to rate and comment on the new components acquired the first round questionnaire. Your final responses are very important and will directly assist athletic trainers and strength specialist when challenged with rehabilitating a hamstring complex injury. I will be conducting this study with the faculty supervisor, Michelle A. Sandrey PhD, ATC to fulfill requirements for a Master's thesis and to complete a Master's of Science degree in Athletic Training from West Virginia University.

For those of you who have already submitted your responses or are in the process, we apologize for this interruption and thank you for your participation. This final round should only take about 30 minutes to complete. Please go to the following website to take the survey:

http://www.surveymonkey.com/s.aspx

Once again, this is a completely voluntary activity and all responses are guaranteed to be anonymous and confidential, as a number system will be instituted so anonymity is secured. You have the option to skip questions, and you have the right to withdraw any data you submit at any time. You job status will not be affected by failure to participate. West Virginia University IRB has approved the study and the approval is on file. Once again, please respond to the online questionnaire by June 7, 2013.

If you have any questions or concerns please contact Caitlin McFadden at (215) 4982369 or cmcfadd2@mix.wvu.edu, or Dr. Michelle Sandrey, faculty supervisor and Graduate Athletic Training Program Director at West Virginia University, at (304) 2930870 or msandrey@mail.wvu.edu.

This is the final stage for your participation in the design of the complete hamstring complex rehabilitation program for the Division I Football athlete. Thank you for your participation in this study and I greatly appreciate your time and commitment.

Sincerely,

Caitlin McFadden, ATC 